The power of sharing and reflecting on meaningful moments

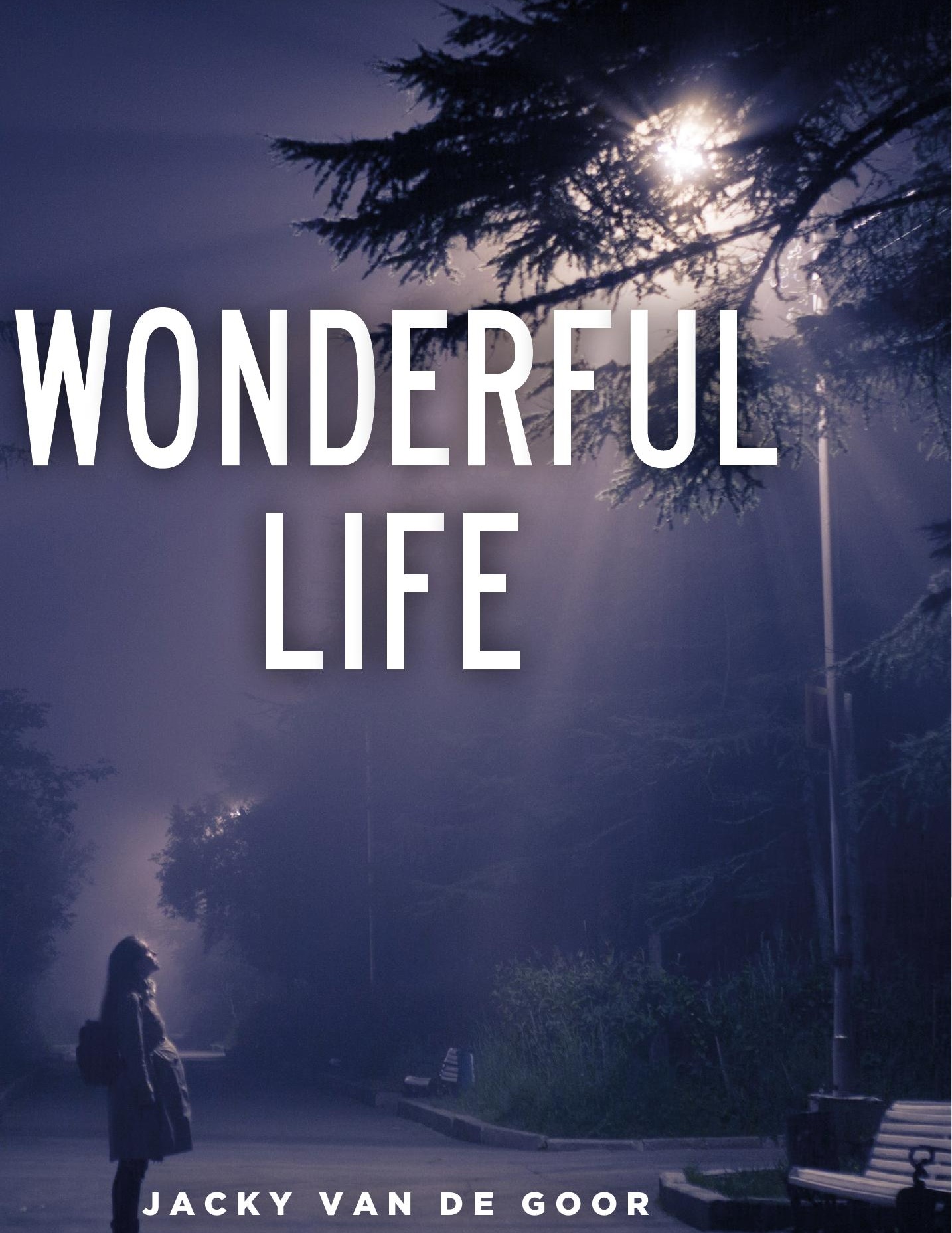




\section{Wonderful Life \\ The power of sharing and reflecting on meaningful moments}

Jacky van de Goor 
Cover photo: Artem Kovalev

Printing: Gildeprint Enschede, gildeprint.nl

Layout: Sanne Kassenberg, persoonlijkproefschrift.nl

ISBN: 978-90-365-5127-4

DOI: $10.3990 / 1.9789036551274$

(C) Jacky van de Goor, 2020. All rights reserved. No parts of this thesis may be reproduced, stored in a retrieval system or transmitted in any form or by any means without permission of the author. Alle rechten voorbehouden. Niets uit deze uitgave mag worden vermenigvuldigd, in enige vorm of op enige wijze, zonder voorafgaande schriftelijke toestemming van de auteur. 


\section{Wonderful Life}

The power of sharing and reflecting on meaningful moments

\section{PROEFSCHRIFT}

ter verkrijging van

de graad van doctor aan de Universiteit Twente,

op gezag van de rector magnificus,

prof. dr. ir. T. A. Veldkamp,

volgens besluit van het College voor Promoties

in het openbaar te verdedigen op

vrijdag 26 februari 2021 om 12.45 uur

door

Marie Jacqueline van de Goor

geboren op 8 december 1968

te Pittsburgh, USA 
Dit proefschrift is goedgekeurd door:

De promotor

prof. dr. G. J. Westerhof

De copromotor

dr. A. M. Sools 


\section{Promotiecommissie}

Voorzitter/secretaris

prof. dr. T. A. J. Toonen - Universiteit Twente

Promotor

prof. dr. G. J. Westerhof - Universiteit Twente

Copromotor

dr. A. M. Sools - Universiteit Twente

Leden

prof. dr. H. A. Alma - Vrije Universiteit Amsterdam

prof. dr. E. T. Bohlmeijer - Universiteit Twente

prof. dr. G. C. Jacobs - Universiteit voor Humanistiek

prof. dr. S. Vanhooren - Katholieke Universiteit Leuven

dr. H. A. van Vuuren - Universiteit Twente 

"Listen to your life. See it for the fathomless mystery it is. In the boredom and pain of it, no less than in the excitement and gladness: touch, taste, smell your way to the holy and hidden heart of it, because in the last analysis all moments are key moments, and life itself is grace."

- Frederick Buechner 



\section{Contents}

$\begin{array}{lll}\text { Chapter } 1 \text { General Introduction } & 11\end{array}$

$\begin{array}{lll}\text { Chapter } 2 \text { Wonderful Life } & 27\end{array}$

Exploring wonder in meaningful moments

Chapter 3 Unraveling the Wonder of the Ordinary 51

A narrative analysis of meaning construction in memories of familiar routines

Chapter 4 The Emergence of Meaning from Meaningful Moments in Life

An integrated framework on the process of discovering and creating meaning

Chapter 5 The Power of Sharing Meaningful Moments

A Buberian analysis of a counseling intervention

Chapter 6 General Conclusions \& Discussion

Appendices References

156

Summary

170

Samenvatting

176

List of publications

182

About the author 184

Dankwoord 186 


\section{6}

It is 1995. I am travelling through India with a friend, and we are at Bombay airport, sitting in a bus. It is about six or seven o'clock in the evening, and I am looking out of the opened window. It is already dark outside, and the atmosphere is hot and damp. We are waiting for the bus driver to arrive. The airport is in the middle of a big slum, and three small children from this slum have seen us, the only foreigners, enter the bus. They walk over to my window, they stick up their hands and start begging, making sounds like "aaaaamaaau, maaaaau!" I cannot understand what they are saying, but it sounds like a cat's meowing. And before I know it, I stick my head out of the window and I meow to them: "meow, meow!" The children are surprised, but almost instantly they start meowing too: "meow, meow!" So I am meowing from inside the bus to them, underneath my window, and they meow back up to me. At first cautiously, then louder and more exuberantly. An from meowing we move on to barking, doing big dogs and little dogs, we howl and growl and wag. Next come the cows, the chickens and the monkeys; we are completely absorbed in this game, and I forget everything around me. Finally, the bus driver arrives. He enters the bus, starts the motor and the bus drives away. And the children run along behind the bus and call after me: "mama, mama!"

\section{y)}




$$
\text { Chapter }
$$

General

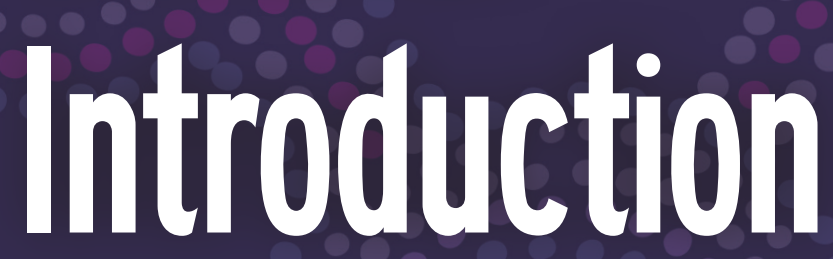


What am I doing here? What is life all about, and what really matters? Questions like these have run through my life since childhood. They strike me at moments of wonder, when I'm overwhelmed by a glimpse of a wider reality, but also arise at times when I feel lost, unable to grasp life and give direction to it. They relate to me on a personal level and are leading in my work as an organizational coach and leadership trainer, in which I contribute to vital working cultures in which meaningful work stands central.

Meaning: it is a deep-rooted desire, a basic human need. Psychiatrist Victor Frankl was among the first to recognize the "will to meaning" as a human motive (Frankl, 1969, 1959/2006), which since has been widely acknowledged in psychology (e.g. Baumeister, 1991; Reker, Peacock \& Wong, 1987; Wong, 2014). Yet though this yearning is natural to our existence, a sense of meaning in life is not self-evident. Living in a society that is increasingly self-centered, focused on pleasure, performance and acceleration brings about the risk of alienation and indifference, and thereby of losing a sense of meaning in everyday life - a warning already given by scholars such as Frankl (1959/2006), Buber (1970) and Maslow (1968), that to this day is still topical (e.g. Machielse, 2015; Rosa, 2013, 2016). Depression and burnout, symptoms related to a loss of meaning, have become major health care issues (Hedayati \& Khazaei, 2014; Kleftaras \& Psarra, 2012; Lépine \& Briley, 2011; Maslach et al., 1986). Loneliness, often an existential phenomenon, has become a vast problem, not only among elderly but also among youth (Killeen, 1998; Michiels \& De Wachter, 2019; Stillman et al., 2009). Furthermore, it is noted that a disproportionate focus on happiness may result in living a life that is felt to be shallow and empty (Baumeister et al., 2013; Peterson et al., 2005; Wong, 2012a).

On the positive side, these societal issues have led to an increasing interest in meaning and the benefits of meaning in life. Over the last decades, many studies have recognized meaning to be crucial to both psychological as well as physical well-being and to relate to positive functioning; a sense of meaning is associated with hope, resilience and overall satisfaction with life (Mascaro \& Rosen, 2005; Roepke et al., 2014; Steger, 2012; Zika \& Chamberlain, 1992). Meaning has become a core concept not only in humanistic and existential psychology, but 
also in medical healthcare and in the positive psychology movement (Huber et al., 2016; Lomas \& Ivtzan, 2016; Wong 2011, 2019).

This thesis aligns with these fields of study and practice and explores meaning as a personal, lived experience. The focus of this thesis is on meaningful moments: on memories of specific events in life that are felt to be of great value and significance. This thesis investigates the way these moments work and the way the recollection of meaningful moments may contribute to enhancing a sense of meaning in life.

In this introduction, I firstly present several conceptualizations of meaning that are relevant to this thesis. After this I look into the nature, functioning and function of meaningful moments: what they are, the way they work and the work they do in establishing a sense of meaning in life. Next, the objectives of this thesis are specified, including the contribution of this thesis to the existing body of knowledge, after which I elaborate on the foundations of the study: the intervention that was developed in which meaningful moments stand central, and the narrative approach that was taken.

\section{Conceptualizing meaning}

What is meaning? A thesis on this subject demands an exploration of this topic, which however is not a simple task. Within the various fields of research, meaning has been approached from a range of perspectives, highlighting different aspects of meaning and its emergence, without clear consensus on the construct of meaning and its theoretical conceptualization. In this paragraph, I attempt to give some clarity by elaborating on three frameworks of meaning that have been employed throughout this thesis: meaning as coherence, purpose and significance, meaning as connectedness and meaning as an affective state.

\section{Meaning as coherence, purpose and significance}

In psychology, explorations of the "meaning of meaning" have led to a variety of terminologies and perspectives. However, within this vast field of research, scholars agree upon three main dimensions of meaning: coherence, purpose 
and significance (Heintzelman \& King, 2014; Leontiev, 2017; Martela \& Steger, 2016; Park, 2010; Steger, 2012).

Coherence is the cognitive dimension of meaning and relates to the comprehension of life, of life making sense and transcending chaos (e.g. Antonovsky, 1987; Heintzelman \& King, 2013; King et al., 2006). Of relevance to coherence is the distinction between the detection and construction of meaning. Meaning is detected when events fit in with existing beliefs and expectations, and requires construction when this is not the case, as a revision of these beliefs is necessary to restore coherence (King \& Hicks, 2009; Park, 2010; Park \& Folkman,1997; Steger et al., 2008). Purpose is the second, motivational dimension of meaning (e.g. Baumeister, 1991, Deci \& Ryan, 2000; Ryan et al., 2008). It is essentially future-oriented and gives direction to life through the identification and the pursuit of higher goals (Martela \& Steger, 2016; Reker \& Wong, 2012). Purpose is value-driven and sets the norms for behavior (Heintzelman \& King, 2014). Finally, significance is the evaluative dimension of meaning (Martela \& Steger, 2016; Park, 2010). Significance is about the value and importance of life, feeling that life is inherently worth living. It follows from the evaluation of life as a whole and is also referred to in terms of self-worth or mattering (Baumeister, 1991; George \& Park, 2014).

\section{Meaning as connectedness}

While the threesome of coherence, purpose and significance provides guidance in the myriad of perspectives on meaning, it excludes an aspect of meaning that is also found to appear throughout the literature: the dimension of connectedness. Connectedness entails the awareness of the self not as a solitary being, but as part of a larger whole (Frankl, 1996; Reker \& Wong, 1988; Steger et al., 2009). It is also addressed in terms of self-transcendence or belonging (Emmons, 2005; Schnell, 2014; Steger, et al, 2009; Wong, 2012b, 2016 a,b). Within the literature, different explanations of meaning as a sense of connectedness are given: it is mentioned to be a fourth dimension of meaning (Schnell, 2014), an important source of meaning (Martela \& Steger, 2016), or as the core essence of meaning itself (Delle Fave \& Soosai-Nathan, 2014). 
Alongside these elaborations on the importance of connectedness to the experience of meaning, scholars also refer to connectedness in another way, thereby pointing to connectedness as a real-time interactional process. Delle Fave \& Soosai-Nathan (2014) note connectedness to entail a dynamic shift from a static self-orientation to the awareness of relatedness. This proposition seamlessly aligns with Martin Buber's philosophy of meaning as a process of meeting (Buber, 1965). Meeting is the real-time experience of an I-Thou connection to the other: a relationship of openness, mutuality and presence, in which the barriers of individual being are breached (Buber, 1958). I-Thou connections contrast I-It connections, in which subject and object are separate and the relationship is merely functional. And while meeting is always a temporary experience, it may have a lasting and transforming impact, contributing to a different way of engaging in the world (Morgan \& Guilherme, 2012; Friedman, 2005). Other studies on the value of connectedness are found to align with Buber's philosophy, emphasizing that it is within and through connection that meaning is made and personal growth may occur (Jordan, 1997; 2017; Kaplan \& Assor, 2012; Kron, 1994).

\section{Meaning as an affective state}

The final conceptualization of meaning addresses its affective nature. Meaning as connectedness is noted to be an emotional process in which people are affected and affect the other (Buber, 1985; Friedman, 2005; Jordan, 2017). The experience of meaning comprises a felt physical shift (Gendlin, 1996), that is proposed to relate to a specific group of emotions: the emotions of wonder, enchantment, awe and being moved. In this thesis, I call these the emotions of wonder.

It is mainly in the field of philosophy that the relation between these emotions and meaning is explored, and in which specifically connectedness as an aspect of meaning is highlighted. The emotions of wonder are opening and possibly mind-stretching emotions (Bennett, 2001; Menninghaus et al, 2015; Vasalou, 2015), that are brought about when people experience a deep connection to others, to objects or core values (Cova \& Deonna, 2014; Cullhed, 2020), to the mystery of life and existence (Schinkel, 2019; Vasalou, 2015), to something larger than the self (Schneider, 2014). They may involve a strong, affirmative 
attachment to life and existence (Bennett, 2001). In the descriptions of these emotions, the significance of the experienced connection clearly comes to the fore. The emotions of wonder are noted to direct attention to what is ultimately of value, either through unintended, surprising encounters or by intentionally re-seeing the unseen and taken for granted (Keltner \& Haidt, 2003; Schneider, 2004; Vasalou, 2015).

\section{Meaningful moments}

Meaning as a sense of coherence, purpose and significance, meaning as connectedness and meaning as an affective state - this thesis complements these conceptualizations of meaning by focusing on meaning as a personal experience. It investigates those specific moments in life that people perceive to be highly meaningful, thereby closely connecting to their felt reality. Throughout this thesis, the three conceptualizations of meaning will be employed to develop a deeper understanding of meaningful moments and the way these moments work. This paragraph presents an overview of what is currently known about these moments. It moves from the concept of meaning to the experience of meaning through meaningful moments: through memories of specific events that are felt to be of great value and significance.

\section{Typologies of meaningful moments}

Within the body of literature, (recollections of) meaningful moments are addressed by a variety of concepts, such as momentous events, personal event memories, self-defining memories, sacred moments, personal memories, nuclear episodes and contrast experiences (Anbeek et al., 2018; Goldstein, 2007; McAdams, 1985; Pillemer, 2001; Singer \& Blagov, 2004; Thorne, 2000). Many empirical studies feature one specific type of meaningful moment, such as epiphanies, peak experiences or death-related autobiographical memories: moments that have a specific valence, emerge in a specific setting, have a specific impact and/or appear in a specific domain or period of life (e.g. Antalíková et al., 2011; Bluck et al., 2008; Hoffman et al., 2012; McDonald, 2008). Overall, there is a focus on atypical, out of the ordinary moments with either positive or negative valence, in which something unintentionally happens that is disrupting 
(e.g. Anbeek et al., 2018; Hoffman et al., 2012, Thorne, 2000). However, though these categories have received less attention, meaningful moments may also be intentionally created, and be part of the ordinary, routinely nature of everyday life (e.g. Ganzevoort \& Roeland, 2014; Goldstein, 2007; Spagnola \& Fiese, 2007).

\section{Functions and functioning of meaningful moments}

From the outer characteristics of meaningful moments I now move on to their impact or function: what they do. Various studies clarify the way different types of meaningful moments may affect life, showing how they may lead to new insights, guide the pursuit of long term goals, increase a sense of life's significance, and contribute to a self-transcendent orientation towards life. These functions may be summed up in four aspects as mentioned by Wong (2012b): meaningful moments are (1) deeply felt, (2) deeply processed, (3) enlightening and (4) transforming.

Deeply felt: this first aspect relates to meaning as an affective state. It is generally mentioned that meaningful moments are emotionally intense, both at the time of happening and when recollected (e.g. Anbeek et al, 2018; Blagov \& Singer, 2004; Pillemer, 2001; Wong, 2012b). The experienced emotions in unintentionally encountered meaningful moments often consist of a paradoxical mix of both the positive and negative: they may bring extreme joy, amazement, and delight, and at the same time cause fear or uncanniness, and disrupt everyday life as they are confrontations with the atypical, unknown and mysterious (Hoffman, 1998; Schneider, 2009; Thorne, 2000). Scholars mention that these moments may also have negative valence, though this does not affect their impact: what becomes visible in both positive and negative moments is the same (Anbeek et al, 2018; Pillemer, 2001; Schneider, 2009).

This brings me to the second aspect of Wong's characterization of meaningful moments: they are deeply processed, connecting people to deeper layers of meaning beyond the factual and superficial (Wong, 2012b). The intense, bodily felt emotions are signs that something of extreme importance is revealing itself: the most significant concerns of our lives, our core values, the bigger picture of life and creation (Anbeek et al., 2018; Blagov \& Singer, 2004; Cova \& Deonna, 2014; McDonald, 2008; Schneider, 2009). Meaningful moments are noted to connect people to something "beyond the self': to universal values, to the 
community, to the mystery of life or the grandeur of the cosmos (Address, 2005; Anbeek et al, 2018; Maslow, 1959; McDonald, 2008; Schneider, 2009). Thereby, this aspect of meaningful moments clearly relates to meaning as connectedness, the second conceptualization of meaning as presented in this thesis. A meaningful moment may be intentionally created to experience this connectedness, but it may also be unintentionally encountered (Cova \& Deonna, 2014; McDonald, 2008; Thorne, 2000).

Finally, I regard the third and fourth aspects of meaningful moments as mentioned by Wong (2012b): they are enlightening and transforming. These two aspects point to the lasting impact that these moments may have: their power to permanently transform people's perspective on life and to influence, inspire and direct action long after their original occurrence (Anbeek et al., 2018; Cova \& Deonna, 2014; Hoffman et al, 2012; McDonald, 2008; Pillemer, 2001; Schneider, 2004). They are often intentionally recalled and retrieved, providing persistent affirmation and guidance (Singer \& Blagov, 2004; Pillemer, 2001). Concerning enlightenment, meaningful moments may lead to a shift in personal identity, a reorganization of values and priorities and a "stretching of the mind" (McDonald, 2008; Cova \& Deonna, 2014; Pillemer, 2001; Vasalou, 2015; Westerhof et al., 2010), which clearly relates to coherence as a dimension of meaning, as existing orders and belief systems are changed or stretched. Meaningful moments with positive and negative valence may both have this effect (Anbeek et al, 2018; Thorne, 2001). Concerning transformation, meaningful moments have the potential to influence morality, to guide action and the pursuit of long term goals (Anbeek, 2018; Pillemer, 2001; Westerhof et al., 2010; Wong \& Watt; 1991), a characteristic related to purpose as a dimension of meaning. Finally, this transformation may increase a sense of life's significance: meaningful moments are noted to make life fuller, richer and more worthwhile (Anbeek et al., 2018; Maslow, 1959) and contribute to a meaning orientation towards life as a whole (Wong, 2011, 2012a).

\section{The objectives of this thesis}

Overviewing the current body of literature, there is no doubt about the potential of meaningful moments to enhance a sense of meaning in life. The body of 
literature provides insight in the occurrence of meaningful moments, their impact and functions. However, three things may be noted:

First of all, looking at meaningful moments as a product, it becomes apparent that meaningful moments have been studied fragmentally; studies typically focus on one specific kind of meaningful moment. As of yet, there is no overview of different types of meaningful moments and their characteristics. Second, the body of literature lacks a cohesive picture of the emergence of meaning as a personal process. Though various aspects of this process are identified, studies do not elaborate on the way people construct the meaning embedded in their meaningful moments, nor do they address the emergence of meaning from meaningful moments as it unfolds over time, showing the way these moments work and impact life. Finally, I notice that, so far, the research on meaningful moments has mainly focused on these moments from a personal perspective: on the way one's own meaningful moments may enhance a sense of meaning in life. An interactional perspective has yet to be taken; for what happens when people share stories of meaningful moments? Investigating the potential of these moments to enhance a sense of meaning in life not just by reflecting on one's own meaningful moments, but by sharing these moments with others in a collective process, is of great value for the development of meaning eliciting interventions.

Following from these observations, the objective of this thesis is to deepen insight in the nature and functioning of meaningful moments, and in the way recollecting and sharing these moments may contribute to enhancing a sense of meaning in life.

\section{Research questions}

The research questions of this thesis are threefold and relate respectively to meaningful moments as a product (1), to the personal process of meaning as it emerges from meaningful moments (2), and to the interactional process of sharing meaningful moments (3): 
1 What are the characteristics of meaningful moments and how may they be categorized?

2 How do people experience meaning to emerge from memories of their meaningful moments?

3 How do people experience a sense of meaning to be brought about in the process of sharing meaningful moments with others?

\section{Foundations of this study}

\section{The Wonderful Life Question}

To understand the material that forms the basis of this study, it is necessary to describe the process that led to this $\mathrm{PhD}$, going back to its origin. Being engaged with questions about meaning both in my personal life as well as professionally, one day, somewhere in the fall of 2012, I came across a Japanese movie: "After Life" (Hirokazu, 1998). In this movie, a group of people who have just passed away check in to some kind of station between life and the afterlife. There, they are asked to choose one memory from their life to take to the afterlife; all other memories will be erased.

Immediately, I was intrigued by this movie, and specifically by the question to choose one memory from the whole of life to take to eternity. I assumed that this one memory, this one small fragment from the complete film of life, must be very meaningful in whatever kind of way.

Being a practitioner, I started using this question, that I named the Wonderful Life Question, in programs aimed at personal development, leadership- and team development. I created an intervention in which people share the memories they choose in answer to this question, listen to the memories of others and resonate on these moments, helping each other to elicit the meaning that is embedded within them. Over time, I continued to develop the intervention, aimed at establishing a sense of connection - to personal sources of meaning, to others which whom these memories are shared and, in a work related setting, to the collective purpose and higher goals. A great variety of people participated in the workshops and programs in which this intervention was employed: I worked with civil servants, bankers, coaching and training professionals, Dutch 
and international students, homeless people, women living in a women's shelter, health care professionals, nurses and festival attendants.

Within this practice, my assumptions about the quality of the Wonderful Life Question to elicit meaningful moments were continuously affirmed. In the programs, I observed the way this question immediately induces a process of scanning life and filtering crucial moments, resulting in a wide variety of selected meaningful moments. Working with meaningful moments in this way sparked wonder in me, and the desire to gain a deeper understanding of the nature and functioning of these moments and the way they may be put to practice. Therefore, with their permission, I started recording and transcribing the stories that people told about their meaningful moments, and I created the website lifeinonequestion.org through which people could donate their chosen memory. In this way, over the years I developed a data collection of meaningful moments from several hundreds of different people, varying in age from approximately twenty to eighty years old. This database of meaningful moments formed the starting point for this PhD. Over the years, different perspectives were taken to collect additional data on meaningful moments and on people's experience with the intervention based on the Wonderful Life Question.

\section{A narrative approach}

To investigate meaningful moments and their functioning, a narrative approach was chosen. Narrative is considered the mode par excellence by which people construct meaning and identity (Brockmeier \& Carbaugh, 2001; Bruner, 1991). "If you want to know me, you must know my story," McAdams says (1993). Narrative psychology accepts that we live in a storied world and that we make sense of events and give meaning to life through the stories we exchange (e.g. Bamberg \& Cooper, 2012; Brockmeier \& Carbaugh, 2001). It is not focused on what actually happens in a story, but on the way the storyteller interprets these happenings and connects the different elements of the story into a coherent whole (Murray \& Sools, 2014). Taking a narrative approach in this thesis means employing this meaning-constructing quality of the stories people tell about their meaningful moments, regarding these moments not only by their general 
characteristics, but by listening closely to the specific way the stories about these moments are told: the words that are used, what is said and what is not said, and the way the different components of the story are strung together into a coherent whole.

However, the question arises if the meaningful moments collected by means of the Wonderful Life Question may rightfully considered to be stories. Looking at meaningful moments as a product (research question 1), the descriptions of these moments in the dataset are generally short, varying in length from several sentences to a couple of paragraphs. The level of detail varies, and while some descriptions contain only the chosen memory, the focal event to take to the afterlife, others also include the context leading to this event. In sum, the descriptions of these short "film fragments" or snapshots of life, without any motivation of why they were chosen, do not fit in the picture of the classical story that has a clear structure, that is told to a specific audience to communicate an explicit moral (Bamberg \& Georgakopoulou, 2008). How then to consider the narratives of these meaningful moments? The answer to this question was found in the small story approach withing narrative psychology. The small story approach stretches the definition of narrative, and diverges from the dominant focus on sequence and emplotment as key features of narrative. It draws attention to under-represented narrative activities such as tellings of ongoing events, seemingly uninteresting small incidents and takenfor-granted truths (Bamberg \& Georgakopoulou, 2008), and recognizes that stories may vary from big to small (Ochs and Capps, 2001; Sools, 2012) on a variety of dimensions.

Narratives of meaningful moments, as collected by means of the Wonderful Life Question, typically have both big as well as small characteristics. They are small in the sense of being brief accounts of short incidents, rather than lengthy elaborations. They are typically big stories in the sense that they are very meaningful and highly tellable: chosen as the only moment from a whole life. Therefore, the small story approach, and particularly the dimension of tellability is particularly adequate to answer the first research question that targets meaningful moments as a product. 
Alongside this, the small story approach is of value to answer the second and third research questions, that focus on the emergence of meaning from meaningful moments as a personal process and an interactional process. The small story approach not only addresses the product of narration, i.e. the narrative, but also the process of narration (Ochs and Capps, 2001; Sools, 2013). It may therefore also be employed to investigate the way people reflect on meaning as it emerges from these moments over time (the dimension of linearity/temporality), and to study the interactional process of co-construction of meaning when sharing meaningful moments with others in the intervention (the dimension of tellership).

In sum, a narrative approach and specifically the small story approach is chosen as the main way to engage in the data of this thesis. Theory and methods from narrative psychology are used as a means of analysis to develop understanding of meaningful moments and their functioning, and put to practice to enhance the functioning of the Wonderful Life intervention.

\section{Outline of this thesis}

This thesis is organized around each of the three research questions:

+ Chapter two addresses the first research question: what are the characteristics of meaningful moments and how may they be categorized? It describes a study of one hundred narratives of meaningful moments from a variety of people, chosen in answer to the Wonderful Life Question. In the study, different types of meaningful moments are distinguished, and an overview is developed.

$+\quad$ Chapter three and four relate to the second research question: how do people experience meaning to emerge from memories of their meaningful moments? As a first step in answering this question, chapter three presents a study on familiar routines. Familiar routines were chosen because of their paradoxical relation to meaning: they may be a rich source of meaning, but just as well become habitual and lose meaning. The chapter describes a narrative investigation of a set of thirteen memories 
of familiar routines, resulting in the distinction of several mechanisms through which these moments are constructed to be meaningful.

Chapter four presents a study on the emergence of meaning from meaningful moments over time. Nine narrative interviews form the basis of this study, conducted about the way people experience a chosen meaningful moment to become meaningful and how this moment affected their life. The results of these interviews are brought together in a framework on the process of meaning emergence.

+ In chapter five, meaningful moments are approached from an interactional perspective, in order to answer the third research question: how do people experience a sense of meaning to be brought about in the process of sharing meaningful moments with others? This chapter describes a case study of the way a sense of meaning is brought about in a group counseling intervention in which meaningful moments are shared. In the study, Martin Buber's (1965) philosophy of meeting as the essence of meaning is operationalized to gain insight in the way the different elements of the intervention contribute to the emergence of meaning.

$+\quad$ Finally, Chapter six summarizes and discusses the results of these studies, including the strengths and limitations. Implications are provided for research and practice. 
General Introduction 


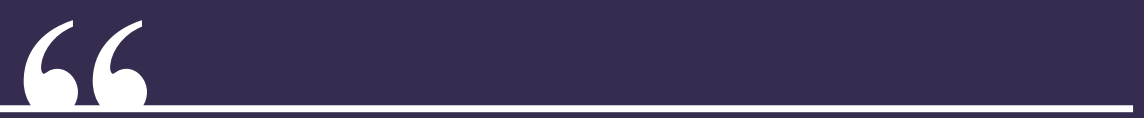

It is April 27, 2001. It is about six o'clock, it has been a very busy day. A day that started rainy, but became very beautiful. We have ended up in someone's backyard, where we are allowed to take pictures. We is my husband and I. And at that moment, we are sitting in a hallway. It has orange bricks, it is a little bit bleak, but there is a cozy place to sit: four chairs, bucket seats, in yellow ochre and blue. That's where we are sitting. And on the table before us are two glasses of water, that we cannot drink, because we are both too nervous. And then, two very sweet people walk by, we know them to be very kind people, and she says: "Look at them sitting there, they are so beautiful!" And I stand up, and with my whole being, from top to toe, toes that were sore because of my shoes, I say: "Yes! I am so beautiful!" I never felt so beautiful. I would want to relive that moment for a thousand times.

\section{y)}




\section{Chapter 2}

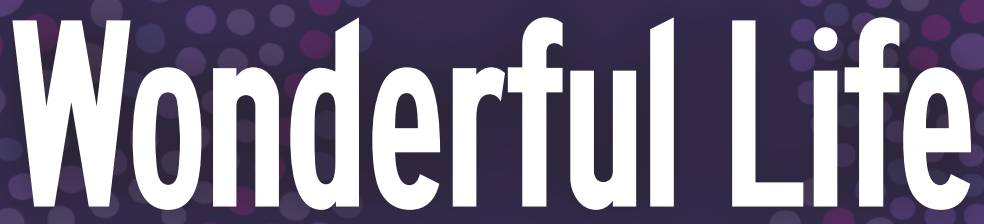

\section{Exploring wonderin meaningful}

moments

Van de Goor, J., Sools, A. M., Westerhof, G. J., \& Bohlmeijer, E. T. (2017). Wonderful Life: Exploring Wonder in Meaningful Moments. Journal of Humanistic Psychology. 
Wonderful Life

\section{Abstract}

In this article, we bring the study of meaning together with the emerging field of study focusing on the emotions of wonder: wonder, enchantment, awe and being moved. It is in meaningful moments that these two meet, and in our empirical study, we used the emotions of wonder as a lens to investigate meaningful moments. We applied a novel intervention, the Wonderful Life question, to elicit narratives of meaningful moments from 100 participants varying in age, profession and social status. Using characteristics of wonder retrieved from the wonder literature to qualitatively analyze these narratives, we identified five types of meaningful moments: opening up to life, facing the precarity of life, celebrations, countering the negative, and familiar routines. The study deepens insight in the way meaning is discovered in different types of meaningful moments. It supports the premise that there is potential meaning in any moment in life, and the mindset of wonder enabling the discovery of meaning. Finally, it pleads for the use of the Wonderful Life question as a means to elicit a wide spectrum of meaningful moments. 


\section{Introduction}

"The world is not inert or devoid of surprise, but continues to inspire deep and powerful attachments, and it is these attachments that we need" - Bennett, 2001 p.4

In this article, we bring together two hitherto largely separate fields of inquiry. The first is the well-established study of meaning, and the second is the emerging field of study focusing on the emotions of wonder, enchantment, awe and being moved - from now on called the emotions of wonder. It is in meaningful moments that these two may meet, as will be described. The aspect of wonder in meaningful moments, however, has only scarcely received attention yet, and with this study we aim to discover what new insights emerge by bringing these two fields closer together.

Therefore, we performed an empirical qualitative study using the emotions of wonder to develop a deeper understanding of meaningful moments in life. Studies on the emotions of wonder - mostly theoretical (e.g. Vasalou, 2015; Bennett, 2001; Keltner \& Haidt 2003; Schneider, 2005, 2014), some empirical (e.g. Bonner \& Friedman, 2011; Cova \& Deonna, 2014; Rudd, Vohs \& Aaker, 2012) - mainly focus on the impact of these emotions, but also give insight in the characteristics of moments that lead to the experience of wonder. In the study presented here we have used these characteristics as a lens to analyze meaningful moments and specifically the role of wonder within these moments.

\section{The Emotions of Wonder as a Lens to Study Meaning}

In this paragraph, we elaborate on our choice to use the emotions of wonder as a lens to study meaningful moments. After describing the characteristics of wonder, we clarify how the emotions of wonder are related to meaning. Finally, we focus on the characterization of meaningful moments and specify our research question. 
Wonderful Life

\section{Characteristics of Wonder}

Though distinctions can be made between wonder ${ }^{1}$, enchantment, awe, and being moved, these emotions are closely related and in this article we choose to focus on their commonalities. In this paragraph we will describe these commonalities, after which we will refer to the emotions collectively as the emotions of wonder and to the moments in which these emotions are experienced as moments of wonder. "To be struck and shaken by the extraordinary that lives amid the familiar and everyday," is how political theorist Bennett (2001, p. 4) describes enchantment, while philosopher and theologian Vasalou (2015, p. 219) relates wonder to a "surprise of the soul." This surprise may come as a response to something unforeseen, or may be caused by intentionally re-seeing the unseen and taken for granted. In line with these descriptions, existential-humanistic psychologist Schneider (2009) refers to awe as the sense of amazement, humility and wonder before the mystery of life. Schneider pleads for the intentional awakening to awe in order to revive the capacity to be moved - an emotion that philosophers Cova and Deonna (2014) have recently described. Being moved, they argue, is triggered by an extraordinary manifestation of core values. As becomes clear at these descriptions, what moments of wonder have in common is their extraordinariness.

This extraordinariness has both a contextual and an intentional dimension. The contextual dimension concerns the way in which the moment sticks out in the context in which it takes place, forming a contrast with the setting. Firstly, this contrast may be the result of an experience sticking out from the ordinary, regular and everyday. This is typically the case in new, unusual, and unique experiences, happening in contrast with the known and familiar; as Keltner and Haidt (2003) mention, when one encounters a stimulus that is strikingly vast in time, scope, complexity, ability or power. Secondly, the contrast may result from the emergence of something positive - an insight, life lesson, or positive value - against a negative background. Schneider (2009) mentions how awe may

1 It is important to make the distinction between wonder why/how (classical Descartian wonder), aimed at gaining knowledge, and wonder at or existential wonder (Sinclair and Watson, 2001; Hepburn, 1998), concerning acknowledgement and admittance of existence or truth. The type of wonder referred to here is wonder at. 
also be experienced in situations of great loss or trauma, as they remind us of the bigger picture of life and creation. In negative events, Cova and Deonna (2014) argue, a specific value may be at threat, and the situation serves as a reminder of its importance. Finally, these last authors note how moments may also be extraordinary without a contextual contrast, as positive values are in some cases salient by themselves.

The intentional dimension shows if the extraordinariness of the moment is induced incidentally, by chance, or by means of intentional action. An experience can be extraordinary, because it happens suddenly and unintentionally (Bennett, 2001). Here, it is the surprise of the unexpected that gives rise to an experience of wonder. Apart from the unexpected, there are also situations that are deliberately created to be extraordinary. Weddings for example are specifically designed to celebrate and make salient important values (Cova \& Deonna, 2014). However, moments may also be intentional in a different way, being neither unexpected or unintended, nor the outcome of especially designed situations. Taking a walk in the park, watching a baby sleeping moments like this happen as a matter of course, but may be perceived to be extraordinary because of an intentional mindset, fostered by a deliberate focus and awareness. It is a passion of inquiry, directed to the familiar, the takenfor-granted, in such a way that the extraordinary becomes visible within the ordinary (Bennett, 2001; Vasalou, 2015). This is the awe-based consciousness or "enchanted agnosticsm" as mentioned by Schneider (2004, p. 175, 2014). Here, it becomes clear that the experience of the extraordinary is not an objective affair, but a conscious act of seeing.

\section{Wonder and Meaning}

What is the connection between wonder and meaning? Within the multifaceted meaning-literature, we have chosen three perspectives to clarify the relation between meaning and the emotions of wonder: the perspectives of coherence (what meaning is about), illumination (how meaning is discovered) and transformation (what meaning does). 
Wonderful Life

\section{Coherence}

The perspective of coherence concerns the presence of order in the world, the sense that there is an underlying pattern beyond the factual and visible. Within the meaning literature, both a more cognitive and a more spiritual approach to this sense of coherence can be found, referred to by Sullivan, Kosloff and Greenberg (2013) as everyday and ultimate meaning. Within the cognitive approach, meaning is experienced when the world "makes sense," when we detect lawfulness, regularity and patterns in the world (Heintzelman \& King, 2013). It is a sense of rightness (King, 2012), an experience of confidence when what happens is predictable and explicable (Antonovsky 1987). This sense of rightness involves (universal) value systems, that take center stage in many theories about meaning (e.g. Baumeister \& Vohs, 2002; Schwartz, 1994; and earlier, Maslow, 1971). From a spiritual approach, coherence concerns the "bigger picture': how we are part of patterns at a higher, holistic or cosmic level, of the "grand narrative of creation" (Wong, 2014 p. 175). This level of ultimate meaning is the level of self-transcendence, acknowledging the mystery of life, a larger whole or higher truth (Frankl, 1966; Maslow, 1971).

Though the relation between the emotions of wonder and coherence has been found to be clarified through the cognitive approach (e.g. by Keltner and Haidt, 2003), the relation is mainly found in the spiritual approach, as made clear by various authors elaborating on the mystical, spiritual and sacred side of these emotions (e.g. Bonner \& Friedman, 2011; Cova \& Deonna, 2014; Curry, 2012; Funk Deckard, 2008). At moments of wonder, Jenkins (2012, p. 29) states, we experience that there is more to life than the material and the rationally explainable, and that "the collective sum of sociability and belonging is elusively greater than its individual parts." Vasalou (2015, p. 219) calls this the irruption of the "mystery" within our being, that "surprises the soul with itself" - a mystery that arouses a spiritual sense of wholeness (Scheider, 2014). Bonner and Friedman's (2011) empirical study of awe, based on personal stories in Schneider's book Awakening to awe (Schneider, 2009) supports the relation between this emotion and spiritual coherence, showing recurring themes of feeling part of something larger than the self, being connected to the universe and in touch with divinity. 
Finally, there is a clear relation between the emotions of wonder and values (Bettelheim, 2010; Curry 2012, Vasalou, 2015). Cova and Deonna (2014) argue how being moved leads to a renewed and reinforced attachment to core values, of which we have lost notice in the ongoing hustle of life. Vasalou (2015, p.31) calls this "wonder's evaluative yes': the virtue of aspiration which orders what is lower to what is higher, directing attention to the value of the object at which wonder is directed; thereby indicating the rightness involved in the sense of coherence.

Illumination

Illumination relates to the emotions of wonder and the process of meaning discovery. It is an aspect of insight (Castonguay \& Hill, 2007) that specifically focuses on the framing of an event in relation to meaning in life. According to Wong (2016), there is potential meaning in every situation, but it is up to us to discover it through reframing the experience into a larger, meaningful context. Similar to Steger and colleagues' notion of the presence and search for meaning (Steger, Kashdan, Sullivan \& Lorentz, 2008), King and Hicks (2009) have distinguished between the detection of meaning, when events fit in with existing beliefs and expectations, and the construction of meaning, when events are not consistent with core assumptions. To examine the construction and detection of meaning, King and Hicks (2009) performed an empirical study in which participants rated the meaningfulness of predefined hypothetical lifeevents, varying in significance and valence. The study shows that major events are perceived to be more meaningful than trivial events, and that meaning is primarily detected in major positive events and constructed in major negative events. The authors note that meaning detection may occur spontaneously in situations that serve as a reminder for (forgotten) assumptions about life, but may also involve the intentional enactment of values. In the case of meaning construction, an effortful meaning making process heals the gap between experience and expectation. Discovering meaning, therefore, is a process of illumination and (re-)connecting the dots. Other studies on meaningful moments supplement these insights. For example, Mc Donald (2008) performed a narrative inquiry with in-depth interviews on five reported epiphanies meaningful moments preceded by periods of anxiety, depression and inner 
Wonderful Life

turmoil. Results reveal several defining characteristics of epiphanies, amongst which is the acute awareness of something new or something that someone has previously been blind to, profound insights with permanent and lasting results.

Within the literature on the emotions of wonder, many references to this process of illumination can be found. Keltner and Haidt (2003) mention how the emotions of wonder provoke a need to update one's mental schema's, as they lead to a "stretching forth of the mind" (Aquina in Vasalou, 2015, p. 74). This boundary confusion (Bennett, 2001), causes not only charm and fear, but also creates space for novelty. Cova and Deonna (2014) mention how this "stretching forth" takes the form of the reorganization of our hierarchy of values and priorities. Therefore, the emotions of wonder can lead to paradigm shifts, as perceived reality, the taken for granted, is disrupted. Apart from these descriptions, mostly correlating with the constructing of meaning, the emotions of wonder are also involved in the detection of meaning. As has been mentioned before, wonder may also involve the intentional re-seeing the taken for granted (Bennett, 2001; Schneider, 2014; Vasalou, 2015).

\section{Transformation}

Meaningful moments and the discovery of meaning may have a lasting and transforming impact on life. Wong and Watt's (1991) empirical study on meaningful moments in life shows how memories in the categories of instrumental and integrative reminiscence, the latter described as the achievement of coherence, the reconciliation of discrepancies between ideal and reality and the acceptance of negative life events, are beneficial to successful aging. McDonald's (2008) study on epiphanies, as referred to before, highlights the profound and permanent change resulting from these experiences, described as "an existential leap into the unknown" (p. 211). This lasting impact is also found in Hoffman, Kaneshiro and Compton's (2012) empirical research on peak experiences among Americans in midlife. Following Maslow's procedure to elicit these types of meaningful moments, participants were asked to report a peak experience and asked to rate the degree to which this experience affected their view of life or attitude toward life. Results show a major impact. 
The theme of transformation is colored in by many studies on the emotions of wonder. Authors mention how the emotions of wonder have the power to transform lives (Schneider, 2004). They may lead to a strong, affirmative attachment to life and existence (Bennett, 2001), to a "felt global attitude directed at the world" (Cova \& Deonna, 2014, p. 456). This sense of being connected to life is accompanied by a feeling of empowerment: we are not an onlooker, but a full participant in life, with the power to affect our surroundings (Berman, 1981; Boje \& Baskin, 2011). An ethical attitude may be part of this transformation, as the emotions of wonder show that the world offers gifts, which in turn inspire people to give something back (Bennett, 2001; Vasalou, 2015). This is what Schneider (2005) designates as the responsibility, the challenge to respond. Here, we see how the above mentioned mindset of wonder as a passion to see the extraordinary in the here and now, may contribute to a meaning orientation towards life as a whole (Wong, 2011), encompassing a holistic worldview as well as the motivation to make a difference in the world.

\section{Characterizing Meaningful Moments}

Above, we have described the characteristics of wonder and have clarified the relation between meaning and wonder by showing how three major perspectives in the recent meaning literature, coherence, illumination and transformation, are reflected in studies on the emotions of wonder. Thereby we have laid a foundation for our study, which focuses on the characterization of meaningful moments through the lens of wonder.

Based on research and practice of working with meaningful moments, Wong (2012b) has developed a model that highlights four characteristics of the impact of meaningful moments, indicating that they are: (1) deeply felt - touching emotions in a deep and lasting way; (2) deeply processed - involving deeper layers of meaning beyond the factual and superficial; (3) enlightening - providing a solutions or leading to new discover and (4) transforming - enriching life, changing life's direction or restoring a sense of purpose and passion. These four characteristics clearly reflect the perspectives of coherence, illumination and transformation, thereby affirming the relation between wonder and meaningful moments. Where Wong focuses on the impact of meaningful moments, our 
Wonderful Life

study is directed at what happens inside these moments that accounts for their extraordinariness: at the aspects of wonder within meaningful moments. Therefore we address the research question: what characteristics of meaningful moments arise through the lens of wonder?

In the remainder of this article, we first introduce a novel method for eliciting meaningful moments: The Wonderful Life question. Next, we describe around 100 memories collected by means of this intervention, using the dimensions of context and intention to characterize and distinguish them. Finally, we reflect on how the proposed lens and method of elicitation contribute to enriching our understanding of meaningful moments in life.

\section{Method}

\section{Background: The Wonderful Life Question}

To elicit a variety of meaningful moments, we have chosen to work with a novel intervention, the Wonderful Life Question: What if there is an afterlife. There, all your memories will be erased, except for one. Which memory do you choose to take with you to eternity?

This question is derived from Hirokazu Koreeda's 1998 movie "After Life," showing people in the process of choosing their own memory to take to the afterlife. Inspired by this film, the first author of this article employed this question over the course of several years in many workshops in various context in her practice as trainer, coach and facilitator (see below under data collection for a more elaborate description of how the question was used).

Because people can take only one memory to eternity, we assume that the selected memory must be very meaningful. More specifically, the combination of small (choosing only one memory) and big (consequences: forever) forces people to focus on the most essential, salient moments of life. In actual practice this effect of the question has been observed on the level of both process and content. The question immediately induces a process of scanning life and filtering crucial moments, and results in a wide variety of selected moments, as will be shown. Therefore, the question seems adequate to elicit a wide range 
of meaningful moments. So, while the question is sufficiently open not to direct to specific types of experiences, it does target meaning that sticks out in the evaluation of a whole life.

The question bears resemblance to other elicitation methods with known relevance to the study of meaning. It can for example be considered to be an extremely compact form of life review, which has been proven to be effective in the improvement of personal meaning (Westerhof, Bohlmeijer, van Beljouw \& Pot, 2010). Moreover, there is a similarity to self-defining memories (e.g. Moffitt and Singer, 1994), yet these serve a different purpose (i.e. narrative identity). Finally, because recycling the memory in the afterlife is central to the selection process, the temporal orientation is more alike the future-oriented Letter from the Future instrument. This instrument has been proposed as prospective reflection instrument with clear meaning-related functions such as providing value and purpose to guide current thought and action (Sools, Tromp \& Mooren, 2015).

\section{Data Collection}

To contribute to the validity of our study, it was important to collect an extensive variety of meaningful moments; therefore we have used data from a diverse group of people in a variety of settings. In total 100 personal stories of meaningful moments have been collected from a total of 50 male and 50 female participants between approximately 20 and 80 years old. A wide range of participants has taken part in the workshops: professionals such as civil servants, bankers and training professionals; students in a school for intermediate vocational education; people living in an institution for homeless people and women's shelter, and festival attendants. Stories have been collected in workshops aimed at personal development; telling a personal memory in answer to the Wonderful Life question being part of the workshop. Data has been collected from a total of 14 workshops, in a range of four to 13 participants per workshop, with an average of eight. In seven workshops participants were completely unknown to each other, in the other seven workshops participants were acquaintances, being (direct) colleagues, classmates or coinhabitants. All participants took part either because the workshop was part of a larger 
(schooling or training) program they already participated in, or they signed up voluntarily. Stories have been audio recorded and transcribed. Informed consent was obtained to use their written memories for research purposes, and ethical approval for the study was given by the Ethics Committee of the Faculty of BMS at the University of Twente.

In the workshop format, people were asked the Wonderful Life question as stated above; the question itself had not earlier been revealed to them. They were given some time alone (around 15') to think of their own memory to take to the afterlife. These were then told and shared in the group and recorded with a data recorder. People were asked to tell their memory like a film fragment of their life, giving as much detail as possible, but without an explanation of their choice. During the sharing of the stories, other participants were asked to listen to the story without intervening; only the workshop facilitator sometimes asked general questions to help make a clear picture. In this way, a "poetical space" was created: resonating on the story, other participants were stimulated in their own process of connecting to meaning.

\section{Data Analysis}

To answer the question what characteristics of meaningful moments arise through the lens of wonder, we have performed a qualitative analysis, using both a deductive and inductive approach. The dimensions of context and intention were used as point of departure for the deductive part of the analysis. The three variations within the dimension context and the two variations within the dimension intention formed the coding scheme to code every story in a procedure with two independent coders, leading to the distinction of five story types. In addition, through an inductive approach by means of constant comparison, an extra dimension was identified to do justice to the variety of moments described. This is the dimension of focus, as will be described. This dimension is used to refine the description of each of the five story types. In our analysis we took a holistic approach, aimed at getting an impression of the complete story (Lieblich \& Josselson, 1994), therefore coding stories as a whole instead of in subsections - an approach also fitting the brevity and narrative character of the data. 


\section{Results}

First, we present a general overview to get an impression of the data. Next, we introduce the five story types that emerge from the dimensions of context and intention, and describe the third and new dimension of focus. Finally, we give a detailed description of each story type, using the dimension of focus to refine the characteristics

\section{General Overview}

In general, there is a wide variety in the memories that participants have chosen. First of all, they vary in length: some memories are very short, only a couple of sentences, where others are extensive and detailed, describing not only the focal event that people wish to take to the afterlife, but also including the context leading to the focal event. There are stories of major life events like marriage, death and the birth of a child, as well as more common, recurring and everydaylike moments like bedtime rituals, meeting with family or friends, or coming home after a day's work. Close family members are often the main people in the chosen memories: the storyteller's mother or father (often only one of the two), own children, love partner, grandparents, or a group of family members together. Apart from these there are stories concerning close friends, as well as complete strangers, and stories in which the storyteller is alone.

The setting of the memories also varies: there are memories in or around home, within nature, during a holiday or trip abroad, and in public places like hospitals, cemeteries or restaurants. Remarkably, there is only one memory in which the storyteller is at work, which is from a nun in Africa. She marvels at the special consciousness of a handicapped boy receiving the holy communion, his awareness of a greater force. This mystical, spiritual aspect is also present several other stories. Stories are set in contexts that can be labeled positive as well as negative, the latter e.g. being sickness, accidents and death, poverty, being in a personal crisis, or feeling lonely.

Storytellers can have both an active or a passive role in the memory. Active, by participating in action with others, acting towards others (giving, helping), or taking action directed at him/herself (making a personal decision, pursuing a 
Wonderful Life

personal goal). Passive, by experiencing the situation as an onlooker, but also as a recipient: receiving something non-material (love, solace, encouragement) or material (a dog, a book of personal memories). Money is not mentioned in any story, and in the few stories that feature material issues ("things"), they seem to have a symbolical meaning: experiencing freedom on a motorcycle, feeling the recognition of a son through his gift of earrings.

Within the stories, a great variety of positive emotions and values are mentioned, such as (ecstatic) happiness, pride, gratefulness, completeness, richness, freedom, trust, peace and love. Also, words like comforting, calming, feeling safe, heartbreaking, and relief are used, and expressions indicating an emotional state, like "feeling everything fell in its place." Negative emotions are mentioned only very sparsely and only alongside a positive emotion. Several times, people mention a feeling of forgetting time, being completely in the present, or feeling emptiness and quietness.

\section{Meaningful Moments: Dimensions and Story Types}

From the 100 memories in our dataset, it was possible to place 99 stories within the variations of the dimensions context and intention, only one story was too short and unclear to be positively assigned. Focusing on the variations within these dimensions, we have found five distinct story types, as shown in figure 1.

Within the data, an additional dimension has been identified. This dimension, focus, has emerged from the observation that each story has one or more points of attention: either the storyteller him/herself, the world and/or relations. The focus on self concerns events that give courage or personal strength to the storyteller. The focus on the world is found in stories in which the storyteller tells of a deep, personal and/or spiritual attachment to the world, as well as in stories in which the storyteller experiences the nature of the world and human life: its qualities, magic, and possibilities as well as its vulnerability and precarity. Finally, the focus on relations concerns the value of intimate bonds with other people. The dimension of focus has been applied within each of the five story types, helping to refine the description of the story types and show the variations within each story type. These story types are presented below. 


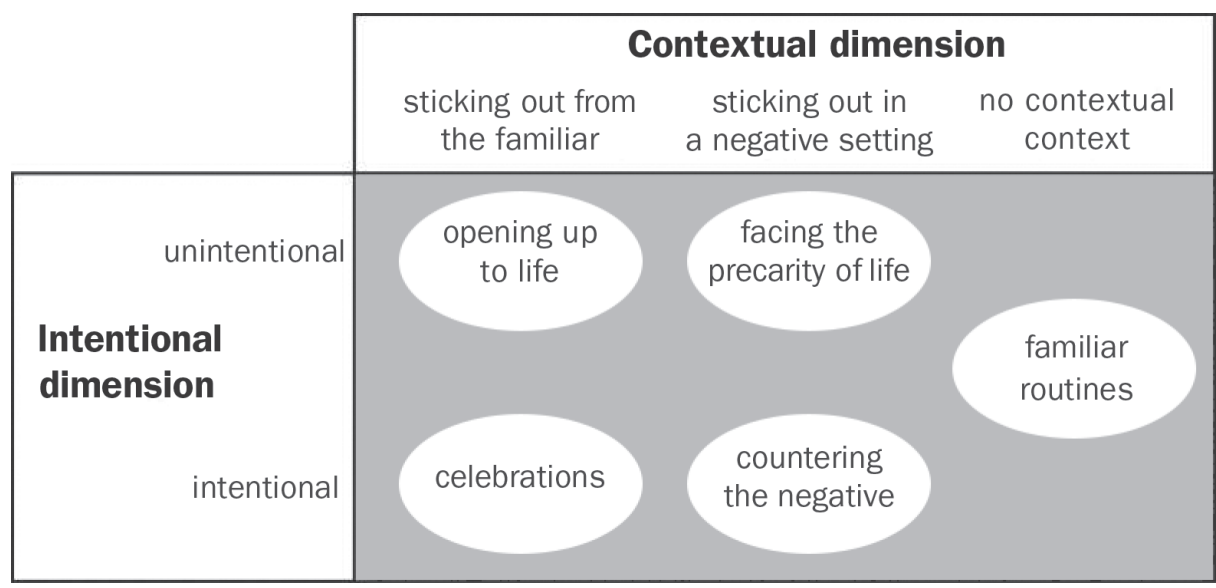

Figure 1 Story types emerging from the contextual and intentional dimension

Opening up to life

Stories of this type tell of events that stick out from the familiar (contextual dimension) and happen unintentionally, often suddenly and unexpectedly (intentional dimension). They are positive experiences, in which the storyteller encounters something unusual, surprising or new, concerning him/herself, but mainly concerning the world or relations (dimension focus). In stories with a focus on the world, the storyteller is usually an onlooker, watching a landscape, situation or event, either completely alone or with people only in the background. Stories tell of a sudden sense of belonging in a certain place, and of the thrill of discovery, like this story of a first visit to New York City," entering through the subway:

"And while others are busy with their own work you enter full of wonder, in the darkness, and at a certain point you go up the stairs [ ] and the moment you see the first rays of sun, hear the first sounds: the honking taxis, the crowds around you, there is so much positive energy and hustle around you, and that arouses so much emotion, such a variety of emotions. From fear of the unknown, excitement for the new, what if I go left, where does that take me, what if I go right, where does that take me..." 
Stories concerning the focus on relations tell of moments of unique togetherness, opening the storyteller to the quality of intimate relations. The storyteller is not an onlooker, but taking part in the event; mostly with close family members, though sometimes with strangers. These are often first time experiences or life events, like meeting a love partner or having a baby:

"It is a little over a year ago, and it was extremely hot outside, and I was
feeling really cold, because I was in the delivery room. And, yes, there
was a completely fresh newborn baby lying next to me, and my boyfriend
was with me, and... the nurse and the obstetrician had just left the room.
And, yes, it was the three of us for the first time, really a family. And for
me the whole world, it still moves me, the whole world around me was
just gone, truly. The only thing that counted to me was... that moment."

Facing the precarity of life.

Similar to the story type described above, stories of the type named facing the precarity of life also happen unintentionally (intentional dimension), but they stick out in a negative setting (contextual dimension). The moments have "dark" characteristics: they concern difficult or demanding situations like illness or accidents, death or dying, personal crisis and difficulties in pregnancy or childbirth. The specific event befalls the storyteller, but he or she experiences a sudden, positive outcome: a happy end, a valuable insight, a spiritual connection or life lesson. The stories are found to be focused on all three variations within the dimension of focus: self, the world, and relations, sometimes interwoven in one story. Stories often tell of experiencing the vulnerability of the world and of human life, especially when this concerns the life of loved ones (relations), like in this story of a dangerous childbirth:

"And.. the moment that.. yes, that he came out and I heard he was alive because he was, had been stuck, and I was, we both actually just survived and that he came out and started breathing and that I, too, had survived, and... that was really amazing! That I thought: okay, we're here! That was it: we're here! He is here, and I am also still here." 
Stories of this type may also concern life lessons, like in this story of a young man telling of a hiking trip in which his father collapsed:

"Yes, that moment. That was... that was odd. Because I hadn't anticipated it, because my father is very strong, physically. And when you see that happening you don't expect it. And then... yes you realize that that's not really all normal, to say so."

\section{Celebrations}

Celebrations are moments that are deliberately created and planned (intentional dimension) to stick out from the ordinary and familiar (contextual dimension). The attention is purposely directed to something positive and valuable. Stories mention life events like weddings, farewell or welcome home parties, as well as more frequent celebrations like birthdays. The storyteller has either intentionally created the celebration him/herself, or is taking part in a celebration created by others. Stories of this type sometimes focus on self, but always together with a focus on relations (dimension focus):

"It is a Saturday evening, and... a big party. Because my boyfriend and I were going to Angola. And [] a hundred people, my boyfriend is Scottish, so, Scotsmen with a kilt, my mother in law, my parents, my family, colleagues, many many friends, also many friends from, from abroad. And.. yes, everyone, just.. full, full in a party mood, in high spirits, dancing. And to us it is a gathering with everyone we know, and [ ] at the same time the closing of a period and the start of a new period, to go away. So that is.. from adventure to adventure. And that adventure itself. Yes, really, it is.. as a memory it is só rich, because everything, really, to me, that moment contains so much."

\section{Countering the negative}

Stories of this type tell of taking positive action (intentional dimension) in a negative setting (contextual dimension). The moments have a similar setting as stories of type 2, facing the precarity of life: difficult or demanding situations often concerning death or deprivation. However, in these stories the negative is countered or opposed by means of an intentional act; the agent being either 
the storyteller him/herself, or someone else acting towards the storyteller. Stories are mainly focused on relations, showing acts of soothing, comforting or healing:

\begin{abstract}
"My, my story is in the hospital [ ] and you see me sitting next to my father's bed. My father, who gave me my first shave when I was fifteen. You know, and then you get that soft hair, which is unwieldy, you can't shave it. The first, I think, two months when it started to grow my father shaved me, with a knife. And now I myself am sitting at my father's bed. He is 55 and heard he had a brain tumor two weeks before. [ ] There was quite a struggle between us, late puberty, [ ] rebelling against my parent's values. But I am sitting at that bed, and shaving him. [ ] The circle was completed. He shaved me, I shaved him."
\end{abstract}

\title{
Familiar routines
}

This is the name given to stories that do not stick out from the familiar and everyday, nor within a negative setting (contextual dimension). The events in these stories are not new or unique, but a recurring routine in the life of the storyteller. The events occur more or less frequently, varying from everyday routines in a homely setting, to less frequent but common holiday rituals and family visits. The intentionality of the stories of this type is not directly clear. From one perspective, the moments may be deliberately created to repeat and relive something special. In this case, stories of this type may be seen as repetitions of two other story types: opening up to life (type 1), and celebrations (type 3). The following childhood memory of a holiday ritual illustrates this repetition of the opening up to life:

\footnotetext{
"We always went to see if the goblin was home. Because there was, around the pond were several trees and one big one with a, at the foot of the tree just something like a little door. And I was always very excited because it could be possible that we were really so quiet that we would actually meet that goblin. Too bad it never happened. But to me, what is so great is that it always could have happened."
} 
However, the moments may also be happening as a matter of course, without a deliberate, conscious intention. In this case, it is an intentional mindset that leads the storyteller to see the value of the seemingly ordinary moment. This may be the case in stories of daily routines, like coming home from work or bedtime rituals:

"I am sitting in my youngest son's room, he is a year and a half old, and.. my other son is also sitting on his bed, he is three years old.. It's after dinner, they both, have taken a bath, they're wearing their pajamas, and I am reading to them. And.. that moment of connection, with.. with my heart and their hearts, and realizing yes, this is what it is all about. That's what I want to take."

Stories of this type fit one or more of the variations of the dimension of focus, though most commonly the focus is on relations, as is shown in the story above.

\section{Conclusions and Discussion}

In this novel, empirical study, we used the emotions of wonder as a lens to develop a novel characterization of meaningful moments. Literature on wonder shows that this extraordinariness is brought about by two dimensions: context and intention. Both dimensions have been found to appear in all but one of our collected stories. Analyzing stories through these dimensions, five types of meaningful moments have been distinguished: opening up to life, facing the precarity of life, celebrations, countering the negative, and familiar routines each extraordinary, wonderful and meaningful in its own way.

Looking at our results in relation to the three perspectives on meaning, we find our study to support the perspective of coherence and reveal new insights in the perspective of illumination in meaningful moments. Concerning coherence, many references to this perspective have been found within the collected stories. As shown, values are often mentioned spontaneously by participants, referring to their judgment of the rightness of the situation. Also, we have found references to patterns and the bigger picture, as participants mention 
Wonderful Life

"everything being just right, falling in place" and "the beauty of merging into, everything blending together, becoming one whole."

Concerning illumination, our study refines this perspective by showing the different ways in which meaning is discovered in each of the five story types. Story type celebrations typically concerns the detection of meaning, the enactment and reinforcement of existing value systems. In stories concerning countering the negative, coherence, or rightness, is restored by an intentional act. The two unintentional story types, opening up to life and facing the precarity of life, seem to connect the storyteller to higher levels of coherence than previously experienced. Stories in these categories tell of connecting to the light side of life, to possibilities, as well as to life's dark side: to precarity and fragility. The moments seem to awaken the storyteller to life's true nature, taking part in its magic as well as its tragedy. These results support Schneider's (2009) notion that moments of awe lead to an appreciation of the whole of life - the fragile as well as the exalting. However, our findings contradict King and Hicks' (2009) finding that meaning is primarily detected in positive events. We have found positive moments that clearly concern meaning construction: stories of opening up to life (and specifically with a focus on the world) typically tell of reframing - of amazement, discovery and thrill. This difference may simply be caused by the fact that King and Hicks worked with a predefined set of meaningful moments, in which events of the type opening up to life were not included. Therefore, we plead for the use of the more open Wonderful Life question in studies that aim to integrally cover meaningful moments.

Finally, concerning the perspective of illumination, our study sheds a special light on the small and seemingly ordinary moments in life that seem to be somewhere in-between intentional and unintentional. This is the fifth story type we have found: familiar, recurring routines. While King and Hick's study (2009) shows that people tend to ascribe less meaning to minor, trivial events, our study reveals how "regular" moments can be extremely meaningful. Apparently, meaning is not only encountered at extreme or rare moments or solely created during special celebrations, but is an inherent part of everyday life, as highlighted by several authors we have referred to (e.g. Bennett, 2001; 
Vasalou, 2015; Wong, 2016). In this category of stories, the special, unique and wonder of life is incorporated in familiar rituals and routines. But how consciously or deliberately are these "everyday celebrations" created? Is coherence intentionally enacted, or merely observed and appreciated? The question arises if it the special that has become habitual, or if it is the habitual becoming special. In the last case, it is the mindset of wonder, the awe-based consciousness, as referred to before, that leads us to see the extraordinary within the ordinary.

Interestingly, we see how our characterization of meaningful moments actually covers all moments in life, intentional as well as surprising, ordinary as well as unique, positive as well as negative. The Wonderful Life question reveals that there is potential value in any moment in life. This may be seen as empirical support for the approaches to meaning that follow Frankl (1969), stating that meaning is inherently there, but it is up to us to discover it. Perhaps it is the Wonderful life question that activates the mindset of wonder, aiding the process of illumination by seeing the extraordinary in any situation - a process that leads us to see more than the rationally explainable: life's magic, value and sacredness.

Concerning the last perspective on meaning we have discussed, transformation, it is not possible to relate our results to this perspective as we have not questioned participants about the impact of the moment on their life. Here, we see how Wong's (2012b) model of meaningful moments, as mentioned in the introduction, is complementary to our characterization. Both characterizations are of value because of their integral approach to meaningful moments, as opposed to studies describing a specific type of meaningful moment (e.g. McDonald, 2008; Hoffman et al., 2012; Bonner \& Friedman, 2011). Where Wong's model characterizes the impact of meaningful moments, our characterization focuses on the aspects of wonder inside these moments. Together, they color in the picture of meaningful moments, covering both what happens within these moments, as well as their deeper impact - or, referring to Mishler (1991) on narratives, showing both how the moment works as well as the work the moment does. 
Wonderful Life

While we have used the dimensions of context and intention to build our characterization, the dimension of focus has solely been introduced to add refinement. A further study of this dimension may deepen insight in meaningful moments, as the variations within this dimension - self, relations and the world - clearly relate to the meaning-themes of agency, communion and selftranscendence. The collected stories themselves are also valuable material for further use, giving insight in a great variety of meaningful moments. The stories show how values can be intentionally passed on to children, how travels to the unknown reveal the vastness of life's possibilities, how rites de passage strengthen feelings of belonging as well as autonomy, how broken relationships can be healed, how battles may be fought for truth and justice, how bonds may be strengthened in times of hardship and grief, ... Building on these results, these inspiring descriptions may be put to practical use to develop interventions to support people in the process of finding meaning in each type of moment in life.

Reflecting on our method, the great variety of participants and the large amount of collected stories contribute to the validity of the study. However, as data was collected in workshops, group dynamics may have influenced people in the story they chose to tell in answer to the Wonderful Life question. Though this question does not mention the emotions of wonder, it was possible to characterize all of the stories by means of the dimensions of wonder, except for one. As we have clarified the relation between wonder and meaning through the perspectives of coherence, illumination and transformation (Bennett, 2001; Berman, 1981; Bettelheim, 2010; Boje \& Baskin, 2011; Bonner \& Friedman, 2011; Cova \& Deonna, 2014; Curry, 2012; Funk Deckard, 2008; Jenkins, 2012; Keltner \& Haidt, 2003; Schneider, 2004, 2009, 2014; Vasalou, 2015), this finding may be taken as support that the Wonderful Life question is a valid way to elicit meaningful moments. However, the dimensions of wonder that we have found within our data may also be part of other emotions, that we have not studied. This is a limitation of the approach we have taken.

To finish, we would like to underscore that storytelling-interventions in groups, such as in Wonderful Life workshops, may facilitate the mindset of wonder and contribute to a meaning orientation towards life (Wong, 2011) . As has 
continuously been observed in Wonderful Life workshops in which data was collected, the Wonderful Life stories are deeply touching, and the story's impact is passed on from the storyteller to the listener. Parallel to the concept of elevation (Haidt, 2000) and its impact on morality, it can be of great value to further investigate this interactional component of the Wonderful Life question and its effect on opening up to wonder, to values, and connecting to a larger whole. For, as we have opened with Bennett (2001, p 4), it is these attachments that we need. 


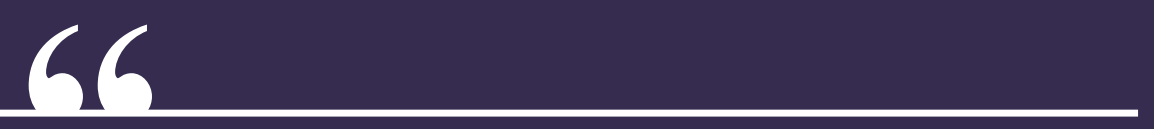

The memory I choose is a very recent one, only one and a half day ago. I picked up my mother from the town where she lives. My mother has Alzheimer's disease. She does not take good care of herself anymore, and she lives in a protected environment. And that afternoon, I give her a bath. And... I wash her. And she enjoys. And I become empty. There is only she and I. 


\section{Chapter 3}

\section{Unaveling tile

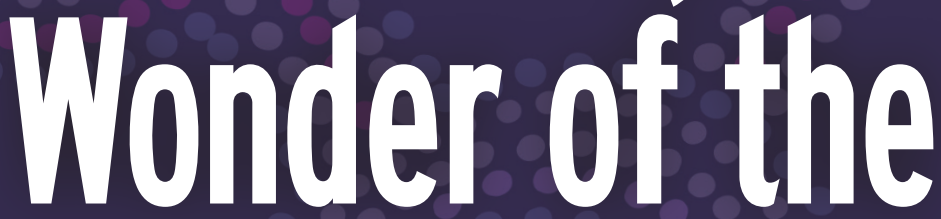

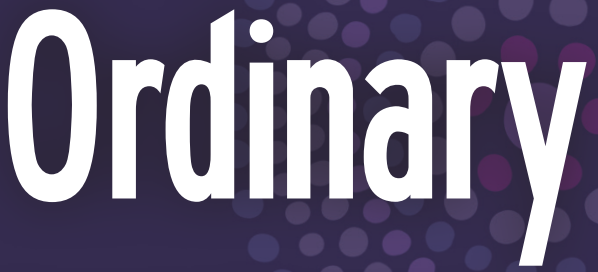

A narrative analysis of meaning

construction in memories of familiar

routines

Van de Goor, J., Sools, A. M., \& Westerhof, G. J. (2018). Unraveling the wonder of the ordinary: A narrative analysis of meaning construction in memories of familiar routines. Journal of Constructivist Psychology, 1-17. 


\section{Abstract}

Familiar routines may be a source of meaning, but just as well become habitual and lose meaning. To understand this paradox, a narrative approach was used to explore how meaning is constructed in memories of familiar routines. Two types were distinguished: routines of transition and routines of harmony. Results show how meaning construction may relate to the contrast between instrumental acts in the memories and their higher purpose. In routines of transition, meaning may emerge through a temporal transformation, while routines of harmony may become meaningful through the awareness of contrasting evaluations within the routine or a contrasting wider context. 


\section{Introduction}

In this article, we investigate how meaning is constructed in memories of familiar routines. Our search for the meaning potential of familiar routines stems from the recognition that meaning in life is a basic human need and crucial to wellbeing (e.g. Frankl, 1969; Mascaro \& Rosen, 2005; Reker, Peacock \& Wong, 1987; Ryff \& Singer, 1998), yet is increasingly under pressure. It is suggested that, in a world of acceleration, reason and rationality, one may easily become alienated or indifferent and lose a sense of wonder, enchantment and meaning in ordinary life (Heschel, 1976; Jenkins, 2000; Rosa, 2013). Familiar routines have the potential to counter this alienation, giving ordinary life a sense of purpose and coherence; as such being "a mechanism by which we can fulfill one of our deepest, most fundamental motivations - to feel as if our lives matter" (Machell, Kashdan, Short \& Nezlek, 2015, p 295). However, familiar routines are paradoxical, as their recurring nature may just as well cause us to take them for granted, thereby contributing to feelings of indifference.

In the meaning literature, familiar routines have only scarcely received acknowledgement for their potential to give meaning to ordinary life. Studies on meaningful moments focus mainly on unique, out of the ordinary moments such as life events, epiphanies and peak experiences: the birth of a child, an ecstatic feeling aroused by music, a sudden life changing insight in a period of turmoil (e.g. Hoffman, Kaneshiro \& Compton, 2012; McDonald, 2008). On the other hand, studies on routines tend to focus on the meaning and practice of routines in special contexts: in times of illness, aging and bereavement, or as part of religious, spiritual or therapeutic practices (e.g. la Cour, Johannessen \& Josephsson, 2009; Meira, Salgado, Sousa, Ribeiro \& Gonçalves, 2017; Pargament, 2011; Schnell, 2003). However, these studies do not explain why familiar routines that occur in ordinary life, outside these pivotal moments and contexts, could be meaningful.

It is this meaning potential of familiar routines, in the setting of ordinary life, that we focus on in this study. Though this potential is acknowledged in a recent study (van de Goor, Sools, Westerhof \& Bohlmeijer, 2017), it tends to be ignored and deserves more recognition (Heintzelman \& King 2014 a, 2014 
b). Specifically, we address the paradox that familiar routines entail: for how do these moments, that just as well may be taken for granted and contribute to feelings of indifference and disenchantment, become meaningful? In this study, we therefore focus on the way meaning is constructed within memories of familiar routines. We aim to gain knowledge about this meaning construction as a basis to develop interventions that counter disenchantment and aid the process of finding meaning in ordinary life.

In this introduction, we first describe the familiar routines that are the focus of this study. After this, we elaborate on both sides of the meaning paradox of familiar routines: on their potential to elicit meaning as well as to become meaningless. Finally, we introduce the narrative approach we adopted to investigate this paradox, focusing on the way meaning is constructed in the memories of familiar routines.

\section{Familiar routines: a description}

The meaning potential of daily activities having been recognized in various studies, (e.g. Machell et al., 2015; Steger, Kashdan \& Oishi, 2008; White \& Dolan, 2009), here we specifically focus on familiar routines: on moments that are familiar because they are known and ordinary (i.e. "to be expected in the normal order of events" (Merriam Webster, 2017)), and routine because of their repetitive nature, recurring more or less frequently over time. Drawing on narrative psychology, familiar routines can be classified as generic moments, which are distinguished from specific moments that are single-event and unique in their occurrence (Singer \& Blagov, 2000). Generic moments "are composed of equivalent events that repeatedly occur over time intervals that are not themselves part of the memory. The events blend or fuse together, and they contain the same characters, settings, happenings, and emotions" (p.12). Finally, concerning the scope of our study, we specifically focus on familiar routines in a regular, "life as usual" setting, that is not directly negative, threatening or precarious. In summary, the familiar routines that are the object of this study are known and ordinary, to be expected in the normal order of events; they have a repetitive nature, occurring over time intervals that are not themselves part of the memory; and they take place in a setting that is not directly precarious. 


\section{The meaning paradox of familiar routines}

In this paragraph, we address both sides of the meaning paradox of familiar routines: how they may be experienced to be meaningful and how they may lose meaning. Firstly, we integrate literature from the fields of psychology, religion and spirituality in two distinct viewpoints on familiar routines as a source of meaning. After this, we switch to the other side of the paradox, giving a short overview of the way familiar routines may just as well become mechanical and meaningless.

After Frankl's call for the recognition of meaning as our basic striving (Frankl, 1969), many studies on meaning have followed, leading to a variety of models and definitions. Two aspects of meaning life seem particularly relevant in relation to familiar routines, i.e. the experience of purpose and coherence (King, Hicks, Krull \& Del Gaiso, 2006; Martela \& Steger, 2016; Reker \& Wong, 1988; Ryff \& Singer, 1998; Steger, 2012). Where purpose refers to reason(s) to live and to long-term aspirations in life that motivate action, coherence refers to the comprehensibility of life, to an implicit order that transcends chaos.

Reflecting on the meaning of routines in relation to purpose, it is relevant to distinguish the ritual and instrumental function of routines. Where instrumental routines are utilitarian by nature, ritual routines are aimed at a higher purpose, e.g. the expression or experience of (group) identity, culture, religion, spirituality or values (Heinze, 2000; Hobsbawm, \& Ranger, 2012; Spagnola \& Fiese, 2007). In their study on family routines, Spagnola and Fiese (2007) clarify this difference by the effect of their disruption: while disrupted instrumental family routines may cause a hassle, disrupted rituals threaten family cohesion. They note how the instrumental and symbolical, ritual function may be found together in one routine. Ganzevoort and Roeland (2014) exemplify this by showing how the routine of gardening, apart from its instrumental function, may become a devotional activity, setting the stage "to receive life as a gift” (p. 92).

Next, we shift our attention from routine as a purposeful practice to routine as an experience of coherence. Meaning may simply be experienced when life and 
the world makes sense (Heintzelman \& King, 2014 a, 2014 b). Coherence refers to this sense of order, of an underlying pattern beyond the factual and visible. It is a sense of rightness (King, 2012), an experience of confidence when what happens is predictable and explicable (Antonovsky 1987). Coherence may be considered cognitively as well as spiritually: as the self-transcendent awareness of the way we are part of patterns and cycles at a higher, holistic level (e.g. Frank1, 1966; Maslow, 1971; Reed, 2008; van de Goor et al., 2017).

The routines we create often follow natural cycles of life, relating to rhythms of the day, season, year or human life phases. As they pattern our life by means of expected repetitions, they provide ways to comprehend and connect to life and existence (Romanoff, 1998). Within therapy, coherence is an orienting principle, aimed at providing structure and order in the context of chaos, trauma or loss (e.g. Gillies \& Neimeyer, 2006; Neimeyer, Herrero, \& Botella, 2006). Familiar routines may help to accept and appreciate the cycles of life, stimulate agency, give hope and facilitate healing (Ganzevoort \& Roeland, 2014; Imber-Black, 1991; la Cour et al., 2009; Mattingly, 1998). They connect us to traditions as well as to the transcendent meaning of our existence, to "something beyond the self" (Address, 2005 p. 224).

In sum, a routine may be a rich source of meaning, an experience of purpose or coherence. On the other hand, a familiar routine may just as well become mechanical and mindless. Because of its ordinariness, its repetitive nature, a familiar routine may become a habit, i.e. an automatic response to a specific contextual cue (e.g. Verplanken \& Orbell, 2003; Wood, Quinn, \& Kashy, 2002). Though habits are intentional and purposeful in their origins, they lose this intentionality in their execution, and are performed with less awareness or consciousness, and less thought and emotions (Bargh, 1994; Verplanken \& Orbell, 2003; Wood et al., 2002). This is more likely to happen to routines that recur frequently, e.g. on a daily basis; though we may just as well become indifferent to less frequently recurring routines, such as a yearly family dinner. Heschel warns for this anesthetizing effect of our over-familiarization with life and reality, pointing out how routine may become spiritual poison, as "life is routine, and routine is resistance to wonder" (Heschel, 1976, p. 49). 
So what prevents us from becoming indifferent to familiar routines, but instead causes us to value them as meaningful moments? Within the body of literature, several studies mention meaning construction to be mindset, a deliberate focus and awareness, a passion of inquiry directed to the familiar, the taken-for-granted, in such a way that the extraordinary becomes visible within the ordinary (Bennett, 2001; Vasalou, 2015). This meaning-constructing mindset is also referred to as the mindset of wonder (van de Goor et al., 2017; Vasalou, 2015) or awe-based consciousness (Schneider, 2004). Machell et al. (2015) suggest that this mindset may be stronger in the context of depression or negative events in life, as people in these circumstances might be more sensitive to daily events that boost meaning. The study of la Cour et al. (2009) supports this idea, showing how the awareness of the end of life may lead to the construction of new meanings in familiar, instrumental routines like cooking. On the other hand, Emmons (2000) refers to this mindset as an intelligence, a character trait, an ability "to invest everyday activities, events, and relationships with a sense of the sacred" (p. 30). While these studies show how the meaning construction mindset may be related to specific contexts or personal qualities, we assume it to be natural to all human beings, as part of ordinary life. But how then does this mindset work - how does the enchantment set in? Therefore, we shift our attention to how meaning is constructed in memories of familiar routines. In the next paragraphs, we introduce the narrative approach we have taken to answer this question.

\section{A narrative approach to meaning construction in ordinary life}

To study the meaning construction in familiar routines, we take a narrative approach, focusing on memories that people tell of familiar routines. It has been proposed that narrative is the mode par excellence by which humans construct meaning (e.g. Bamberg \& Cooper, 2012; Brockmeier \& Carbaugh, 2001; Bruner, 1991). Narrative psychology accepts that we live in a storied world and that we make sense of events and give meaning to life through the stories we exchange (Gergen, 1994; Murray \& Sools, 2014). However, within the larger field of narrative inquiry, there are different approaches and conceptualizations of narrative. Over the last decades, the usefulness of narratological and structuralist approaches to narrative for understanding storytelling in 
everyday life has been critically reviewed. For the purpose of understanding the way meaning is constructed in memories of familiar routines, we find the dimensional approach to living narrative, e.g. the so-called big and small story approach, particularly relevant (Bamberg, 2006; Georgakopoulou, 2006; Ochs \& Capps, 2001; Sools, 2013). This dimensional approach can be taken to depict text sorts, to sites of locating narrative, and may be applied as analytical lens for investigating stories. As text sort, small stories are literally short in contrast to whole life stories. As sites of engagement, small stories draw attention to under-represented narrative activities such as tellings of ongoing events, future or hypothetical events, seemingly uninteresting small incidents and taken-forgranted truths (Bamberg \& Georgakopoulou, 2008). This small story approach is aimed at understanding those other stories "that are still in the fringes of narrative research" (Georgakopoulou 2007, p. 36), changing the focus from narrative as product to narration as a process (Sools, 2013). Importantly, a small story approach stretches the definition of narrative, and diverges from the dominant focus on sequence and emplotment as key features of narrative. The dimensions of this approach, on which stories may vary from big to small (Ochs and Capps, 2001; Sools, 2013) are:

$+\quad$ tellership: personal experience of one narrator versus shared experience by multiple narrators

+ tellability: the degree to which a story or incident is worth telling as judged by the narrator

+ linearity/temporality: the time focus and manner of ordering in the story, varying from a past oriented, closed, causal path to other ways of ordering, including thematic and spatial orderings, and a focus on hypothetical, future or ongoing events

+ embeddedness: the extent to which the narrative stands on its own or is part of local discourse contexts

+ moral stance: the way the moral meaning of events is pieced together, varying from constant to uncertain, fluid and dynamic

Regarding these dimensions, memories of familiar routines typically have both big as well as small characteristics. They may be small in the sense of being 
brief accounts of short incidents, rather than lengthy elaborations. They are typically big stories in the sense that they are retrospective accounts of past experiences. In the way these memories are ordered, they may take the shape of a linear account of how events evolve over time from beginning to middle to end (big story), or may be ordered differently (small).

In relation to the meaning paradox of familiar routines, particularly the dimension of tellability is of interest. Events become tellable when they are significant, surprising or unusual, and worth reporting - which is typical for big stories. Low tellability concerns events that are expected or taken for granted, they are "no big deal" (Ochs and Capps, 2001). In the above mentioned literature on familiar routines, we find support for both high as well as low tellability. Familiar routines may be highly tellable because they are created to be valuable intentional actions or are experiences of coherence. On the low end of tellability, they are ordinary, not unique or surprising; as familiar routines may be instrumental, become habitual and thereby not worthy of telling. Thus, the dimension of tellability seems particularly apt to address the meaning construction paradox of familiar routines. In this study, we therefore use tellability as a lens to discover how memories of familiar routines are constructed to be meaningful.

\section{Method}

We used a qualitative, exploratory method to elicit memories of meaningful familiar routines, and performed a narrative analysis to investigate how these memories become tellable.

\section{The Wonderful Life Question}

The memories of meaningful familiar routines in this study have been collected by means of the Wonderful Life Question: What if there is an afterlife. There, all your memories will be erased, except for one. Which memory do you choose to take with you to eternity? 
This question, derived from Hirokazu Koreeda's movie "After Life", has proven to be a powerful way to elicit meaningful moments that stick out in the evaluation of a whole life, without directing to specific types of experiences (van de Goor et al., 2017). It elicits a great variety of memories of meaningful moments, both intentional and unintentional, special and ordinary, and in positive as well as negative settings. Memories describe major life events like marriage, death, depression, severe illness, and childbirth, as well as encounters in nature, trips and travels and more common, everyday-like moments like meetings with family or friends. Familiar routines have been distinguished as a specific category of meaningful moments elicited by this question (van de Goor et al., 2017). These memories, that fit the description of familiar routines as given in the introduction, differ from other categories as they do not form a contrast with the known and familiar (as is the case in the memories of unexpected, unusual and unique moments), nor do they stick out in a negative, precarious setting.

\section{Data collection procedure}

The Wonderful Life Question has been asked to people in workshops aimed at personal development. These workshops were held with a diversity of groups, varying from professionals in leadership training, students, homeless people, women living in a women's shelter, and festival attendants. In the workshops, participants were asked the Wonderful Life question, after which they were given some time alone to choose a memory. These were then told and shared in the group and recorded with a data recorder. People were asked to tell their memory like a film fragment of their life, giving as much detail as possible, but without explaining their choice or describing the wider context in which the film fragment took place. During the sharing of the memories, other participants were asked to listen to the story without intervening; only the workshop facilitator sometimes asked general questions to help the narrator make a clear picture and to "zoom in" on the essential part within a longer film fragment. Thus, a "poetical space" was created for participants to resonate on the memory and personally construct meaning from it. In this way, a total of 116 memories of meaningful moments have been collected in 16 different workshops; all have been transcribed, and consent was given for use in this study. From the total 
dataset we selected 13 memories in the category familiar routines, adhering to the criteria of familiar routines as described in the introduction.

\section{Narrative analysis}

To analyze how the collected memories of meaningful routines become tellable, we use the heuristic devices of evaluations and breach. Evaluations focus on what is mentioned in the narrative about the way the event is subjectively experienced by the narrator, relating to personal beliefs, desires, values and emotions (Bruner, 1991; Fludernik, 2003; Labov, 1972). Both the nature (i.e. the tone and character) of the evaluations and their manner of appearance in a narrative give clues about the way an event is experienced to be significant, unusual or surprising. Evaluations may be specifically and clearly stated, or they may be implied. Of interest to our study is also the distinction made between embedded and external evaluations (Labov, 1972). Where embedded evaluations are descriptions of feelings and values of the narrator within the narrative, during the event, external or extra-narrative evaluations are reflections from the narrator taking position outside of the event, commenting on the narrated situation.

Breach as a device focuses on the structural components of the narrative. It refers to a disturbance or fracture with the expected, the canonical or the takenfor-granted, that makes it worth telling (Bruner, 1986; Bruner, 1991; Murray $\&$ Sools, 2014). The breach arises out of the imbalance between two structural components or storyline elements that make up the narrative: the setting /scene (where?), agent/character (who?), acts/events (what happens?), means (with what help or hindrance?) and (5) purpose/goal (what for?). It is this imbalance that motivates the story and makes understandable how the storyline elements are connected into a meaningful whole (Burke, 1969; Murray \& Sools, 2014).

Concerning evaluations, we analyzed the nature of the evaluations that appear in the memories and how they appear in the course of the moment. Therefore, we firstly coded all explicit and implicit emotions, feelings, values, desires and beliefs within the narrated moment, after which we clustered them into groups of evaluations that are similar in nature. Also, we coded the way these 
evaluations manifest themselves in the course of the moment, discerning embedded evaluations from external evaluations. To discover the breach within the memories of familiar routines, we performed a storyline analysis as developed by Murray and Sools (2014), focusing on the storyline elements mentioned above: setting/scene, agent/character, acts/events, means, and purpose/goal. First, each storyline element was identified and characterized, and missing elements were detected. Next, we determined whether a breach could be found between two story elements, and if yes, we summarized the breach in one sentence.

In both the analysis on evaluations and breach, we critically regarded the influence of the researcher in her role as workshop facilitator, i.e. the dimension of tellership of the small story approach. Tellership concerns the involvement of conversational partners in the process of narration. Where the big story approach focuses only on the main narrator, an in-depth yet decontextualized analysis of personal experiences, the small story approach shifts attention to co-construction by multiple narrators. In the analysis of our data, it is important to recognize that the researcher has sometimes effected the narration by intervening in the narration and asking the narrator to bring focus in the chosen memory. Therefore, the small side of this dimension is of relevance in our analysis, and interventions by the researcher have been separately analyzed.

The analysis was performed by the first author of this article and then discussed with the second and third author to establish intersubjective agreement.

\section{Results}

To give an impression of our data, we first present a general overview of the characteristics of the thirteen memories of meaningful familiar routines in our study. Next we present our findings concerning the evaluations and breach, that have culminated in two types of memories of familiar routines.

\section{General overview}

The familiar routines in our study are from nine female and four male adults, varying in age from mid twenty to fifty. They all describe moments of family life, 
in which close family members are the main people: parents and grandparents, partners and children. The narrator is never alone. Ten memories are set in or around the own home or the home of a close family member, describing routines like family visits, Sunday morning hugs and frolics, coming home, and caring for children. Three memories are in a setting that is leisure-related, describing a holiday or summer routine: a walk in the woods, boating and sailing. Six memories are childhood memories, the other seven describe routines in the narrator's adult life. The descriptions tend to be short, varying from just several sentences to a couple of paragraphs. All of the memories contain positive feelings and values like safety, calmness, feeling connected, freedom, love, warmth, energy, flow, aloneness, completeness, and goodness.

Finally, we look at the attributes related to purpose and coherence: ritual vs instrumental in relation to purpose, and patternedness in relation to coherence. While all memories have been found to have ritual characteristics (e.g. celebrating), ten also have an instrumental function (e.g. preparing food). The patternedness of the memories relates to both cultural and natural cycles. Their recurrence varies from frequent, (the routines being part of daily life), to infrequent: (recurring on a yearly basis, e.g. relating to summer or Christmas holidays, or seasons).

\section{Two types of memories of familiar routines}

On the basis of the analysis of evaluations and breach, two types of familiar routines could be distinguished in the memories: routines of transition and routines of harmony. Where routines of transition describe a buildup of events, a transformation over time from one state of being to another, routines of harmony describe a stable situation with solely positive evaluations. In table 1 an overview of the frequency and characteristics of these two main memory types is presented, followed by an in-depth description of how these types differ with regard to the use of evaluations, the way the breach is narrated, and the way these are co-constructed between narrator and researcher. These variations within and between the two types are illustrated by means of six memories. In order to facilitate referral to these memories, each of these has been given a number and a name by the researchers. 


\begin{tabular}{|c|c|c|}
\hline & $\begin{array}{c}\text { \# of } \\
\text { memories }\end{array}$ & Characteristics \\
\hline $\begin{array}{l}\text { Routines of } \\
\text { transition }\end{array}$ & 5 & $\begin{array}{l}\text { Transition in time, sequential buildup of events } \\
\text { Evaluations } \\
\text { • express a polarity: two complementary or opposing } \\
\text { evaluations } \\
\text { - emerge in the form of a transformation from one } \\
\text { pole to another, sometimes higher valued pole (e.g. } \\
\text { aloneness } \rightarrow \text { togetherness) } \\
\text { Breach } \\
\text { - between instrumental act and higher purpose } \\
\text { - temporal breach that sequentially unfolds; the } \\
\text { instrumental act enables the transformation from one } \\
\text { pole into another }\end{array}$ \\
\hline $\begin{array}{l}\text { Routines of } \\
\text { harmony }\end{array}$ & 8 & $\begin{array}{l}\text { Stable situation without a buildup in events } \\
\text { Evaluations } \\
\text { • solely positive embedded evaluations, emerging } \\
\text { simultaneously, in two forms: } \\
\circ \quad \text { as a balanced polarity between two complementary } \\
\quad \text { or opposing evaluations or poles (e.g. safety } \leftrightarrow \\
\quad \text { freedom) } \\
\text { ○ only one single positive evaluation } \\
\text { - contrast may emerge between embedded evaluations } \\
\text { and external evaluations } \\
\text { Breach } \\
\text { - may be implied between instrumental act and higher } \\
\text { purpose } \\
\text { - non-temporal breach: the instrumental act enables } \\
\text { (opposing) evaluations to emerge simultaneously }\end{array}$ \\
\hline
\end{tabular}

Table 1 Two types of memories of familiar routines

Routines of transition

Memories of this type describe the transformation from one state of being to another, often more favorable state. These memories contain multiple actions or events in a clear sequence, resulting in a change or transformation. Looking at the nature of the evaluations and their manifestation in the course of the moment, we see how they appear as a polarity, i.e. two evaluations or poles that are complementary or opposite to each other. Examples of polarities that we 
have found are seriousness and playfulness, togetherness and autonomy, and reality and possibility. In memories of routines of transition, these poles appear sequentially, one evaluation transforming into another. In the memory below, 1 Coming home, we see how work/aloneness is transformed into togetherness/love.

\section{Coming home (male respondent, middle aged)}

Participant: "The image or the film fragment I see...It is a gentle day, a weekday. I am riding my bike home from the station... after work. My girlfriend has a cottage-like, little white house. I arrive home, put the bike in the shed, open the door, and... I'm just received with so much warmth... And yes, that is what I want to take. A, yes, just a harmonious and respectful relationship."

Facilitator: "So you enter the house, can you describe that?"

Participant: "Yes, that's hugging, and just, a lot, talking though the things of the day. And then together, being together. And that.... Yes it just feels so full of love..."

Facilitator: "And what if we have to shorten the film?"

Participant: "The part where I come home. The memory I want to take is that lovingness."

Facilitator: "How do we see that in your film?"

Participant: "The moment I enter the house."

Identifying a breach always involves some degree of interpretation, but the relative brevity and sparsity of the memories made breach identification in this study particularly challenging. Sometimes storyline elements were found missing or be described only very briefly. However, despite these difficulties, we were able to identify a breach in all memories describing routines of transition, and more importantly the breach was consistently found between the acts and purpose.

In memory 1 (Coming home) for example, we have defined the breach as "finding love (purpose) by entering the house (act)." This breach was detected in the following way, taking into account the co-construction of the narrated memory by researcher and narrator. In this memory, "receiving the warmth" of "a harmonious and respectful relationship" is initially constructed as desired 
result or purpose, but it is not entirely clear what it contrasts with. Is it the situated possibility of receiving warmth, the lack of access to this specific relationship, or the unavailability of other potentially warm relationships? In the first part of the excerpt, the narrator sets up a series of seemingly mundane acts (riding his bike home, arriving home, putting the bike in the shed, opening the door), which at the same time suggest anticipation. Here, the seemingly ordinariness and instrumentality of the acts are in contrast with the meaning and value found in the result of this action: in the warm welcome, the love and harmony (purpose). The researcher then zooms in by asking to specify the moment of entering the house, which is alluded to before but not explicitly mentioned. This facilitator intervention is successful in eliciting a more detailed account of the desired result, which gives further clues about what is so meaningful about that moment: "Yes, that's hugging, and just, a lot, talking though the things of the day. And then together, being together. And that.... Yes it just feels so full of love...." We learn in more detail about what constitutes "warmth" for him, e.g. "hugging," "talking through the things of the day," togetherness and a feeling "full of love." Next, the researcher requests to "zoom in" by asking to shorten the film. The narrator then chooses "The part where I come home," thereby specifying the essential part of the memory: "that lovingness." In response, the facilitator asks "how do we see that in your film?." In the narrator's reiteration of "The moment I enter the house" as the final act, we find extra support for the defined breach between act and purpose; the act transforming the situation to the desired state.

Although content-wise a completely different memory, the breach in the following memory, 2 Raising the sail, is technically similar: a breach between act and purpose. We identified a breach between the utilitarian act of hoisting the sail, and the higher purpose experienced as a result of this: experiencing freedom and autonomy. In this memory, there is no co-construction between narrator and researcher that helps to define the breach, but we see how the narrator herself "zooms in" and highlights the essence of the moment by saying "raising the sail, yes, that moment." Similar to memory 1, Coming home, we see how it is at this specific moment within the memory that a simple act transforms the situation and leads to the higher purpose. 


\section{Raising the sail (female respondent, middle aged)}

"My moment, well, imagine, I... I have a boat. And I am on this boat, it's a sailboat, about 11 meters long. My family is on board, two daughters, my husband. And...we are going on holiday, and then we... usually, when the weather is good, we set onto the ocean, so it is clear blue weather, a nice breeze, we navigate into the sluice here in IJmuiden, and after that the sluice opens, the sail is raised. You hear the seagulls, and the sun. And the... the moment the motor is turned off, that is the moment I would like to take. You know, just the sail, and me at the rudder, and the rest, well, yes they're on board, but that's of secondary importance. Raising the sail, yes, that moment."

Finally, as the examples above illustrate, we have found the breach in memories of routines of transition to emerge in a temporal way: the higher purpose emerges as a result of the instrumental act, after the instrumental act has finished. It is a breach that sequentially unfolds; the instrumental act enabling the transformation from one evaluation or pole into another.

\section{Routines of harmony}

Memories of this type describe a moment of harmony or wholeness: a stable situation that contains solely positive evaluations. Typical for these memories is that there is only one single act/event, or multiple events that do not build up to a certain point. In the memory below, 3 In the meadows, this is the act of playing in the fields. Concerning the nature of the evaluations in routines of harmony, we found that the evaluations within one memory often express a polarity, as in routines of transition. In memory, 3 In the meadows, we see a polarity between connectedness (safety, calmness, connection to each other and the land) and autonomy (playfulness, freedom from the rest of the world):

\section{In the meadows (female respondent, mid twenties)}

"I choose the moment that I step out of the car with my two sisters and my father, at one of our meadows, cornfields, at the end of a beautiful summer day. We are in the twilight, it is still comfortably warm, the atmosphere is calm and safe. This was a custom that occurred several 
times a week in the summer months: my father often took us to see how the grasslands and corn were doing at the end of the day. There, we played calmly in the nature, in our dresses and boots. Around us the sounds of grazing cows, a summer breeze, humming insects, the car radio in the background. The feeling of connection to each other, to the soil that my parents worked, and freedom from the rest of the world. I think I was around eight years old."

Regarding the manifestation of the evaluations in the course of the moment, we found the evaluations or poles to emerge simultaneously in the memories of this type. As there is no temporal buildup of events in the memory, there is also no temporal buildup in the evaluations. In memory 3 In the meadows, we see how autonomy is experienced at the same time as the connectedness to each other and the land. However, it was not possible to find a polarity in every memory, as the descriptions were generally very short. In these cases the evaluations seem to come together in one positive evaluation, e.g. happiness, as we see in memory 4 Frolicking:

\section{Frolicking (female respondent, mid fourties)}

"I have a very short memory. I am in bed with my family, with my husband and children. And they are frolicking delightfully. And...the, the love and happiness is overwhelming. And I am just enjoying that very much. Yes. That is a memory I want to take."

The results described above concern the embedded evaluations within the memories: the evaluations in which the narrator takes position within the event. These were all found to be merely positive evaluations. However, in several memories that also contain external evaluations, a contrast emerges between the embedded and external evaluations, i.e. evaluations in which the narrator takes position outside of the event, reflecting on the moment. While the embedded evaluations are all positive, the external evaluations have a different tone. This becomes clear in memory 5 Together on the boat, in which the external evaluations are underscored. While the embedded evaluations are all positive, an experience of togetherness, they form a contrast with the external 
evaluations that emphasize how this togetherness is not to be taken for granted, and is absent in the here and now, in which the narrator is alone.

\section{Together on the boat (female respondent, middle aged)}

Participant: "I just had a very happy childhood. And I was lucky to have that, because many children do not have happy childhood memories." Facilitator: "Can we cut out one fragment of that childhood movie?" Participant: "Well yes, that I am an only child, and I have.. yes, a father and a mother. I lost them both at a very young age... And the part before that I want to keep with me very much. I don't know how clear I have to be about that, but yes, I just think that is very precious, that I just. experienced that so preciously."

Facilitator: "You choose a whole period of your life. Can you choose a smaller fragment within that period?"

Participant: "Well, that's difficult, everything was beautiful. Oh yes, that the three of us, my father, he was a carpenter, and once he made, he made a boat. A rowing boat, and well, being on the water with the three of us. [ ] That's it actually, those were very beautiful moments, being on that boat with the three of us. And well, I would really like to keep that memory. And that it was really the three of us."

Facilitator: "And what happened there?"

Participant: "Yes, having fun, my father went fishing, I went swimming, I helped my father take the fish off the hooks and... throw them back into the water. And, and my mother she, yes, she was also with us, pleasantly, and she also went swimming with me,... and yes..."

In this memory, the contrast between the embedded and external evaluations is clearly a result of the co-construction between narrator and researcher. We see how the researcher asked the narrator to "zoom in" to a specific moment in her childhood: "can we cut out one fragment of that childhood movie?" and later: "can you choose a smaller fragment within that period?" From the answers to these questions, we learn what was so meaningful in the childhood of the narrator, i.e. being together with her parents: "being on the water with the three of us," "those were very beautiful moments, being on that boat with the three 
of us," "And that it was really the three of us." From the question to become more specific ("And what happened there?"), we learn about the setting and acts that contribute to this togetherness: father, mother and daughter each doing their own thing, and also engaging in each other's activities: "my father went fishing, I went swimming, I helped my father take the fish off the hooks and... throw them back into the water. And, and my mother she, yes, she was also with us, pleasantly, and she also went swimming with me." While this "zooming in" by the researcher has elicited these embedded evaluations, the narrator herself "zoomed out," taking position outside the event and reflecting on her childhood, leading to the underscored external evaluations that emphasize the absence and unusualness of togetherness in the here and now. It is through this combination of zooming in and zooming out that a contrast emerges.

Finding a breach in memories of routines of harmony was even more challenging than in routines of transition; these moments generally being even more compact. However, in several memories of this type a breach between the same storyline elements as in routines of transition may be implied: between a simple, instrumental act and higher purpose. In the following memory, 6 Storytime, interpretation of the storyline elements in this way may lead to the breach "connecting the hearts (purpose) through reading a story (act)." While the purpose is quite clearly mentioned by the narrator ("that moment of connection, with.. with my heart and their hearts") and highlighted through the sentence "realizing yes, this is what it is all about," the act is only briefly named ("I am reading to them") thereby possibly pointing to its smallness:

\section{Storytime (female respondent, middle aged)}

"I'm sitting in my youngest son's room, he is a year and a half old, and.. my other son is also sitting on his bed, he is three years old... It's after dinner, they both have taken a bath, they're wearing their pajamas, and I am reading to them. And... that moment of connection, with.. with my heart and their hearts, and realizing yes, this is what it is all about. That's what I want to take." 
Other than in memories of routines of transition, we have found the breach in memories of routines of harmony to be solely structural and not temporal. In memories of routines of harmony, the instrumental act and higher purpose that constitute the breach emerge simultaneously - when the act stops, the higher purpose stops as well. In memory 6, Storytime, the heart of the mother and the children's hearts are connected in the process of reading.

\section{Conclusions and discussion}

To discover how familiar routines are constructed to be meaningful, we took a narrative approach, using the heuristic devices of evaluations and breach to analyze how a set of 13 memories of familiar routines become tellable. A distinction was found between two types of memories: routines of transition and routines of harmony. In memories of routines of transition, meaning construction is evidently related to the process of change: the temporal transformation of evaluations within the memory, and to the contrast between the small, instrumental act and the higher purpose of the routine. In these routines this breach sequentially unfolds; the co-construction between researcher and narrator helping to "zoom in" on this breach. Routines of harmony are stable, solely positive moments without a build-up in events. Our findings show how memories of these routines may be constructed to be meaningful through the simultaneous emergence of contrasting, complementary evaluations within the routine - an unusual state of balance or harmony. As shown by the contrast between embedded and external evaluations in the memories, memories of routines of harmony may also be constructed to be meaningful through the co-constructed combination of zooming in and zooming out, i.e. valuing the specific memory against a wider, contrasting context. Though less clear than in memories of routines of transition, in memories of routines of harmony a similar contrast may be implied between the small, utilitarian act and the higher purpose of the routine. In memories of routines of harmony, this breach is non-temporal, the purpose emerging during the act instead of after the act.

Regarding these conclusions, we now reflect on the narrative approach we have taken to analyze meaning construction in memories of familiar routines. First 
of all, this approach has lead to a deepening insight on purpose in familiar routines. As shown, there is a large contrast between the ordinariness and instrumentality of the acts in the routines and the higher, ritual purpose that emerges as a result of these acts. Our study thereby confirms that the instrumental and ritual functions are often combined in one routine, empirically supporting Ganzevoort and Roeland (2014) and Spagnola and Fiese (2007), and highlights that higher purpose does not have to be sought in separate religious, cultural or spiritual rituals, but may be found through and within the instrumental routines of ordinary life. Additionally, it shows how these two functions manifest themselves differently in routines of transition and routines of harmony. The awareness of this contrast between the simple, instrumental act and its higher purpose may be an important factor to meaning construction in familiar routines. In resemblance to sacred objects (Goldstein, 2007), the cultivation of instrumental acts of ordinary life as "gateways to meaning" is a valuable field for further study.

Second, in relation to coherence, the narrative approach has shed light on the paradoxical, simultaneous appearance of opposing or contradictory values within familiar routines, thereby deepening insight in the way harmony or wholeness may be experienced. Though the fact that the analysis was performed on generally short memories raises questions about the validity of this finding, polarities (referred to in Maslow's later works as dichotomy-transcendence, (Maslow, 1971)) are an interesting topic for further study in the field of meaning research and specifically self-transcendence and coherence, showing how either-other thinking may be countered with and-and thinking.

Apart from polarities, of interest to coherence is also the process of "zooming in and out" in the narration process, brought about by the co-construction of narrator and researcher. While the researcher's focus on zooming in helped point to the breach, the narrator's zooming out shed light on the value of the routine against a wider context. Only against this wider time frame, that received a different evaluation than the routine itself, did a contrast emerge that accounts for the meaning found in the routine. While the body of literature is clear about the meaning of routines in a context of precarious or negative life 
events (e.g. Ganzevoort \& Roeland, 2014; la Cour et al., 2009), our study shows that this contrast may also be found in everyday life: though there is no explicit, direct precariousness, there may be some degree of disorder or disharmony, as the external evaluations in the memories have pointed out. And while external evaluations were not available in all memories, a context of disharmony may be implied - as we may understand how in the hassle of a busy working mother's life (memory 6 Storytime), the act of bedtime reading becomes a meaningful, harmonious moment of connection. The process of zooming out and reframing the routine against the inherent incoherence of ordinary life may be crucial to meaning construction in routines of harmony: in the awareness of disharmony, harmony becomes special.

The process of zooming out or reframing also aligns with the idea of meaning as a process of integrating past, present and future (Baumeister, Vohs, Aaker \& Garbinsky, 2013). Here, the question arises if it takes place during the routine, at the time of happening, or only in retrospective. After all, we have studied memories of familiar routines, which is inherently a process of looking back. Though our study thereby cannot directly answer this question of real-time or retrospectively experienced meaning, real-time reframing is suggested through the numerous embedded evaluations in our data. Further study is necessary to investigate if this is indeed a real-time process, and to provide empirical backing for the meaning-constructing mindset or mindset of wonder, that leads to experiencing meaning within the moment (Schneider, 2004; Vasalou, 2015).

In regard to the purpose of this study, we align with the small story approach, agreeing that there is a great challenge to create a space for telling seemingly ordinary experiences (e.g. Sools 2013). As an intervention, the Wonderful Life Question has proven to fulfill this need, highlighting not only the unique or extreme as meaningful, but also the small and ordinary. Additionally, its dual temporal focus is of interest, as it entails both an orientation to the past (a memory) as well as to the future (the afterlife). The Wonderful Life Question as an intervention thereby relates to "therapy in the poetic dimension" that does not center around recovering the past but around "the generation of a discourse of desire, that is, a discourse that creates images of a future that nurtures hope, 
excites and entices." (Gergen, 2006, p.173). As a means to gather data, we were sure to collect familiar routines that are extremely meaningful: The Wonderful Life Question immediately sends us "on holiday" (Freeman, 2006) and activates a process of reflection. However, the lack of extra contextual and evaluative information in the data have formed a restriction in the reflection on the construction of meaning. Additionally, we question if the amount of memories in our dataset was enough for a saturated analysis, leading to the possibility that there are other ways of meaning construction in familiar routines than in the two types we have found.

Finally, back to the object of our study: the meaning potential of familiar routines. Though raising new questions and leaving open ends, our study has deepened insight in meaning construction in familiar routines - repetitive experiences of paradox, wonder or awe, that open up to something valuable. An impact that possibly befalls us the first time we encounter it, but may be intentionally re-created to re-experience the wonder. These insights may contribute to the development of interventions that counter disenchantment and aid the process of finding meaning in ordinary life. For, while routine may be spiritual poison that kills wonder, the opposite is just as well true: that routine may be a spiritual potion, that brings alive wonder and unveils the meaning of ordinary life. 
Unraveling the Wonder of the Ordinary 


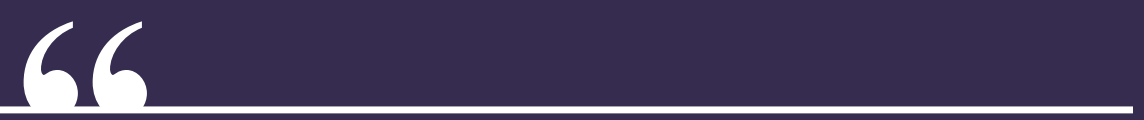

My father is from Poland, he came here during the war. But when he left, he took some sand from his family home. Right outside the front door, he scooped some sand in a bag and brought that with him. It is the sand he always walked on and that has been with him since childhood. And he brought it here, not knowing that he would never go back to live there. For after the war, he stayed in The Netherlands. The bag of sand was in a closet in our house. And he always said: "when I die, I want to be buried with that sand, because it is my birth sand." The moment I wish to take is at his funeral. I am standing around his coffin with my mother and my brothers. And I, as his youngest child, place that bag of sand at his feet, and then we close the coffin. 


\section{Clapter 4}

The Energence

of veaning

from veaning

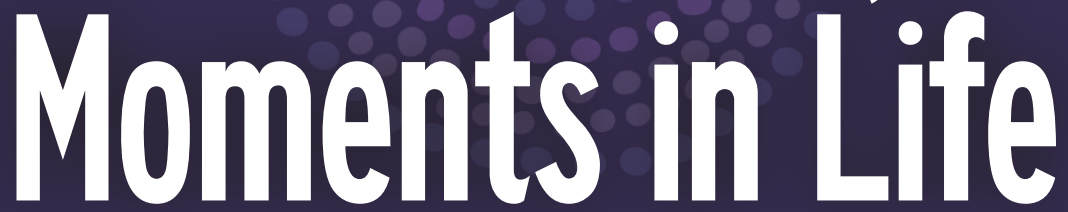

An integrated framework on the

process of discovering and creating

meaning

Van de Goor, J., Sools, A. M., \& Westerhof, G. J. (2020). The Emergence of Meaning From Meaningful Moments in Life. Journal of Humanistic Psychology. 


\section{Abstract}

Meaningful moments are specific events in life that are felt to be of great value and significance. This empirical study presents a framework on the way a sense of meaning emerges from these moments. Out of an existing dataset of narratives of meaningful moments, a purposeful sample of nine narratives was chosen from different participants, all middle-aged, higher educated and with an interest or profession in personal development. Interviews were conducted about the way these moments were experienced to be meaningful. A holistic content analysis led to the distinction of five main themes in the process of meaning emergence. The study showed how meaning discovery may lead to meaning creation, which in turn may lead to retrospective meaning discovery. Results highlighted the crucial role of the awareness of contrasts and letting go. Finally, the study showed a variety of ways in which meaningful moments have a lasting impact on life. The value of the developed framework lies in its focus on meaning as a process, integrating the concepts of coherence, purpose, significance and self-transcendence, and illustrating how meaning emerges through forward acts and discoveries as well as in retrospect. 


\section{Introduction}

Meaning in life is essential to wellbeing, yet a sense of meaning may easily get lost - not only to people living in difficult circumstances but also to "ordinary" people, caught in the disenchanting mechanisms of modern life (Rosa, 2013, 2016). This study focuses on the recollection of meaningful moments as a means to connect to meaning in life. Meaningful moments are specific events in life that are felt to be of great value and significance. However, as yet there is no clear understanding of the way these moments work. In this study the emergence of meaning is addressed as a process, investigating the way meaning is elicited from moments in life that people note to be distinctly meaningful.

\section{The emergence of meaning}

The question how people obtain a sense of meaning in life has been approached from a range of perspectives that highlight different aspects of meaning and its emergence. Although there is no clear consensus on the conceptualization of meaning, four dimensions are predominant across various perspectives: coherence, purpose, significance and self-transcendence.

Coherence is the cognitive dimension of meaning that refers to the comprehension of life (e.g. Antonovsky, 1987; Heintzelman \& King, 2013). Meaning is detected when events fit in with existing beliefs and expectations, taking the form of passive awareness or of intentional enactment of beliefs and values (King \& Hicks, 2009). On the other hand, when confronted with events that are inconsistent with core assumptions, meaning requires construction, i.e. the revision of these beliefs and assumptions to restore coherence. In the literature, this distinction is also addressed in terms of global and situational meaning (Park, 2010; Park \& Folkman,1997) and the presence and search for meaning (Steger, Kashdan, Sullivan \& Lorentz, 2008). While the presence of meaning is mentioned to be a state, the search of meaning is a process (Wong, 2017).

Purpose is the motivational dimension of meaning (e.g. Baumeister, 1991, Deci \& Ryan, 2000; Ryan, Huta \& Deci, 2008). Purpose is essentially future-oriented and gives direction to life through the identification and the pursuit of higher 
goals (Martela \& Steger, 2016; Reker \& Wong, 2012). It is value-driven and sets the norms for behaviour (Heintzelman \& King, 2014). Coherence may form the natural basis from which purpose emerges, a coherent framework for life being the "springboard" for motivational, goal-oriented action (Steger, 2012). In Maddi's works $(2004,2013)$, the motivational component of meaning is related to choice making, and a distinction is made between "choosing the past," in line with the familiar and comprehended, and "choosing the future," choosing the new and unknown, which expands a person's frame of meaning.

Significance is the evaluative component of meaning (Martela \& Steger, 2016; Park, 2010). Significance, also referred to in terms of self-worth and moral worth (Baumeister, 1991) or mattering (George \& Park, 2014) is about the value and importance of life and the feeling that life is inherently valuable and worth living. It follows from the evaluation of life as a whole, and thereby differs from happiness in the present moment (Wolf, 2010). A sense of significance seems to follow from both coherence as well as purpose: it is related to feeling "a valued member of a reality that transcends death" (George \& Park, 2014) as well as to eudaimonia, to the creation of a "good life" by behaving in a way that fits one's purpose and values (Martela \& Steger, 2016; Ryan, Curren, \& Deci, 2013).

The final dimension of meaning addressed in this study is self-transcendence. While coherence, purpose and significance are often approached from a personal perspective, i.e. in regard to one's own life, a more spiritual interpretation is also found within the body of literature, based on the notion that humans are not a closed system (Frankl, 1966). Self-transcendence is acknowledged to be a prominent source of meaning in most studies on meaning in life (Delle Fave \& Soosai-Nathan, 2014; Emmons, 2005; Wong, 2012a), and seems to run through each of the other dimensions. Coherence then is the sense of being connected to something larger than the self, transcending one's own life story, while purpose is related to serving a goal that is significant beyond the self (Firestone, Firestone \& Catlett, 2003; Park, Park, \& Peterson, 2010; Peterson, Park \& Seligman, 2005; Wong, 2014, 2017). A self-transcendent sense of significance is the outcome of these. This transcendent perspective on meaning goes back to the works of Frankl (1966) and Maslow (1971), who clearly acknowledge the 
mystery of life, a larger whole and higher truth. Frankl mentions three ways to experience meaning: through a creative path of purposeful action, through an experiential path of openness and receptivity towards the world, and through an attitudinal path of choosing a positive stand in any situation, specifically towards suffering (Frankl, 1959/2006; Wong, 2012a).

\section{Meaningful moments}

From these general insights on the emergence of meaning, the focus now shifts on the emergence of meaning through reminiscence of meaningful moments. Reminiscence, the recollection of personal memories, has proven to contribute to a sense of meaning in life (Westerhof, 2019; Westerhof \& Bohlmeijer, 2014; Westerhof, Bohlmeijer \& Webster, 2010). It occurs as a natural process and is applied in interventions, of which specifically life review, that focuses systematically on the entire lifespan, has shown to be of value. However, memories of single, particularly salient life events are also recognized for their potential to enhance a sense of meaning (Van de Goor et al., 2017; Wong, 2012b). These particular events, from now on referred to as meaningful moments, are the object of this study.

Meaningful moments are addressed by a variety of concepts, such as momentous events, self-defining memories, personal memories, nuclear episodes and contrast experiences (Anbeek, Alma, \& van Goelst Meijer, 2018; McAdams, 1985; Pillemer, 2001; Singer \& Blagov, 2004; Thorne, 2000). Empirical studies tend to focus on specific types of meaningful moments according to their valence, setting, impact and/or the domain or period of life in which they appear (e.g. Antalíková, Hansen, Gulbrandsen, De La Mata \& Santamaría, 2011; Bluck, Dirk, Mackay \& Hux, 2008; Hoffman, Kaneshiro, \& Compton, 2012; Hoffman \& Muramoto, 2007; McDonald, 2008). Overall, there is a focus on atypical, out of the ordinary moments, in which something positive or negative accidentally happens that is disrupting (e.g. Anbeek et al., 2018; Hoffman, Kaneshiro, \& Compton, 2012, Thorne, 2000). However, moments may also be deliberately created to be meaningful, and be part of the ordinary routines of everyday life (e.g. Ganzevoort \& Roeland, 2014; Spagnola \& Fiese, 2007; Van de Goor et al., 2017; Van de Goor et al., 2018). 
The impact and function of meaningful moments have been adequately summed up by Wong (2012b), mentioning them to be (1) deeply felt, (2) deeply processed, (3) enlightening and (4) transforming. In regard to the first, meaningful moments are generally noted to be emotionally disruptive and intense (e.g. Anbeek et al., 2018; Blagov \& Singer, 2004; Pillemer, 2001; Wong, 2012b). The experienced emotions are often a paradoxical mix of positive and negative, thereby relating to wonder and awe (Hoffman, 1998; Schneider, 2009; Thorne, 2000; Van de Goor et al., 2017). Meaningful moments are also deeply processed: they connect people to deeper layers of meaning beyond the factual and superficial. The intense emotions are signs that something of extreme importance is revealing itself: the most important concerns of people's lives, core values, the mystery of life, the bigger picture of life and creation (Anbeek et al., 2018; Blagov \& Singer, 2004; Cova \& Deonna, 2014; Maslow, 1959; McDonald, 2008; Schneider, 2009). In these descriptions a clear relation to self-transcendence can be found. Wong's third and fourth characteristics highlight the lasting impact of meaningful moments: their power to transform perspectives on life and to motivate, inspire and guide action long after their original occurrence (Anbeek et al., 2018; Cova \& Deonna, 2014; Hoffman et al., 2012; McDonald, 2008; Pillemer, 2001; Schneider, 2004). They are often deliberately recalled, providing persistent affirmation and guidance (Blagov \& Singer, 2004; Pillemer, 2001). There are many references to their enlightening quality: how they lead to new discoveries, to a change in personal identity, a reorganization of values and a "stretching of the mind" (Bennett, 2001; Cova \& Deonna, 2014; McDonald, 2008; Pillemer, 2001; Vasalou, 2015; Westerhof et al., 2010). Concerning the transformative impact of meaningful moments, Wong (2012b) mentions how they may change life's direction and restore a sense of purpose and passion. They have the potential to influence morality and guide the pursuit of long-term goals (Anbeek et al., 2018; Pillemer, 2001; Westerhof et al., 2010; Wong \& Watt; 1991). In this way, they may increase a sense of life's significance, make life fuller, richer and more worthwhile (Anbeek et al., 2018; Maslow, 1959), and contribute to a self-transcendent orientation towards life (Wong, 2011). 
Reviewing the literature, many insights were found on the occurrence of meaningful moments, their impact and functions, with parallels to the meaning dimensions of coherence, purpose, significance and self-transcendence. However, the body of literature lacks a cohesive picture of these aspects in relation to the emergence of meaning from meaningful moments over time. Therefore, in the present study, attention is directed to meaning as a process, with the purpose to develop an integrated view of the way people experience meaning to emerge from meaningful moments as they naturally occur in the flow of life. The research question is: how does meaning emerge from meaningful moments?

Building on the proposition that people make sense of events and give meaning to life through the stories they exchange (e.g. Bamberg \& Cooper, 2012; Bruner, 1991; Murray \& Sools, 2014), a narrative approach was taken to answer this question. The study therefore focuses on accounts of personal experiences with the process of meaning emergence: on narratives of meaningful moments and on the subjective interpretations of how this meaning unfolds over time.

\section{Method}

\section{Participants and their meaningful moment}

An existing dataset of memories of meaningful moments formed the basis for this study. The memories in this set were collected in various ways: in storytelling workshops aimed at personal development, through a form on the public website of the research project and through e-mail. Through each of these channels, people were asked to choose and write down one meaningful moment from their life in answer to the Wonderful Life Question: What if there is an afterlife. There, all your memories will be erased, except for one. Which memory do you choose to take with you to eternity? This question has proven to be a powerful way to elicit meaningful moments that stick out in the evaluation of a whole life, without directing to specific types of experiences (Van de Goor et al., 2017). In this way, a total of 43 meaningful moments were collected from a variety of people, of whom only sex and contact information were known beforehand, and in some cases also age and profession. 
For this study, a mixed criterion and maximum variation strategy was used to select a purposeful sample of meaningful moments from this set (Palinkas, Horwitz, Green, Wisdom, Duan, \& Hoagwood, 2015). The sample was chosen to represent each of five categories of meaningful moments as distinguished by Van de Goor et al. (2017), from a mix of both male and female participants. As other demographic information was not available for all participants, it was not employed in the selection process. Nine participants were selected in this way. Table 1 gives an overview of the participants (whose names are pseudonyms) and the categorization of their meaningful moments along the dimensions of context and intention. All participants were native Dutch by nationality and higher educated; many of them have a degree or interest in psychology, philosophy, spirituality and/or personal development; their professions vary from teacher, philosopher, psychologist, trainer and counselor to musician and civil servant.

\begin{tabular}{|c|c|c|c|}
\hline \multirow[b]{3}{*}{ unintentional } & \multicolumn{3}{|c|}{$\begin{array}{l}\text { Contextual dimension } \\
\text { the way in which the moment sticks out in the } \\
\text { context in which it takes place }\end{array}$} \\
\hline & $\begin{array}{l}\text { sticking out from } \\
\text { the familiar }\end{array}$ & $\begin{array}{c}\text { sticking out in } \\
\text { a negative setting }\end{array}$ & $\begin{array}{c}\text { no contextual } \\
\text { contrast }\end{array}$ \\
\hline & $\begin{array}{c}\text { Harry }(m, 55) \\
\text { Jonathan }(m, 63)\end{array}$ & $\begin{array}{c}\text { Patricia }(f, 51) \\
\text { John }(m, 54)\end{array}$ & \\
\hline $\begin{array}{l}\text { Intentional dimension } \\
\text { if the meaning emerges from an } \\
\text { experience that is incidentally } \\
\text { encountered or not preconceived to } \\
\text { be meaningful, or if the moment is } \\
\text { deliberately created to be meaningful } \\
\text { through purposeful action. }\end{array}$ & & & Anne (f, 45) \\
\hline intentional & $\begin{array}{c}\text { Joe }(m, 69) \\
\text { Carmen }(f, 54)\end{array}$ & $\begin{array}{c}\text { Otto }(\mathrm{m}, 39) \\
\text { Charlotte }(\mathrm{f}, 58)\end{array}$ & \\
\hline
\end{tabular}

Table 1 Selection of participants according to category of meaningful moments 


\section{Materials and Procedures}

Narrative interviews (Bauer \& Gaskell, 2000) were conducted with each of the participants to discover the way they elicit meaning from their chosen memory. In a narrative interview, the researcher asks open-ended questions that stimulate the participant to respond in a narrative form. To support the interview, a topic list was prepared by the three researchers collaboratively. It was designed to give room for participants to address various aspects of the emergence of meaning from their chosen moment; the topics loosely relating to Wong's (2012b) aspects of meaningful moments and the four dimensions of meaning, without addressing them directly. The topic list is presented in table 2.

\begin{tabular}{|c|c|}
\hline Topic & Questions \\
\hline Feelings & $\begin{array}{l}\text { Going back in time to the moment as it happened: how did you experience } \\
\text { it then? Can you describe your feelings at the time? } \\
\text { How do you feel about the moment now, looking back on it? }\end{array}$ \\
\hline Meaning & $\begin{array}{l}\text { Why did you choose this particular moment? } \\
\text { What is the most important part of the moment and why? } \\
\text { How would you describe the essence of this moment (in terms of a value } \\
\text { or insight)? }\end{array}$ \\
\hline Context & $\begin{array}{l}\text { The moment is a small fragment from the larger story of your life. How } \\
\text { does the moment fit in that story: what happened before and after? }\end{array}$ \\
\hline $\begin{array}{l}\text { Impact in } \\
\text { context }\end{array}$ & $\begin{array}{l}\text { Looking at the moment from its place in your life story: how did it impact } \\
\text { your life then, at that moment? And how does it impact your life now? }\end{array}$ \\
\hline $\begin{array}{l}\text { Nature of } \\
\text { impact }\end{array}$ & $\begin{array}{l}\text { In which way did the moment have impact on: } \\
\text { - Your relation to yourself? } \\
\text { - Your relation to others? } \\
\text { - Your relation to a larger whole? }\end{array}$ \\
\hline
\end{tabular}

Table 2 Topics used in the narrative interview

In the interview, conducted by the first author of this article, the participant was firstly asked to retell the chosen memory and freely elaborate on it. This enabled the participant to "relive" the chosen moment and gave the researcher insight into spontaneously mentioned aspects of the emergence of meaning. Next, the interview was conducted with support of the topic list; topics only actively being brought in by the researcher if not spontaneously addressed by the participant. 
To stimulate the participant's reflection on the emergence of meaning from the chosen moment, the interviewer asked follow-up questions in response to both the content and to the emotions expressed during the interview (e.g. "can you elaborate on that?," "can you tell how this moves you?"), sometimes relating given answers to what participants mentioned earlier in the interview.

Each interview was audio recorded and transcribed verbatim. After the interviews Joe's memory, initially categorized as intentional, was replaced in the category unintentional, as the interview gave more clarity on the deliberateness of the moment than initially interpreted from the text.

\section{Data analysis}

In order to develop a holistic understanding of the emergence of meaning from the chosen memory in the participant's life, it was of importance to take into account the stories as a whole instead of focusing on separate elements. A holistic content analysis (Lieblich et al., 1998) was found to be particularly appropriate for this, as it retains the temporal dimension of the story in order to understand its elements in relation to each other. Holistic content analysis is an interpretative process, in which each interview is read and reread several times to let the whole narrative speak, and to discover specific themes that stand out in the story. For a description of the steps in this process, see Lieblich et al. (1998).

In this study, the holistic content analysis was performed by the researcher who held the interviews, interpreting the data and noticing themes in regard to the research question concerning the emergence of meaning. A general impression was written of each interview, including these themes, as well as other characteristics that stood out. These general impressions were discussed with the other two researchers, after which the method of constant comparison (Hallberg, 2006) was employed to oversee all interviews and select the themes most relevant to the emergence of meaning. Next, the first author of this article coded these themes in the interviews and followed them through the texts, paying attention to their (dis)appearance, context and prominence. These results were discussed again with the other researchers, thereby working towards an integrated framework on the emergence of meaning from meaningful moments. 


\section{Results}

First, to give an impression of the interviews, the portraits of three different participants are presented. Doing justice to their stories as a whole, these portraits illustrate the way these participants experienced the emergence of meaning from their chosen meaningful moment. Next, a description is given of the themes in relation to the emergence of meaning that were found to run through the three portraits and all of the other interviews. Finally, these themes are brought together in an integrated framework.

\section{The emergence of meaning: three portraits}

John's moment of meaning discovery

In John's chosen memory, he and his wife are in the hospital, and he holds their baby daughter while she is dying. Though the moment is a deliberate farewell, it is the new, unknown experience of death within this moment that striked him the most: "Slowly, I felt life leaving her. And I felt, then, what death was... It had a tremendous impact on me. Yes, a depraving experience. Like something is cut through, and says: this really isn't here anymore." John elaborated on the horror of the experience, though at the same time he was aware that it was special, mentioning that "it is awful. Like holding a bag of potatoes: there's no life in that either, it's just mass. So that's very, very miserable, but at the same time you feel this is something very special and unique." To John, this intense experience of death was at the same time a moment in which he discovered meaning: what it is like to be really alive, to be connected to the essence of life:

\footnotetext{
"Connection to yourself, [experiencing death] brings you deeply in contact with who you are and what you feel. Also because it is burdensome. And because it is burdensome, it is pure, it is real, and by experiencing, feeling it and saying it, you think yes, apparently, this is life. This is the essence, what you feel."
}

As these quotes show, John unexpectedly experienced a strong contrast between life and death in the moment, a polarity. This contrast contributed to the salience of the moment and to the discovery of meaning: to the experience of being connected to the essence of life. In this polarity between life and death 
the characteristics of self-transcendence can be recognized: connecting to life's universal forces. The emotions that John experienced also relate to this polarity, as he mentioned the moment to be both horrible as well as special and unique in a positive way - a combination typical for wonder and awe, as is John's heightened sense of awareness: "You see everything very differently. Clearer, sharper, more from a higher viewpoint. You just feel that you experience things in a different way than normal."

John mentioned that he went through these emotions several times in his life, reliving the moment of his daughter's death. During the interview, this also happened. He elaborated on his comprehension of the value of going through this emotion:

\footnotetext{
"Yes, certainly, it strengthens you. You do not feel any doubt anymore. Yes...that's why you have to admit it [the emotion]. Of course you're afraid of it, because it always precedes that, that moment of loss of control, you lose control, are overwhelmed by emotion. [ ] But every time it feels like a liberation. If you would hide it, yes, then then then you would die. So by making room for it, it feels like a relief."
}

In this explanation, John described how he learned the necessity of letting go of control and surrendering to these emotions as a precondition to feel the connection to life. He mentioned that if you don't admit the emotions, "you lose contact with yourself. And through this experience, I have learned not to avoid things. However difficult they may be, and how hard it is to express your emotions, you just have to do it." Here, it becomes clear how this discovery seamlessly led to the purposeful creation of meaning in John's life: the insights guided his attitude towards life. His higher purpose lying in being connected to the self, he deliberately endured the emotions that he encountered in order to fulfill this purpose. Reflecting on this, John mentioned that "most of the trouble in the world is caused by that. That people experience things, don't get room to process them properly [ ] and because of that get completely messed up, and cause a lot of damage..." Here, John created a contrast by zooming out to society, thereby emphasizing the value of processing emotions. This zooming 
out relates to the motivational aspect of self-transcendence: serving himself as well as humankind.

Finally, looking back on the moment and what followed, John mentioned how it had a lasting impact on his life: "Well it enriched my life, but I don't wish it on anybody. It's crazy to say yes, actually everybody should lose a child, that's absurd!" He explained this paradox by saying that "if I can find my way in this, well then things must become really crazy for me not to withstand them." The experience has given John "a sense of self-respect, self-confidence, it makes you stronger, because you know you can handle that." These quotes illustrate how the experience has strengthened him as an individual. Alongside this, it has also led to a strengthened self-transcendent connection to humankind and life as a whole. John mentioned how it strengthened his belief in "human resilience and the power of human life" and how it helped him to accept death as part of life, for "that is just what life is: being born, dying, that's not so special. That happens every day. But of course for the individual and also for me of course the birth or death of a child is a very intense experience. But after all, that's life!"

\section{Anne's moment of meaning creation}

Anne's memory is of the ritual of having breakfast with her husband and daughters on the weekends, a ritual still actively performed in her ongoing life: "Everybody is relaxed. Sometimes all is calm, sometimes the girls have the giggles. It is a moment without obligations. Actually the world consists only of the four of us at that moment, and that is a lovely feeling." Anne mentioned that she purposely creates this moment to be meaningful, the essence of the moment lying in "the connection between the four of us." This essence relates to her childhood dream: "I always wanted to become a mother, have a family, and this is the ultimate family moment." Anne was found to affirm and justify this meaning in several ways:

"Well, maybe that it is given to us, that we can be so happy together. Maybe it has to do with the fact that of course my parents are divorced, [ ] so I haven't, I don't have my home family anymore you know, it doesn't exist anymore." 
In this quote, Anne created a contrast by zooming out to a different time frame in her own life history. She expressed how special the connection in her family is, as she has experienced the absence of this connectedness in her youth. Anne created many more contrasts to highlight the importance of the moment. She also zoomed out to the dynamics of daily life outside of the routine: "it is like an island in the hustle and bustle of family life [], yes an island of peace. Maybe also that you, that I don't have to care and organize and plan.” Apart from this, she zoomed out to a different aspect of her life, i.e. the serious diseases that three of them deal with: "It [disease] just doesn't matter then. People say well health, that's the most important thing in life. But we know that that's not true, it's just this [connection], yes." Also, she created a contrast by zooming out to society:

"Trump, or Putin [ ], they should have breakfast with us! [laughs]. If they see it can be this way, then everything is possible, I would say.[ ] I wish it for everybody, that connection, and I think it is important for people to have it, in a family or otherwise."

While the first three contrasts relate to Anne's own life and put emphasis on the value of connection for her personally, the last contrast transcends the personal, showing how connection is of value to humankind. Anne expressed this self-transcendent motivation also through generativity, the concern for establishing and guiding the next generation (Slater, 2003): "that we pass it on in some way, because to the girls breakfast is also very important. [] And when they make breakfast, they also do eggs and juice and a cup of tea."

Next, by reflecting on this ritual in the interview, Anne discovered additional meaning within the moment. In the interview, Anne introduced a contrast by mentioning how she feels like a "participant" during the breakfast ritual, more than a mother. When asked about the difference between these roles, she answered: "Then [as a mother] I have more responsibility, more care, really. Strange huh. Maybe I can make a better connection at that moment because I'm not in the caretaker's role." The researcher then went on to question her: 
Researcher: "So when you don't have to be a caretaker, you experience that connection?"

Anne: "Gee, that is a confrontational observation. [ ] I'm always caretaking."

Researcher: "Yes, it was your dream!"

Anne: "Yes, yes. But if the bottom line is that I don't really connect at those moments..."

Researcher: "And is that right?"

Anne: "Yes I think so. Because then... I'm more in a role, than that I am just myself. That responsibility, is has less of me in it, then I'm busy with what the other needs."

Researcher: "So you mean that when you feel connected, you are more yourself?"

Anne: "Yes, yes. Pfff [sigh, laugh]. Yes! I'll have to think about what that means!"

In this quote, Anne discovered that letting go of the responsible mother role is a precondition to be herself and thereby experience the connection to her family.

Finally, Anne elaborated on the lasting impact of the ritual on her life. She mentioned "how it makes her more human," that it gives her "a feeling of value, mattering" which she mentions to be "a basic need for people." Also, the ritual gives her confidence in the strength of the connection in her family, as "at times when it is difficult, I just know that at a deeper level, it's just okay. So then that other stuff is not, it's not nice but it's not that bad." She concluded by stating how the ritual helps her to set priorities: "when I have to make choices because I don't have so much energy, then this is always something that like, oh wait, this is what really matters to me, so all other choices become easier."

Otto's moment of meaning creation and discovery

Otto chose the teenage memory of playing his grandmother's favorite song to her on the piano, her last request to him before dying. He mentioned how special she was, and willful, choosing to leave life through euthanasia: 
"And as a teenager I'm there. Together with my parents and grandpa. But it was a few days before, while all preparations were being made, that my grandma asked me to play the piano to her one more time. And that's what I did. I played her favorite song. And then, also, my parents and grandpa were in the room."

Otto's memory clearly involved deliberate action: he is creating meaning by fulfilling his grandmother's wish. However, he also seemed to sense that there is more meaning enclosed in the moment than just that, though he could not grasp it. This additional meaning, yet to be discovered, can be found in Otto's confusion: when asked to reflect on his feelings at the time of happening, he noted how he felt "a strange mix of completely not knowing what's going on, about life and death and euthanasia, [ ] of purposeless bobbing or, no idea what I'm up to, and pride or happiness, that I could do that then." He mentioned how playing the piano gave him "grip, guidance," and "the idea that this is my island, kind of, the fact that I'm behind my familiar thing, my piano, and can do my own thing." However, Otto remarked that it is difficult for him to distinguish his feelings then and now, commenting that "maybe it is wishful thinking that I felt that then. But I think it is true, though maybe I wasn't completely aware of it." These feelings and confusion seem to be related to several contrasts within the moment, that take the form of a polarity: life and death, purposeless bobbing and purposeful action, the known and the unknown, the positive emotions of pride and happiness and the - less articulated, but plausibly also experienced negative emotions related to not understanding the situation and death. These polarities clearly contribute to the salience of the moment, and possibly to feeling wonder, though Otto did not mention this directly. In his confusion over these polarities, the chosen memory apparently is not only a moment of meaning creation, but also of meaning discovery; they seem to be intertwined and do not appear in a linear way. Later in the interview, Otto mentioned another contrast in the chosen moment: "that she's there, my grandma, her uniqueness, I'm doing my own thing, making music; and that my parents are there, who, well, that really characteristic, iconic side that grandma had, my parents taught me to "just be normal." It is through this contrast between the authenticity of his grandmother and the conforming attitude of his parents 
that Otto discovered that there is another layer to the meaning he is creating within the moment: that by playing the piano, he was being true to himself: "the contrast between, at least that's how I see it now, just being yourself and not giving a shit, and on the other side: just be normal, just work hard, and.."

This "doing his own thing" is his personal purpose in life, Otto mentioned later in the interview. He discovered that at the chosen moment, he was actually realizing that purpose, though he "was not ready to realize that" at the time of happening - the creation of meaning preceded its understanding. In the interview, the researcher noticed that the boy in the memory was already realizing that purpose, after which Otto commented:

Otto: "Yes, yes, yes, and and maybe there's yet another layer, because that boy was doing that there, but somehow it started with... 'will you do that for me."”

Researcher: "Okay. And what does that mean, grandma's question?"

Otto: [emotional] "Well yes, the beautiful image I have now is that... with that question she put me on that stage."

Researcher: "Yes, and which stage is that? What would you call it?"

Otto: "Yes... do your own thing!"

In the last part of this fragment, Otto discovered that it is actually his grandmother who puts him on the stage: through her question, she calls him to realize his purpose. Reflecting on this purpose, Otto mentioned that this is not an end-state but a process of becoming more and more authentic. In this process, he mentioned letting go as an important precondition: "letting go of my parents and thus doing my own thing.. giving up my job," "not by adding safe layers, masks and whatever, but by daring to let go of those layers and [ ] have the courage to keep the higher purpose in mind and just stand there almost naked...”

Though in the interview Otto elaborated mainly on the value of this purpose in his personal life, a self-transcendent motivation was also found: zooming out to society, he mentioned how it serves not only himself but that "by crossing that 
threshold, yes that I can contribute to other people's feelings or well, make the world a bit more beautiful. [ ] It is important, really of value to others."

The moment has had a lasting impact on Otto's life; and in the interview he referred to the moment as "an anchor," stating that "an anchor was dropped there, because I would need it later on. [ ] And probably there's still extra layers underneath that I cannot grasp now, but at least that's how I see it now." This anchor motivates him to continue to live his purpose, "it's like an encouragement, [ ] yes that anchor... that I take it for what it is and that I, more and more try to live up to it, now." Otto said that he keeps the sheet music he played as a reminder of this anchor, and, showing a picture of this to the researcher, mentioned how he "once put the sheet music in a frame, but lost sight of it. After [the invitation to the interview] I brought it back out again and gave it a prominent place in my studio." In this last comment, it can be seen how the Wonderful Life Question triggered Otto to revalue this moment. Finally, he valued the interview itself for giving him extra insights on this anchor: "it helps me to come closer to the memory, to relive it, understand it better.... Without it becoming an in-depth "lie down on the couch" session."

Overseeing the portraits of John, Anne and Otto, five themes were found that also ran through the stories of each of the nine participants, with (1) meaning discovery and (2) meaning creation as the main themes. The additional themes of (3) contrasts and (4) letting go were found to contribute to the discovery and creation of meaning, a process that has a (5) lasting impact on the participant's life. Table 3 gives an overview of the appearance of these themes in all of the interviews. Category A comprises moments like John's, in which incidental meaning discovery leads to deliberate meaning creation; category B consists of moments like Anne's, in which meaning is deliberately created and additional meaning is discovered retrospectively; and category $\mathrm{C}$ contains moments like Otto's, in which meaning creation and discovery are more intertwined and seem to appear simultaneously. 
The Emergence of Meaning from Meaningful Moments in Life

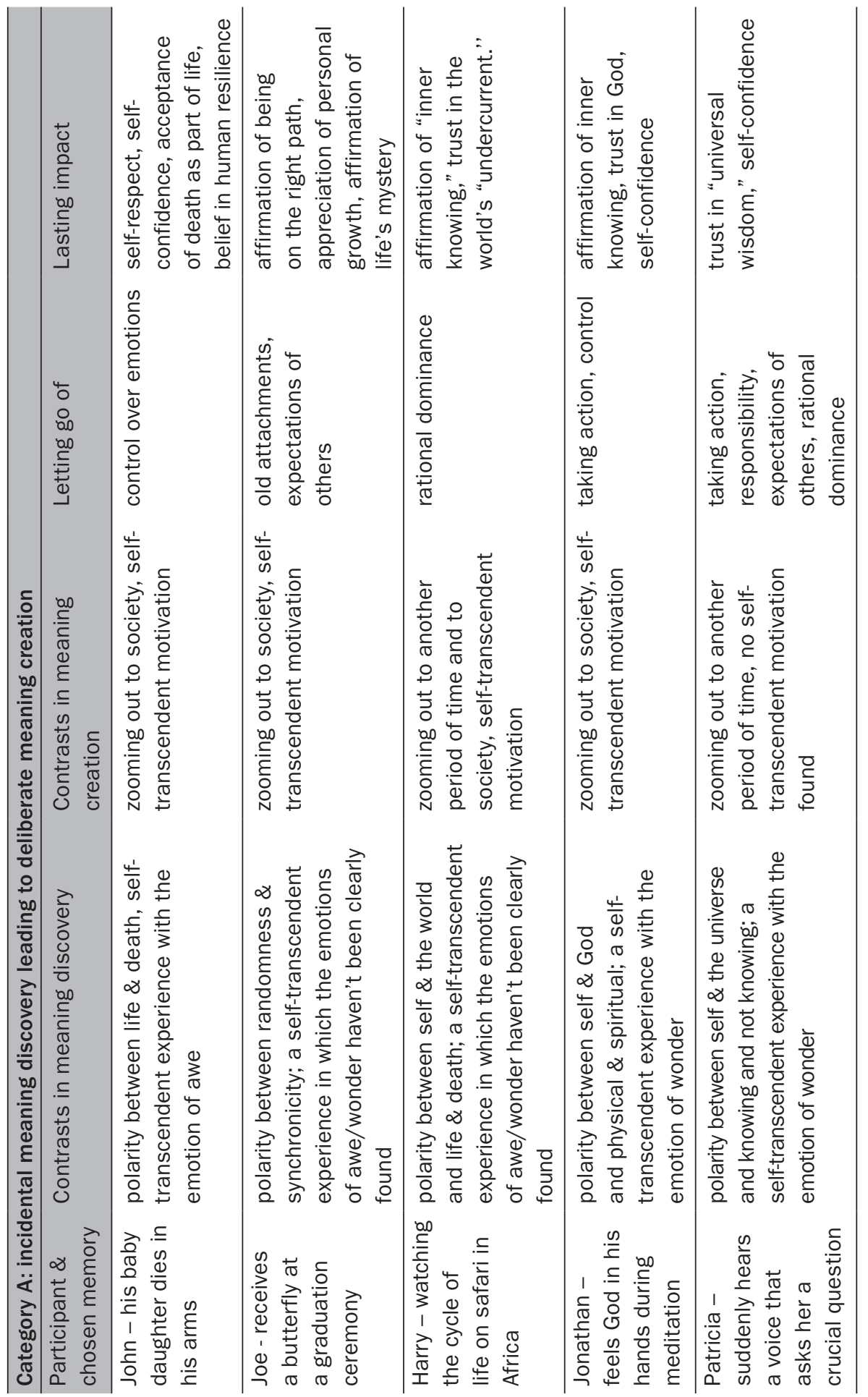


The Emergence of Meaning from Meaningful Moments in Life

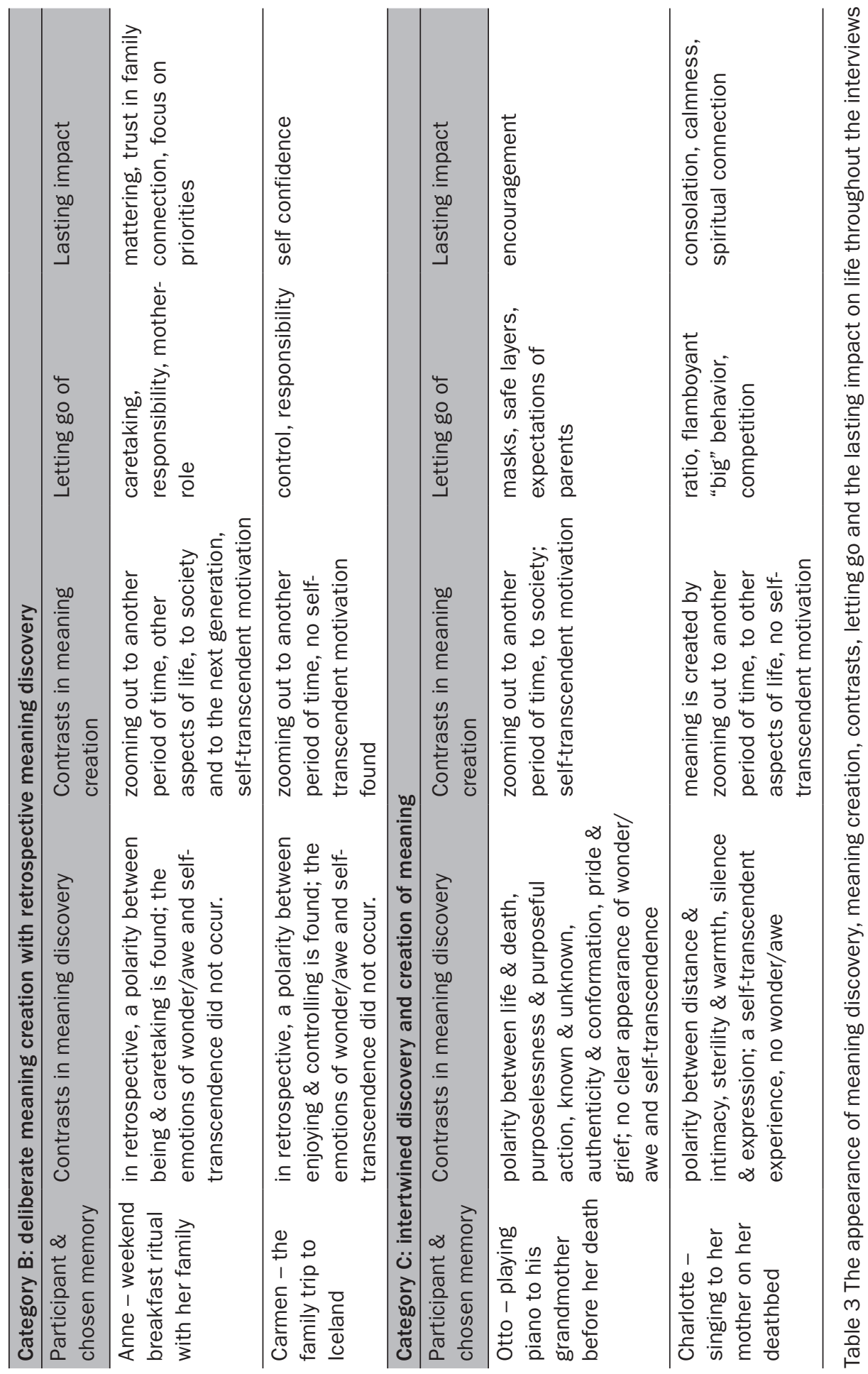




\section{An integrated framework}

In this section, the five themes are brought together in an integrated framework on the emergence of meaning from meaningful moments.

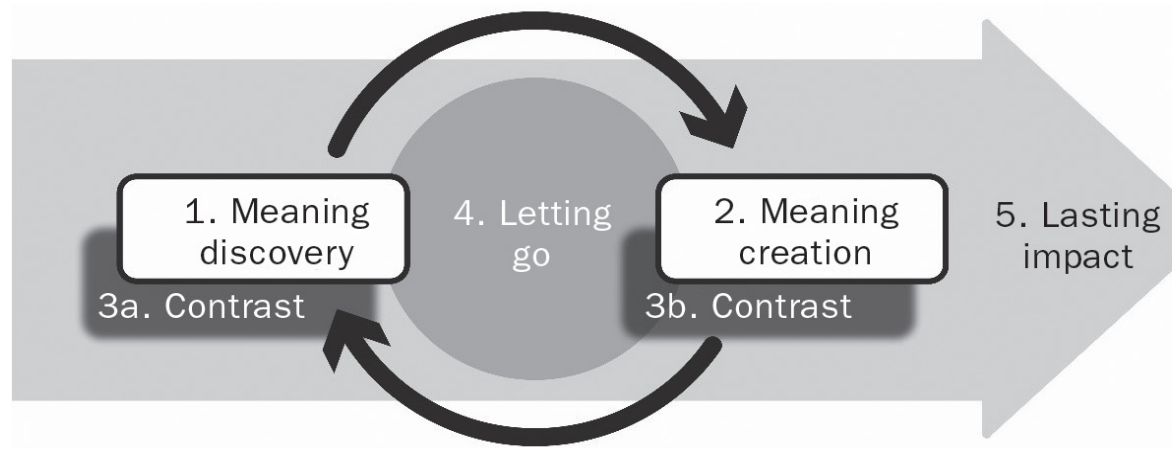

Figure 1 The emergence of meaning from meaningful moments: an integrated framework

\section{Meaning discovery}

Moments were described as meaningful because they incidentally trigger the discovery of meaning. Meaning discovery related to a broadening of perspective, the development of new or deepened insights on life, humanity and/or the self by opening up to aspects of life and reality not previously encountered or forgotten and now re-seen. Though the moment was sometimes deliberately created to be special in the context of everyday life or in a precarious setting such as illness or death (e.g. meditating in church, going on safari), the meaning drawn from the memory emerged from what unintendedly happens within this setting. This meaning was often not fully understood directly, but discovered and "peeled off in layers" over time. Here, a relation to coherence can be found.

$1 \rightarrow 2$ Meaning discovery may lead to meaning creation

In all of the memories that triggered meaning discovery, the discovery of meaning led to the creation of meaning. The created meaning sometimes took the form of a higher life purpose, e.g. helping others in their personal development, but at other times it was more attitudinal, a life lesson put into practice, e.g. letting go of dominant rational thinking. 


\section{Meaning creation}

Meaningful moments were sometimes planned and created to be meaningful, to stand out in the context of everyday life or in a precarious setting. Meaning creation thus concerned deliberate acts, attitudes and choices that were considered to be valuable and contribute to fulfilling a higher purpose in life. In these moments, participants were intentionally taking part in purposeful action.

\section{$2 \rightarrow 1$ Meaning creation may lead to retrospective meaning discovery}

Deeper layers of meaning were also discovered retrospectively from deliberately created moments. All of the participants that chose a deliberately created moment mentioned how the full meaning of what they were creating was not yet clear to them within the moment itself. Reflecting on the moment, they discovered additional meaning within the memory of creation of meaning.

\section{3a Contrasts in meaning discovery}

Contrasts played an import role in the discovery of meaning (1). These contrasts took the form of a polarity: of opposing values, states of being or realities emerging together within the moment, such as life \& death, the universal \& the personal, distance $\&$ intimacy. The awareness of this polarity contributed to the salience of the moment, and in the descriptions of their feelings the characteristics of the emotions of wonder and awe were found several times: a combination of not knowing, of strangeness, confusion or even fear, and of knowing: recognizing that this is a special experience in a positive way. The characteristics of self-transcendence were frequently found in the polarities. While one end of the polarity often related to the personal, the other end was found to relate to something that transcends the self, such as God, universal wisdom, or oneness with others. Polarities also emerged in the retrospective discovery of meaning from deliberately created moments $(2 \rightarrow 1)$.

\section{$3 b$ Contrasts in meaning creation}

Contrasts also played an important role in the creation of meaning (2). In this case, the value of what is created is affirmed through contrasts resulting from zooming out of the memory to e.g. a different period of time (e.g. an earlier period in life), a different aspect of life (e.g. a hectic household), or a different 
setting (e.g. society) in which the created value is absent. Through this contrast, participants found extra motivation, justification and validation for their choices, goals and purposes, i.e. the meaning they are creating. While polarities were found to relate to the experiential component of self-transcendence and meaning discovery, zooming out clearly relates to the motivational component of self-transcendence and meaning creation. By zooming out to a setting that surpassed participants" personal lives, they emphasized how the created meaning served not only the self, but also other people or humanity as a whole.

\section{Letting go}

In all of the interviews, the same precondition to the emergence of meaning was found: letting go of control, or to surrender. Participants described this as an important lesson they have learned: in order to discover and create meaning, it is necessary to let go of (over)attachments to e.g. ratio, responsibility, expectations of others, and to develop an attitude towards life that is more open, vulnerable, appreciative and responsive.

\section{Lasting impact}

The chosen memories had a lasting impact on life; participants referred to them as "enriching," a "gift" or "anchor-moment," and mentioned feeling grateful. Several participants cherished an object (such as a picture of the chosen memory, used as a screensaver) that reminded them of this gift in their daily life. Gifts were found that positively affected participants" connection to life as a whole, and gifts that strengthen participants" connection to the self. In the first category, memories reaffirm participants in their (tacit) knowledge about life and its deeper mysteries (gift of truth), giving confidence in life, humanity and/or the spiritual (gift of trust), which may be seen as the self-transcendent aspect of significance. In the second category, participants mentioned the gift of growth, relating to personal development, cherishing this process and the lessons learned. As this process was often still continuing, the memory may be seen as a gift of encouragement: it reaffirms and stimulates to continue. It was also referred to in terms of a gift of self-confidence: showing participants that they mattered and were able to make a difference. Finally, participants mentioned the gift of focus, as the moment has brought clarity about what is meaningful in life, helping to set priorities. 


\section{Conclusion and discussion}

In answer to the research question of how meaning emerges from meaningful moments, an integrated framework was developed in which meaning discovery and creation stand central. The framework illustrates that meaning is not just an outcome or experience, but a process in which the receptive component of discovery and the active component of creation belong together like breathing in and out. The results of the study resonate with many threads on the emergence of meaning found in literature, such as Frankl's pathways to meaning, the enlightening and transforming impact of meaningful moments, significance as an evaluative component of meaning and self-transcendence as a dimension running through the whole process. In the framework, these threads are brought together by means of a temporal dimension, which leads to a deeper understanding of meaning as a continuing process in life.

Meaning discovery has been clearly found to thrive on paradox and incomprehension; it is a broadening and enriching process that opens up to a greater, mysterious reality; to the "grand narrative of creation" (Wong, 2014, pp. 175) or, as an atheist humanist may interpret it, to the "awe and wonder of evolution" (Wilkinson \& Coleman, 2011, pp. 99-11). The findings thereby align with recent studies that point to openness, existential wonder and awe as a precondition for meaning (Alma, 2018; Schinkel, 2018; Schneider, 2009; Wong, 2011). While the process of meaning discovery starts with this wonderinvoking component of meaning, the study shows how the understanding of this meaning unfolds over time, thereby indicating that coherence is a component that naturally follows in this process. Meaning discovery thus involves both the embrace of the unknown, the disruptive and disturbing, as well as comprehension and coherence - both openness and closure. Wonder and coherence thereby seem to form a polarity, contrasting and complementing each other in the process of meaning discovery.

Additionally, findings indicate that the discovery of meaning is for many participants an ongoing process that remains present also in the creation of meaning, i.e. in the dimension of purpose. Here, results align with Maddi's (2004, 2013) "choosing the future': the choice to not solely act from an existing, 
coherent frame of meaning, but to step into the unknown and develop a deeper understanding on the way. Coherence thereby may be a springboard for purpose, as Steger (2012) states, but it also develops on the go, whilst fulfilling this purpose. The finding of letting go as an important precondition to experience meaning also falls into place here, as choosing the future entails openness instead of control and preexistent comprehension. Purpose therefore is paradoxical, as it involves both focus and direction as well as the willingness to detach from proven paths and patterns.

In the study, contrasts prominently emerged as vital mechanisms in the discovery and creation of meaning. Contrasts created by zooming out were found to be a means to see and affirm the value of what is being created. Findings show that meaning emerges by zooming out in time, thereby aligning with Baumeister, Vohs, Aaker and Garbinsky (2013), but also by zooming out to other settings and other aspects of life. Polarities were found to contribute to the discovery of meaning, frequently reflecting the characteristics of self-transcendence and in some cases also of wonder and awe. It is of interest to deepen insight in the relation between the awareness of polarities and the experience of meaning in more extensive research.

Reflecting on the methods used, the holistic content analysis has been of great value, as its focus on the story as a whole does justice to the process of meaning emergence. Also, the Wonderful Life Question appeared to be particularly adequate to give insight into the emergence of meaning, as its dual temporal focus - a moment from the past to take to the future - leads participants to choose a moment that has explicitly or implicitly triggered a process of meaning discovery and creation. Participants spontaneously mentioned how they had become aware of this process when choosing and writing their memory in answer to the Wonderful Life Question; the interview giving this an extra impulse. Their experiences plead for the Wonderful Life Question not only as a method to collect data, but also as a meaning eliciting intervention.

Finally, there are several limitations of this study. First of all, the selection of participants on the basis of their meaningful moment (and not on demographic 
characteristics) lead to a quite homogeneous group: all participants were middleaged and had affinity with personal development. Therefore, it is necessary to validate the findings on a larger and more diverse group of participants, in age as well as profession and background. Also, it would be of value to work with participants to whom a coherent life story is at stake. Another limitation to be mentioned is the role of the researcher in both the interviewing and analysis. Though the interviews were carefully prepared and a topic list was employed, it is impossible to rule out effects of the interaction between interviewer and participant. This interaction, of which the last block quote in Anne's interview is a clear example, will therefore to some degree have influenced the results. Finally, though multiple researchers were involved, narrative analysis always entails a risk over overinterpretation.

Overseeing the study, its main value lies in the recognition of meaning as a process of both discovery and creation, highlighting the interplay between the dimensions of coherence, purpose, significance and self-transcendence, and addressing the role of contrasts and letting go within this process. 
The Emergence of Meaning from Meaningful Moments in Life 


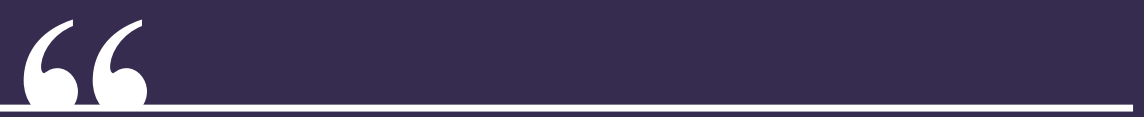

I think I am ten years old. My parents had just bought a new carpet for the living room. They had taken all the furniture out, so there was only a big, empty space. And that carpet was there and we, my three brothers and three sisters and I, we all thought it was a very ugly carpet. It had a certain pattern in it, a certain design. My parents had chosen it because you don't see dirt on it very well, and because it was very strong and durable. We were all at home to see it, there in that big empty space with only that carpet. We were sitting against the wall, I can still see us sitting there. And actually, it was just a very happy moment: we were there laughing, having fun because of that ugly carpet. And I had the feeling: this is just a good moment. All together. Everybody having a good time, my brothers and sisters and my parents. There was nothing in the room except for us.

\section{y)}




\section{Chapter 5 \\ The Power of}
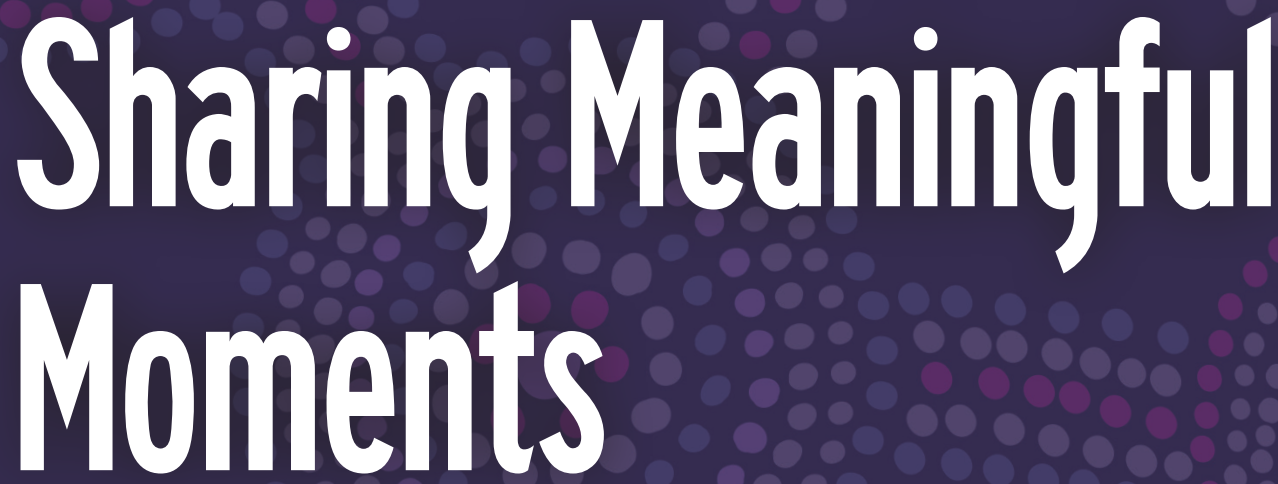

A Buberian analysis of a counseling intervention

Van de Goor, J., Sools., A.M., Smits, M. \& Westerhof, G. J. Under review 
The Power of Sharing Meaningful Moments

\section{Abstract}

"All real living is meeting," Buber states. This article presents an empirical study of the way a sense of meaning-as-connectedness is brought about in a group counseling intervention in which meaningful moments are shared. Results from a thematic analysis exemplify and at one point extend Buber's philosophy of meeting. 


\section{Introduction}

Meaningful moments are specific events in life that are felt to be of great value and significance. They are acknowledged for their potential to enhance a sense of meaning in life: to transform our perspective on life and to inspire purposeful action (Wong, 2012b). In this article, we build on this potential by investigating the deployment of meaningful moments in a group counseling intervention.

Meaningful moments come in a variety of appearances. They may have positive as well as negative valence; they may be encountered unintentionally but also be intentionally created; they may be unique, atypical and disruptive, but also be part of the familiar routines of ordinary life (Van de Goor et al., 2017). Various studies give insight in the way different types of meaningful moments may affect our lives, showing how they may lead to new insights, guide the pursuit of long term goals, increase a sense of life's significance, and contribute to a self-transcendent orientation towards life (e.g. Anbeek et al., 2018; Hoffman et al., 2012; McDonald, 2008; Pillemer, 2001). Meaningful moments are often intentionally recalled and can provide persistent affirmation and guidance long after their original occurrence (Blagov \& Singer, 2004; Pillemer, 2001). Retrospective reflection on meaningful moments has shown to deepen insight in the meaning that is embedded in the moment and to the discovery of important sources of meaning in life (Van de Goor et al., 2020).

In sum, there is no doubt about the potential of (recollecting) these moments to enhance a sense of meaning in life. However, up till now research has solely focused on meaningful moments from a personal perspective: on the way one's own meaningful moments may enhance a sense of meaning in life. An interactional perspective has yet to be taken. For what happens when people share stories of meaningful moments? How can a sense of meaning in life be enhanced not just by reflecting on one's own meaningful moments, but by sharing these moments with others in a collective process? In this article, it is this interactional perspective that we focus on. Therefore, we present a qualitative case study of a meaningful moment group intervention. In this study, we explore the way participants experience the emergence of meaning in the process of sharing: choosing, telling, listening to and reflecting on memories of meaningful moments with others. 
Meaning is a multifaceted concept, and while the individual, separate self is prominent in many theories on meaning, in this study we address the multifaceted concept of meaning from a relational perspective. For as humans we are not a closed system, Frankl (1966, p. 97) points out, "being human profoundly means to be open to the world, a world, that is, which is replete with other beings to encounter and with meanings to fulfill." In recent articles, humanistic scholars point out that our well-being is inherently related to the larger relational processes we are part of, and that throughout our lives, we grow through and toward connection (Gergen, 2015; Jordan, 2017). Delle Fave and Soosai-Nathan's (2014) study supports this perception, noting how connectedness is the thread that runs through a variety of classifications of sources of meaning found in literature. Their findings reflect Martin Buber's (1965) notion of man as a relational being, this relation being threefold: to other people, to the world and things, and to a larger whole.

Acknowledging connection as the heart of meaning, we have chosen Buber's (1970) philosophy of meaning as connectedness as a framework to study the emergence of meaning in the presented case study. "All real living is meeting," Buber states; we experience meaning when we transcend the individual and experience an I-Thou connection. I-Thou is a relationship of openness, mutuality and presence, an encounter in which we experience a deep connection to the other in which the barriers of individual being are breached. I-Thou connections contrast I-It connections, in which subject and object are separate and there is merely a functional relation. Buber's philosophy is particularly of value to this study as it introduces several concepts to describe the process through which the I-Thou connection emerges, a process he calls "the dialogical" (Buber, 1957). This process of meeting occurs in the interhuman, Buber states, the sphere where things happen that reach out beyond the sphere of each, in which we experience the absolute and unlimited (Buber, 1970; Friedman, 1999). This solely occurs when people enter the relation with their whole being, authentically and open, not keeping anything back or being concerned with their own image (Friedman, 2005). We encounter the other by what Buber calls imagining the real: by swinging over to the side of the other and experiencing vividly what the other is thinking, feeling and willing, without 
losing our own ground or mixing in our own emotions or judgements (Buber, 1957; Friedman, 1996, 2005). Imagining the real leads to confirmation, to being seen in our whole being, in our uniqueness and in what we are called to become (Friedman, 2005). What follows from confirmation is responsibility, for as we are confirmed by the other, we are called to respond by becoming our highest selves (Buber, 1965; Friedman, 1996, 2005). Finally, Buber mentions that while I-Thou encounters are temporary, they may have a lasting impact, transforming the I and contributing to a different mode of being in the world, seeing the new and unique in every situation (Morgan \& Guilherme, 2012; Friedman, 2005).

Buber's philosophy also relates to this study in other ways. The I-Thou framework seamlessly applies to the material that is being shared in the intervention: the memories of meaningful moments. Meaningful moments have been found to show characteristics of self-transcendence (Van de Goor et al., 2020), and thereby may be considered to be moments in which or through which an I-Thou connection is experienced. It is of interest to see how this material influences the process of meaning emergence, i.e. the way sharing memories of I-Thou experiences from the past influences the emergence of I-Thou connectedness in the here and now. The I-Thou framework also applies to this study on a meta-level, as it helps to indicate the relevance of this study. For Buber's distinction between I-Thou and I-It, first published almost one hundred years ago, is still topical: in our increasingly accelerating society a sense of meaning may easily get lost, and depression has become a major problem (Lépine \& Briley, 2011; Rosa, 2013, 2016). Therefore, it is of value to explore how I-Thou connectedness may be facilitated.

The purpose of this study is to investigate the way this meaning-asconnectedness is brought about in a group counseling intervention. The research question is: how does a sense of meaning emerge in the process of sharing meaningful moments in a group? Buber's philosophy on the emergence of meaning through the dialogical is used as a lens to study this process. 


\section{Method}

In this paragraph, we firstly introduce the meaningful moment group intervention that was deployed in the case study. After this, we present the design of the case study, describing the participants, the role of the counselor, the focus group that was held to collect data, and the way Buber's philosophy was grasped in six sensitizing concepts to be employed in the data collection and analysis.

\section{Wonderful Life: a Meaningful Moment Group Intervention}

The Wonderful Life intervention is a group intervention in which people share and reflect on memories of meaningful moments, with the purpose to discover and connect to personal sources of meaning in life. The intervention is used both in the context of personal life and in work-related settings, and has been developed and finetuned over the course of many years by the first author of this article in her work as a counselor. In the intervention, participants choose one single meaningful moment in answer to the following question: What if there is an afterlife. There, all your memories will be erased, except for one. Which memory do you choose to take with you to eternity? This question, derived from the Japanese movie "After Life" (Hirokazu, 1998), has proven to be a powerful way to elicit meaningful moments that stick out in the evaluation of a whole life, without directing to specific types of experiences (Van de Goor et al., 2017). After choosing a memory, a counselor guides the participants, typically a group of eight to twelve people, through a series of steps to elicit the meaning enclosed in this memory, as described in table 1.

\section{Case Study Design}

Case study as a research method is an empirical enquiry that investigates a contemporary real-life phenomenon through detailed contextual analysis of a limited number of events or conditions, and their relationships (Zainal, 2007). In this qualitative case study, the group intervention as a whole was taken as the unit of analysis. Two researchers also working as counselors performed the study, facilitating the intervention, moderating the focus groups in which participants elaborated on their experience in the intervention, and analyzing the data. Ethical approval for this study was obtained from the University of Twente Ethics Committee, BCE 18706. 


\begin{tabular}{ll}
\hline Intervention step & Description \\
$\begin{array}{l}\text { Welcome and } \\
\text { "landing" }\end{array}$ & $\begin{array}{l}\text { The counselor creates an open, appreciative and relaxing } \\
\text { atmosphere. }\end{array}$ \\
\hline $\begin{array}{l}\text { Choosing a } \\
\text { memory to take }\end{array}$ & $\begin{array}{l}\text { The counselor introduces the Wonderful Life Question and invites } \\
\text { participants to choose one memory. Participants are given time, } \\
\text { in silence, to make their choice. }\end{array}$
\end{tabular}

Sharing memories One by one, participants share their memory. They are asked to in the group tell it vividly, like a film fragment, without an explanation of their choice. Others listen in silence. After each story is told, participants are asked to reflect on what moved them in the story. They write these reactions on note-paper and give these to the storyteller, who receives them in silence. When all reflections are handed over, the next person takes his or her turn to share the chosen memory.

Reflection on the Working on their own, participants reflect on the meaning of their essence of the own memory with help of several questions. The reactions received moment from the other participants serve as an inspiration.

Writing a letter Participants are asked to "let the memory speak" and write a for the future letter to themselves in which they translate the insights from their memory into an advice for their future, i.e. "what their memory calls them to do."

Sharing the letters Participants are invited to read their letters to the others, who in the group listen in silence.

Closure Space for sharing reflections on the experience

Table 1 The Wonderful Life intervention

\section{Participants and Counselor}

For this case study, the participants in the intervention were professionals in the domain of mental healthcare; the subject of meaning being of relevance to them both as a professional and in supporting clients. In order to rule out issues of team dynamics, we worked with people who do not have a direct working relation. One of the participants hosted the intervention and invited the other participants, selecting them on the basis of their interest in the subject and their capacities to reflect on their experience. Apart from the host, the other participants did not know each other beforehand. A total of eight participants took part, four of them women and four men, varying in age from 30 to 63 . The intervention, with a duration of 2,5 hours, was facilitated by one of the 
researchers/counselors, trained in the Wonderful Life intervention by the other researcher/counselor, who was also present during the intervention. To prevent an I-It relation to the participants which could disturb the process, both researchers/counselors actively participated in the first three steps.

\section{Data Collection}

This case study is part of a larger study on the Wonderful Life intervention, in which not only qualitative but also quantitative data were collected to monitor the change in the participants' sense of connectedness directly before and after the intervention. In this article, we solely focus on the qualitative data relating to the process of meaning emergence, collected by means of a focus group. A focus group is a form of group interviewing in which specifically the interaction within the group is of value to gain insight in a variety of perspectives on a certain topic (Morgan, 1997). The focus group was held directly after the intervention in order to catch participants in their real time experience, thoughts and feelings. It was performed in two separate subgroups of four participants; each researcher/counselor moderating a separate subgroup. Within each subgroup, the single focus group method was employed (Morgan, 1997), in which all participants take part in the discussion as one group in one place, directly reacting to what others bring in to the conversation.

In the focus groups, the moderators started with two general questions on the participants' overall experience of the intervention: (1) what happened between you, and (2) to what did you connect? Next, they walked through the main steps of the intervention and specifically asked for the participants' experience with respect to the emergence of meaning and connectedness in each step. For this purpose, Buber's philosophy of dialogue was operationalized into a set of five sensitizing concepts and related questions to address these concepts, as presented in table 2. Buber's philosophy being quite abstract, specifically the works of Friedman (1996, 1999, 2005) were found to be helpful in this process. The interviewers were alert to these concepts being spontaneously mentioned by the participants in the focus groups, only actively bringing them in to the conversation when this was not the case. Each interview was audio- and video recorded and transcribed verbatim. 
The Power of Sharing Meaningful Moments

\section{Being}

Entering spontaneously with one's whole being. Is not: holding back, entering only rationally or emotionally, or being concerned with the own image.

How real and authentic did you show yourself / see the others? How did this happen?

Imagining the real

Seeing the other's uniqueness and wholeness. Intensely "swinging over" to the other's side, experiencing the other's perspective without giving up one's own reality. Is not generalization, objective understanding, one's How did you experience what the others shared? How did you see the other in what was own truth, imagination or judgement.

\section{Confirmation}

Being seen in your whole being and uniqueness, as the How were you seen by others person you are called to become: with the capacity to actualize your own potential. Is not solely social, nor in what you shared? How did

this happen? does it involve being seen only in appearance.

\section{Responsibility}

Being called to answer and become your highest self. Implies being free to respond to your own vocation. Is not being unfree, nor being free to choose what you want to be. Is opened up through confirmation. shared? How did this happen?

\section{Meeting}

The I-Thou encounter that is the essence of meaning: overcoming separateness, transcending individual limitations and experiencing relatedness to other human beings, to nature and/or to "the mystery of being." Meeting transforms the I and ideally will have a long term impact life.

What is the appeal from your own memory/letter? What is the appeal from the memories/ letters of others?

Did you experience a change in connection when sharing your memory/letter? And when listening to others? What was the change and how did this happen?

Table 2 Sensitizing concepts from Buber's philosophy and questions used in the focus group

\section{Data Analysis}

Following the method developed by Braun and Clarke (2006), a thematic analysis was performed on the focus group transcripts. To that end, the researchers firstly read the two transcripts to familiarize with the discussions that took place in both focus groups. After this, the transcripts were taken together to be analyzed as a whole; the researchers focusing on the participants' comments on the emergence of meaning throughout the intervention. The researchers individually coded the transcripts taking both a deductive and inductive approach. Deductively, the data 
were coded using the Buberian sensitizing concepts as predefined categories, selecting phrases that exemplify these concepts and illustrate their relation to specific aspects of the intervention. Inductively, the researchers coded phrases concerning other factors that contribute to the emergence of meaning, being specifically attentive to factors that extend the Buberian sensitizing concepts or contradict them (i.e. the black swans, Taleb, 2007). After this round of coding, the results from both researchers were compared and discussed, bringing the codes together to develop an overview of concepts in the process of meeting and related aspects of the intervention. Finally, the researchers returned again to the transcripts to review this overview, making sure it accurately represents the data.

\section{Results}

How is a sense of meaning-as-connectedness brought about throughout the meaningful moment intervention? In the following paragraphs, we present the results of the analysis of the focus group sessions. Overall, results across the two focus groups were found to be surprisingly similar, with only minor disagreements between participants, as will be shown. The results mainly relate to comments made by multiple participants, though sometimes only a single participant was found to refer to a specific aspect of the emergence of meaning. In the data, all of the Buberian concepts were found to appear, the data exemplifying and sometimes extending these concepts without contradictions. One additional concept was found: swinging back. The following paragraphs illustrate these concepts and the way the different aspects of the meaningful moment intervention relate to their appearance. Table 3 gives an overview of these findings. All names of participants are pseudonyms; to distinguish between the two focus groups, names starting with A relate to focus group 1 and names starting with B to focus group 2.

\begin{tabular}{ll}
\hline Concept \& empirical findings & Related aspects of the intervention \\
\hline $\begin{array}{l}\text { Being } \\
\text { Genuine; open and spontaneous; }\end{array}$ & - Choosing, sharing and listening to memories \\
$\begin{array}{l}\text { respectful; without façade, trepidation } \\
\text { or hesitance. }\end{array}$ & $\begin{array}{l}\text { in answer to the Wonderful Life Question } \\
\text { - Listening in silence }\end{array}$ \\
& - Reciprocity of telling and listening a letter as a response to the universal \\
& values underlying the chosen memory
\end{tabular}




\section{Imagining the real}

Envisioning the other's story; bodily feeling the story; arousal of emotions; seeing the wholeness of the other: seeing the other in his or her authenticity and values, in a more complete way.

\section{Confirmation}

Being seen in a warm and affirmative way; lack of criticism; disclosure of personal values; widening perspective of the self; transforming.

\section{Responsibility}

Granting the self something for the future; value-related; mild and selfcompassionate though not without obligation; follows from confirmation; vulnerable; genuine responding.
- Written reactions of others - but not all of the reactions

- Silence, lack of immediate reaction
- Writing a letter in response to the values and longings in the chosen memory, connecting past and future

- Reading the letter out loud to others

- Listening to and resonating with the message in letters of others ( $\rightarrow$ swinging back)

\section{Swinging back (new)}

Finding or searching for similarities to the other; taking back to the own side from what was encountered on the side of the other.
- Listening to and resonating with the memories of others

- Listening to and resonating with the letters of others ( $\rightarrow$ responsibility)

\section{Meeting}

Occurring in the interhuman; physically

- Sharing the own memory as a (vulnerable)

felt, not rational; connecting to others, means of self-expression ( $\rightarrow$ being)

to humanity, to shared human values,

- Sharing the own letter as a (vulnerable)

to a larger reality; transforming impact.

means of self-expression ( $\rightarrow$ being)

- Listening to and being moved by the memories of others ( $\rightarrow$ imagining the real)

- Witnessing others in their (vulnerable) process of transforming the memory into a letter ( $\rightarrow$ imagining the real)

- Seeing the others in their written reactions $(\rightarrow$ imagining the real)

- Listening to and resonating with the memories of others ( $\rightarrow$ swinging back)

Table 3 (Buberian) concepts in the process of meeting and related aspects of the intervention 


\section{Being}

Meeting requires entering the relation with the whole being, Buber states. Participants tell how the Wonderful Life Question contributed to this way of being present, leading them to choose a moment that is genuinely meaningful. "We could have asked a different question, but what did this particular question do?" the moderator asked the group. "You get to the essence very quickly," Amelia answered, "it is not just any question you are asking." Anne commented that she did not need to think, as "it was immediately that picture that emerged." However, the question initially also led to several other reactions. Amelia was irritated by the question at first, as it felt like depriving people and aspects of her life that were not in the chosen memory. Others started philosophizing about the afterlife, mentioning that to participate in the intervention, "it is necessary to join the thought experiment." The Wonderful Life Question was also mentioned to have an impact on a being mode of listening. "You know everybody is going to tell something that is of great value," Anne explained this attitude, which "immediately leads to an attitude of respectful listening," according to Barbara. Alex described this as "careful and tender listening to what the other is saying. Because this is really a very important question."

Listening in silence throughout the intervention relates to being in a similar way. Though the silence was a bit uncomfortable at first to some, the lack of interference leaves the story intact: "So it's mainly in just letting the story be, be what it is," Amelia said, "you tell your story, it is yours." It is a different mode of listening, she remarked, "often, people listen to accomplish something with that listening. So I listen to you and then next, I want to ask a question in return, and then blablabla. [ ] But now we were only asked to listen." "And what does that do?" the moderator asked her, to which she answered "that I really listen to what you are telling." In this comment, we see how Amelia contrasts her open and unaffected listening experience in the intervention to an I-It mode of listening, in which her focus is on herself and her own concern.

Participants also note how the reciprocity of telling and listening in the intervention contributes to being. Though several participants noted there was some hesitance at first, they were surprised how quickly they shared 
their very personal memories and letters, without holding back. "I don't know you at all, and that you still immediately start sharing," Britt remarked; which is "definitely not self-evident," Benjamin said. The reciprocity in the intervention clearly relates to this; in Amelia's words: "that you listen, but that you subsequently realize that when you or when I tell my story, that you will also be listened to. Because that is the agreement." Or as Bert noted: "the giving and receiving and the, the attentive attitude of the others and, yes, that reinforces each other."

Finally, Buber's being is found in comments from several participants on writing their letter. Specifically, they note how writing the letter in answer to the universal values underlying their chosen memory encouraged them to write freely, without trepidation. "It's just about values; values that actually apply to everyone," as Benjamin noted. Anthony opposed the letter to the façade that is often put up when writing a cv, "often you have to sell yourself in that way, because others expect that of you," he said. However, he notes that underneath this letter "is a completely different essence. Here, there are human values underlying it; values that actually may be manifested more." These values helped him to overcome any hesitation in writing his letter.

\section{Imagining the Real}

How did the participants see the others during the intervention? In their comments on various aspects of the intervention, many references were found to imagining the real. First of all, the vivid way participants described their chosen memories, as instructed, was found to contribute to imagining the real. "A real image appears," Britt, noted, "you see that film.” And then "you get more carried away," Benjamin added. Many participants noticed the sensory qualities of the memories that were shared: the tangible description of the surroundings, smells and atmosphere, and how storytellers were moved when telling their story. They reported how this, in turn, moved them as a listener, leading to real, physically felt emotions. To Bert it was "moving, sometimes... [ ] also just because of the energy that such a memory contains." An energy that Benjamin felt in his body: "A kind of energy of, here, struck in my stomach, yes, whoa." Which did not happen once, but kept happening, with every story he heard, he said: "every time 
again, well now I can’t be touched again but yes, I can, again.” To Bert, this vivid living through the other's story happened even when it reflected an experience he never had in his own life. Commenting on Britt's memory of giving birth, he said: "I really felt, I think, also the relief and I think the ease of that delivery! Yes, wow! [ ] Yes, so overwhelming!" In these comments on the way participants experience the stories of the others, we find a reference to "swinging over to the side of the other" as an aspect of imagining the real.

Apart from seeing the other in the memory that was shared, Amelia specifically mentioned she also saw the others in their written reaction to the memory that she herself shared in the group. "And what I found to be really beautiful is that, in the reaction, you again see the other," she explained - a comment which may also be related to imagining the real.

Finally, several participants' reports on witnessing the process of others transforming their chosen memory into a letter for the future give color to Buber's notion of "seeing the wholeness of the other" in imagining the real, highlighting different aspects of this "wholeness." "That connection, between what we started with and what we finally finished with, that was wonderful to see," Amelia said. She refers to wholeness in terms of opening up to a deeper, more authentic knowing of the other. In Anthony's comments, we find a relation between wholeness and values: "listening to the way someone gives value to, to a tree, to things, the way they connect their values to them. [ ] They lead me to see things I usually do not see," he explained. Being the only participant who knew all of the others, he noted how this led him to see the others in a more complete way. "That's a different level, right, that is the depth you're looking for. [ ] But I don't see a different person! I see the same one!" he explained.

\section{Confirmation}

Imagining the real contributes to confirmation, to being seen in an affirmative way, Buber states. Several participants note that listening to the memories in silence, with solely a written reaction after the story is told, contributes to their sense of being confirmed. "What caused you to be seen?" the moderator asked. "Not immediately reacting, you know, that causes, that you notice that 
people really resonate on the story, that they really listen," Bert answered. Alex articulated that he experienced "genuine interest, there were no improvements." Participants used words as "warm" and "affirmative" to express this experience of being seen in the intervention. "Sometimes you see words that you recognize, so that is a confirmation that you are seen, and sometimes you think: well, I hadn't seen it that way yet," Benjamin commented on the reactions. This comment reflects what was mentioned by almost all of the participants: how the written reactions led to a widened perspective on their own life and their personal values, expanding the self. To Barbara, the words of others helped to make the implicit more explicit; "that you... do have that feeling but haven't found the words for it yet. But that it's, that it's right, to say so," she explained. "Those notes, they showed me something, they made visible to me what I don't see myself." Anthony said. To Alex, the comments on paper helped him to understand the value of his memory and specifically the meaning of specific elements in his memory: how a waterpool in his chosen memory stands for trust and freedom. These comments reflect not only the supportive aspect of confirmation, but also the broadening aspect of being seen in your potential, who you can become, but have not yet opened our eyes to. They show how confirmation involves not only affirmation of the known and familiar, but may also include a change in self-perception, i.e. a transformation.

However, specifically Benjamin and Amelia mentioned that they did not find confirmation in all of the written reactions; Benjamin referring to this in terms of the "mirror of the other." "Sometimes I thought: ooh!" Amelia said. "And what does ooh mean?" the moderator asked her. "Those are the things I didn't recognize. [ ] The other reflects from his or her side. And some of those things do appeal to me, and other things don't."

\section{Responsibility}

According to Buber, responsibility follows from confirmation; which we see reflected in our data and mainly in the phase of writing a letter for the future. Participants note how specifically the fact that the letter is written in response to their chosen memory contributes to this. "You take your memory to the future and from that experience you derive your strengths, and then you employ them," 
Britt explained. "What does that memory grant you, what do you want to grant to yourself, actually," as Benjamin said. Participants recognize the letters as a call to answer to the values and longings in the chosen memory, using words like "mildness" and "selfcompassion" to express their feelings about their letters. "You look at the future, so you grant yourself that happiness..." as Britt said. Here, we see how the responsibility expressed in the letters is mild in its nature, though not without obligation. "It is connected to a deeper value in yourself, so the chance that you will really put it to practice only increases," as Benjamin said. Participants note that the confirmation they experienced through the written reactions contributes to their sense of responsibility and gives them the courage to express this responsibility. "Because of those notes, now I dare to give words to it more easily. I think, well, why wouldn't I say it, the others also say it about me!" as Anthony exclaimed.

To several participants, reading the letter out loud also led to a deeper sense of responsibility. "When you share your letter, you commit yourself even more to it. Then it becomes real!" as Anne said. "By sharing it, I feel more, a stronger connection to, to yourself. Because you hear yourself saying what you wrote," Benjamin said. "Then you have to do it," Barbara commented on him. "Well, sort of," he replied, "because it becomes more your own. That helps me." In sharing the letter in the group, Bert mentioned that it felt vulnerable to do this, specifically because the other participants had also heard his chosen memory and therefore could relate these two and judge his sincerity. "Are you honest to yourself, or something. Yes, they can see that too." In this comment, we see how reading the letter out loud triggers what Buber calls genuine responding.

Finally, several participants note how they also respond to letters of the others: how the letters of others also speak to them personally. "Of some of the advices that came by I thought well, that's also a good advice for me," as Bert said. Amelia explains that this is caused by the fact that the letters clearly expressed the values underlying the memories that she listened to: "and then I thought to myself, o yes, great, I should go and play!” This finding sheds a different light on Buber's notion of responsibility: how participants also "swing back" from the letter of the other and take up its message as a call to personal action. 


\section{Swinging Back}

This last comment on responsibility reveals the additional concept found to relate to the emergence of meaning in the intervention: swinging back. Swinging back may be seen as the counterpart of imagining the real: it relates to moving back to the reality of the own personal life, after swinging over to the reality of the other. This was described by several participants when listening to the letters of others and taking a personal message from it, but also in the first phase of the intervention, in listening to the memories of others. They tell of finding or actively searching for similar memories in their own life. It "evokes images in my own life" as Anne said, or in Britt's words: "o yes, o yes! Those o yes moments." To Anthony, moving back from these memories to his own life was an enriching experience. "When someone tells about being in that bubble, I think: we all, we all have a bubble so I start thinking about my own bubble," he explained. "And then I think, well that is another way of dealing with a bubble!" To Bert, however, it triggered other feelings. He told that the story of giving birth really moved him, after which the moderator asked him: "and what was that? To what did you connect?" "To me that is in missing out," he answered. "You project it on yourself," Britt replied. "Yes. Kids, that's something I would have like to have experienced" Bert answered. This swinging back from the memories to the own life was also found to manifest itself in the written reactions, as described earlier: participants did not feel confirmed by all of the reactions, noting how these also revealed the reality of the other.

\section{Meeting}

The essence of meaning is in meeting, Buber states. Overall, participants made several comments on the nature of meeting in the intervention. "Together, you experience something unique," Amelia summarized, "and that is not just your own experience, it really happens in connection to the others." This comment reflects Buber's notion of meeting occurring in the interhuman. Several participants mention they experience this meeting in a very vivid and physical way. "A physical undercurrent connection, [ ] which wasn't visible, but I did feel it," as Benjamin explained. "You know it's actually there, but now you also really see it!" Anthony exclaimed. "And what then is "it"?" the moderator asked. "That connection between people without being attached by an umbilical cord," he answered. 
Looking at what participants say about the emergence of meaning, we find the concepts of being, imagining the real and swinging back to contribute to meeting. Concerning being, participants note how expressing their true selves by sharing their memory and letter with others contributed to meeting. "You get more connected as a group. Because again, you express something," as Benjamin noted about sharing his letter. Several participants emphasized the vulnerability of this sharing; Bert saying that "stepping over this trepidation and just doing it" led him to feel a deeper connection to the others. Concerning imagining the real, participants tell how they experience meeting both in listening to the memories and the letters of others, as well as in seeing the other in his or her written reactions. Listening to the memories was addressed by Anne in terms of wonder: "wonder about the story of the others. And the way they experienced that and how that, in turn, moves me." She explained that "you get a different kind of connection because it touches your feelings, and you let go of your head, your thinking." In being a witness to the other's vulnerable process from memory to letter, participants also experienced a deeper connection to the other. "Beautiful that everyone dared to show so much vulnerability. [ ] Just honest and open and sincere," as Barbara declared. Finally, specifically Amelia mentioned how seeing the other in his or her written reactions contributed to meeting this person: "You tell your story, it is yours. And from it, I take something for myself. And that can be, I can, I can take out something completely different than you. And still, somewhere we have that connection." Finally, swinging back was found to contribute to meeting as well. Finding similarities in your own life leads to a sense of connection to the other, several participants said. "Because a memory, something that someone shares, that you can picture it yourself, a picture that is close to something that you experienced yourself," Anne explained. "And that almost instantly connects to the other," Amelia added.

What or whom did the participants meet? Most comments, as shown above, relate to meeting other participants in the intervention, to "feeling a deeper connection to each other" as Benjamin expressed. However, participants also refer to a kind of meeting that transcends the group. Several remarks were made about feeling a connection to humanity and to shared human values, to what is common to us all. As Barbara stated: "the realization, or the confirmation, 
that everybody is actually just the same, and experiences things, and that things remain with them from those experiences, and that that has an impact. The similarities in that. Everybody... everybody is different but also the same, to say..." Anthony specifically connected to the nature of humanity, to our inherent goodness. While talking about the listening to the letters of others, the moderator asked him: "So you see how someone clarifies, the words and the values, and, how does that affect you?" "It makes me feel good to see that people are actually just good," he answered. "So... And I know, in the future, whoever I will meet, that there is always this value somewhere beneath, and sometimes people have been so grind down that you don't get their stories into the open in this way." Anthony also elaborated on another aspect of meeting. In his comments he shows how he not only meets the others in the memories they share, but also a larger reality of life:

\footnotetext{
"When they were telling... I was still on the beach with Alex, looking at the mountains with Amelia, and I saw you with the curls of your daughter... I was in all those stories. [ ] In fact, you are still connected to the other's story, and you just move on in the story. [ ] Actually, it is one big story. In which people show different scenes. That's what I mean with appearing, that I think: wow!"
}

In this comment, we see how this meeting leads to a transformation of Anthony's perspective. The appearance of "one big story" seems to open him up to the wholeness of life, by seeing how the different stories are all pieces of this whole. Meeting this self-transcendent larger reality leads him to "start thinking differently," he states, and changes his perspective on his own life: "it helps me to broaden my own bitterness, the narrowness in which I got stuck." Finally, several participants mentioned to experience a stronger connection to themselves. "It connects between the others and then also more to myself," as Anne explained.

\section{Discussion}

The presented case study is a rich account of the emergence of meaning-asconnectedness throughout the group intervention, and exemplifies the role of the 
Buberian concepts within the process of meeting in each of the steps. It shows how being is enhanced by choosing one meaningful moment in answer to the Wonderful life question, by the silence and the reciprocity of telling and listening, how the vividly told memories and vulnerable letters contribute to imagining the real, how the silent, written reactions aid confirmation and how responsibility is expressed through the letters that connect past and future. In addition, the empirical findings give color to these philosophical Buberian concepts. They highlight the genuineness of being, the way imagining the real is physically and emotionally felt, how confirmation may broaden self-perception and responsibility can be mild and self-compassionate. And while no contradictions were found to Buber's theory, the study adds an additional concept to explain the process of meeting in the intervention: swinging back. Though related to "not losing one's own ground" as the counterpart of "swinging over to the side of the other" in Buber's imagining the real, Buber does not address the value of what seems to be a temporal flow of swinging back and forth, taking back to one's own side from what was encountered on the other side. Finally, our study sheds light on the overarching concept of meeting as the essence of meaning. It recognizes meeting to be a physical, selftranscendent and possibly transformative experience.

\section{Implications for the Counseling Practice}

The findings align with studies that emphasize meeting to be a crucial factor in the therapeutic relationship, referred to in terms of relational depth or existential empathy (Cooper, 2005; Vanhooren, 2019a). Overall, the findings reflect the core conditions of relational depth as mentioned by Rogers (1989): unconditional positive regard, genuineness and empathy. In more detail, they show how swinging over and swinging back are elements of subjective empathy as described by Clark and Simpson (2013), and mirror many counselor factors that contribute to relational depth as found by Tangen and Cahswell (2016), e.g. tuning in, stillness and genuine connection. Moving from the dyadic relation between counselor and client to the interactional process between participants in a group counseling intervention, the findings complement these studies by presenting an account of the way the counselor may facilitate this group process to enhance the participants' sense of meaning in life. 
Meeting is a physical experience, the study shows. This finding supports Gendlin's notion that the emergence of meaning involves a felt physical shift (1996), and relates to studies that elaborate on the relation between meaning and the specific emotional states of wonder, being moved and elevation (Cova \& Deonna, 2014; Haidt, 2000; Schneider, 2009; Vasalou, 2015). The awareness of these bodily sensations is acknowledged to be of great value in therapies aimed at enhancing a sense of existential wellbeing (Leijssen, 2007; Vanhooren, 2019b). Building on these findings, we believe there is a great opportunity to address the physical and emotional aspects of meaning more prominently in both the Wonderful Life Intervention and other meaning enhancing interventions.

Foremost, the study shows the value of working with meaningful moments at the heart of the intervention, functioning as gateways to being and facilitating the self-transcendent experience of connecting not only to other participants, but also to humanity and the larger whole of life. By sharing meaningful moments, "one big story" appears, as Anthony said, which has a transforming impact. This quality of sharing meaningful deserves more attention, and it is of value to further investigate the way it may be employed in meaning enhancing interventions. In addition, participants point to the appreciative way the intervention builds on both the past (one memory) and future orientation (the afterlife) of the Wonderful Life Question used to elicit meaningful moments, translating the values underlying the chosen memory in a letter with a call to action. The Wonderful Life Intervention thereby not only relates to meaningeliciting interventions that make use of the power of reminiscence (Westerhof, 2019; Westerhof et al., 2010), but also to interventions in the field of narrative futuring (Sools \& Mooren, 2012; Sools et al., 2015).

Within themselves, people have vast resources for self-understanding, for changing their self-concept, attitudes and behavior, Rogers states (1989). Meaningful moments chosen in answer to the Wonderful Life Question appear to be one of these resources, and a specifically compact and powerful one. However, the question also entails a risk, as the idea of an afterlife and the restriction of choosing only one memory may distract participants and lead to unwanted effects. 


\section{Limitations and Future Research}

In order to obtain a rich account of the way meaning-as-connectedness is brought about, the case study was carried out in circumstances as ideal as possible for this purpose: participants were highly motivated healthcare professionals with the skills to reflect on their experience, and the counselor was experienced in facilitating the intervention, knowing when and when not to interfere and how to create the right setting. However, this raises questions about the applicability of the intervention in other circumstances and the degree to which the results may be generalized. Further research is necessary to investigate the impact of less ideal conditions on the outcomes, e.g. working with less experienced counselors, with participants who are (professionally) more acquainted with the I-It mode of being, or applying the intervention in situations when conflicts or safety-issues threaten I-Thou relations. Also, it is of value to investigate the way these insights as obtained by means the Wonderful Life Intervention may be extrapolated to other meaning enhancing interventions. Finally, it is important to note that the focus group was held directly after the intervention. For the participants, this demanded an immediate change from the confirming I-Thou mode of being to a more reflective and critical I-It related attitude, with the counselor now in a different role. Though not observed by the moderators, this bold switch may possibly have influenced their contributions in the discussion.

\section{Conclusion}

Overlooking the outcomes, the study is of value for its empirical account of Buber's philosophy of meeting as the essence of meaning, as it enfolds in the process of sharing meaningful moments. It expresses the value of meeting in the counseling process and the way counselors may facilitate this meeting in a group counseling process. With this study we hope to contribute to the development of interventions in which meeting stands central. For all real living is meeting, Buber says; or in the words of one of the participants: "it is the other who gives meaning." 
The Power of Sharing Meaningful Moments 


\section{6}

It was probably eleven years ago, when I went to my grandparents' hometown. My grandfather was very sick at the time, and when I was born, he already could not speak properly, he could not speak. He could only nod "yes, yes" to react to everything that was said to him. The moment I choose was when I was playing with my cousins in front of my grandparents' house. And while we were playing, I saw my grandfather looking at me and my cousins from behind the window, just smiling. And at that moment it was very calming to see his smile, but at the same time I was very sad because he could not play with us. He was very sick, he could not stand up, he was always in his wheelchair. He could only see us from a far distance. It is the most calming and saddest moment I've ever had in my life.

\section{y)}


Chapter 6

General

Conclusions \&

Discussion 
This thesis aligns with the growing fields of research and practice that recognize meaning in life as vital to human wellbeing and functioning. It is in and through meaningful moments in life that meaning is experienced. A sense of meaning may emerge from meaningful moments as they happen "in the wild," but also by intentionally recollecting the memories of these moments. This study focuses on this meaning enhancing quality of meaningful moments in life. In general, the study has deepened insight on the nature and emergence of meaning from meaningful moments, and the way a sense of meaning in life may be enhanced by reflecting on and sharing these moments.

In this chapter, I firstly present and discuss the key findings of this thesis, addressing its contributions to the field of knowledge, and its strengths and limitations. After this I reflect on these findings by going back to the relevance of this thesis, giving implications for further research and practice.

\section{Key findings}

\section{Meaningful moments: an overview and categorization}

Key finding in relation to research question 1: what are the characteristics of meaningful moments and how may they be categorized?

Peak experiences, epiphanies, sacred moments, self-defining memories: a selection from the variety of names given to experiences that have been recognized to enhance a sense of meaning in life (Goldstein, 2007; Hoffman et al., 2012; Maslow, 1959; McDonald, 2008; Singer \& Blagov, 2004). Current studies tend to focus on specific types of meaningful moments, according to their valence, setting, impact and/or the domain or period of life in which they appear. This thesis complements these studies by introducing an overview of meaningful moments, as presented in chapter two. This overview is of value as it (1) colors in the overall picture of meaningful moments and (2) divides the landscape of meaningful moments into categories with clearly distinguished characteristics.

First, I look into the developed categories of meaningful moments. The dimensions of context and intention, derived from the literature on the third 
conceptualization of meaning in this thesis, the emotions of wonder, were employed to make a distinction within a large dataset of meaningful moments collected by means of the Wonderful Life Question. In this way, five categories of meaningful moments were identified: opening up to life, facing the precarity of life, celebrations, countering the negative, and familiar routines. Relating these categories to the current body of literature on meaningful moments, the question arises if each category has as of yet received equal recognition for its meaning potential.

The category of opening up to life is perhaps the most "classical" type of meaningful moment, as these unintentionally encountered, positive moments relate to peak experiences that have been the object of study since Maslow firstly became interested in these moments over half a century ago (e.g. Ebersole, 1972; Hoffman, 1998; Maslow, 1964).

Celebrations as moments of intentional meaning creation may be seen as manifestations of purpose - a prominent and well-studied aspect of meaning. However, purpose is mainly addressed as an overarching life goal (e.g. Martela \& Steger, 2016), while celebrations resonate with what Frankl calls situational meaning, aimed at making a difference in a specific situation (Frank1, 1959/2006; Wong, 2016 a,b). The findings of this thesis thereby empirically substantiate this more down to earth, situational approach to purpose.

Regarding the categories facing the precarity of life and countering the negative, it becomes apparent that meaning is not restricted to happy moments in life. Findings align with the second wave positive psychology (or positive psychology 2.0) movement, that counters the dominant focus on happiness and positive experiences, and pleads for a meaning orientation towards life. It is a vision that goes beyond mere acceptance of difficult moments as part of the inherent nature of life, by highlighting the potential of these moments to enrich life and stimulate personal growth (Ivtzan et al., 2015; Lomas, \& Ivtzan, 2016; Wong, 2011, 2019). As examples of existential experiences (Jacobs, 2020; Yalom, 1980), findings on meaningful moments in the category of facing the precarity of life substantiate this vision, while the category of countering the negative exemplifies the intentional, eudaimonic aspect of second wave positive psychology (Wong, 2011). 
Finally, it is of interest to look into the last category of meaningful moments that was distinguished in this thesis: familiar routines. Of each of the five defined categories, these small, recurring moments of ordinary life have as of yet been least recognized for their meaning potential - the modest amount of literature on these moments reflects the modesty of their nature. Current studies on routines mainly focus on their meaning and practice in special contexts: in times of illness, aging and bereavement, or as part of religious, spiritual or therapeutic practices (e.g. la Cour et al., 2009; Meira et al., 2017; Pargament, 2011; Schnell, 2003). In contrast, this thesis particularly points to the value of familiar routines as part of "life as usual." As a large part of life is routine, this finding is of great interest to enhance a sense of meaning in the hustle and bustle of everyday life: to revitalize old, rusty habits and infuse them with a sense of wonder and purpose.

Looking lastly at the whole landscape of meaningful moments, that varies from intentional to surprising, from ordinary to unique, from positive to negative, it may be seen to support Frankl's (1969) premise that any moment in life is potentially meaningful. A premise, however, that immediately gives rise to a question: for how do these moments become meaningful? How does the magic set in? The following findings from this thesis shine their light on these issues.

\section{Meaning as a personal process of discovery and creation}

Key finding in relation to research question 2: how do people experience meaning to emerge from memories of their meaningful moments?

While meaningful moments are fleeting experiences, they are generally recognized to have a value and impact that proceeds the momentary (e.g. Anbeek et al., 2018; Pillemer, 2001; Westerhof et al., 2010; Wong, 2011; Wong \& Watt; 1991). They are mentioned to be deeply felt, deeply processed, enlightening and transforming (Pillemer, 2001; Wong, 2012b). Findings from this thesis align with these qualifications; the results from the narrative interviews presented in chapter four giving in-depth insight in the functioning and impact of these moments as they naturally occur in the flow of life. Moreover, they articulate that the emergence of meaning from meaningful moments is a process that 
unfolds over time, in which a distinction can be made between the discovery and the creation of meaning. In this thesis, insights on this process are brought together in an integrated framework on the emergence of meaning, leading to a deeper understanding of meaning as a continuing process in life.

Within the current body of literature, references to this process of meaning emergence are found in terms of e.g. the presence and search for meaning and the detection and construction of meaning (King \& Hicks, 2009; Park, 2010; Steger et al., 2008). However, the interrelatedness between the different aspects of this process has as of yet not clearly been noted. Findings of this thesis integrate these aspects into a coherent framework, indicating that meaning discovery may lead to meaning creation, and meaning creation may lead to retrospective meaning discovery. The framework is also integrative in another way, as it encompasses each of the conceptualizations of meaning as presented in the introduction: the dimensions of coherence, purpose and significance, connectedness, and the emotions of wonder.

Though - mainly theoretical - suggestions are made about the interdependency of coherence, purpose and significance, and (to a lesser extent) connectedness (e.g. George \& Park, 2013; Martela \& Steger, 2016; Steger, 2012), they are generally referred to as separate facets of or needs for meaning, which may bring about the risk of regarding them as a checklist of "things to do" in order to live a meaningful life. This thesis makes a contribution to the current body of knowledge by uniting these aspects of meaning into a coherent whole, empirically showing the way they work together to bring about a sense of meaning and significance in life. In sum, coherence was found to relate to meaning discovery and purpose to meaning creation, with significance as the outcome of the process. Connectedness was found to run through each of these dimensions. Alongside this, the thesis points to two additional aspects that are of importance to the emergence of meaning, that appear to be the counterparts of coherence and purpose: wonder and letting go.

In regard to coherence, findings suggest that the process of meaning discovery starts with and thrives on the emotions of wonder, while the understanding of this meaning tends to unfold over time. They indicate that coherence as a 
dimension of meaning is preceded by an opening, wonder-invoking experience; an experience through which people experience a sense of connectedness. Meaning discovery thus involves both embracing the unknown, the disruptive and disturbing, as well as comprehension and coherence - both openness and closure. Findings thereby highlight the value of the third conceptualization of meaning as an affective state, and resonate with recent studies that point to openness, existential wonder and awe as a precondition to meaning (Alma, 2018; Schinkel, 2018; Schneider, 2009; Wong, 2011). The emotions of wonder appear to be vital to the experience of meaning, for without wonder, there would be no "stretching forth of the mind" (Aquina in Vasalou, 2015, p. 74), and we would remain forever in the comfort and restrictions of our existent perceptions of reality.

In relation to purpose, the study points to another important precondition to meaning: letting go, an open, vulnerable and appreciative attitude. Where wonder teams up with coherence in meaning discovery, letting go particularly teams up with purpose in meaning creation. The thesis shows that purpose is not fixed and controlled, but develops on the go: by letting go of overattachments to e.g. ratio, responsibility and expectations and stepping into the unknown, gaining deeper understanding on the way. This open, responsive attitude in relation to purpose aligns with Maddi's $(2004,2013)$ idea of "choosing the future" as opposed to "choosing the past," which is based on preexistent comprehension and control. Purpose therefore is paradoxical, as it involves both focus and direction as well as the willingness to detach from proven paths and patterns.

Looking at the meaning literature, wonder and letting go are found to be markedly less studied than their counterparts in the processes of meaning discovery and creation: coherence and purpose. From this observation, the question arises if comprehension, focus and control are not overvalued in their role to enhance a sense of meaning in life. I find support for this notion in Wong's (2011) article on positive psychology 2.0, in which competence-andsuccess values are attributed to a happiness orientation, against humility and acceptance that relate to a meaning orientation. The findings from this thesis, 
at least, plead for more recognition of non-comprehension, openness and surrender as vital contributors to the meaningful life.

\section{Meaning as a mindset}

Key finding in relation to research question 2: how do people experience meaning to emerge from memories of their meaningful moments?

The third finding of this thesis zooms in on the meaning orientation towards life. While a sense of meaning may emerge from events that trigger meaning discovery or in which meaning is deliberately created, the meaning orientation transcends the momentary and is directed towards life as a whole. It is a mindset with both an active, eudaimonic component, aimed at serving a higher purpose and making a significant difference in the world, and a receptive, chaironic component, an intentional, mindful attitude of awe and gratitude, grounded in a sense of connectedness: to nature, the world or a transcendent reality (Passmore \& Howell, 2014; Wong, 2011).

This thesis specifically sheds a light on the chaironic component of the meaning mindset. I refer to this component as the mindset of wonder, as it relates to the third conceptualization of meaning presented in the introduction: meaning as an affective state. For while wonder is an emotion that may befall people, it is argued that wonder may also an intentional mindset, fostered by a deliberate focus and awareness to see the extraordinary within the ordinary and takenfor-granted (Bennett, 2001; Vasalou, 2015).

As of yet, only little is known of this open, appreciative mindset, which is also referred to as awe-based consciousness or "enchanted agnosticsm" (Schneider, 2004 , p. 175, 2014). It has received remarkably less research attention than its eudaimonic counterpart. While some suggest that this mindset of wonder specifically arises when people are confronted with difficult and precarious situations (La Cour et al., 2009; Machell et al., 2015), others refer to this mindset as a character trait (Emmons, 2000). Findings from thesis help to clarify this mindset. The study in chapter three was specifically performed for this purpose, looking in to this mindset by investigating the way people see the extraordinary within the ordinariness of familiar routines. The study resulted 
in the distinction of several meaning-constructing mechanisms that appear to be fundamental to the functioning of the mindset of wonder.

Specifically, contrasts were found to play a major role in the mindset of wonder - a finding that arises from the study on the paradoxical nature of familiar routines (chapter three), and from the study on the emergence of meaning from meaningful moments over time (chapter four). Though these studies employed different methods of narrative investigation, respectively storyline analysis and holistic content analysis, both point to the awareness of contrasts as a vital meaning-constructing element of the mindset of wonder.

Furthermore, several different types of contrasts were discerned that contribute to the construction of meaning in and from meaningful moments. First of all, findings show how meaning construction may relate to the awareness of the contrast between instrumental acts and their higher purpose. The mindset of wonder entails focusing not on the utilitarian nature of daily activities, but on their symbolical function, as moments of connection to others or to higher values. Contrasts may also concern the awareness of opposing values or states of being emerging either simultaneously or subsequently within a moment, the latter involving the transformation from one value or state of being to another, contrasting value or state. Finally, contrasts may arise by zooming out from the moment to another period of time, to another setting or aspect of life in which the value experienced in the moment is absent.

Reflecting on these findings in the light of the current body of knowledge, these meaning constructing mechanisms seem to have received surprisingly little attention so far. While Maslow (1969) lightly touched these mechanisms in his article on the various meanings of transcendence, and, more recently, Baumeister and colleagues (2013) refer to the emergence of meaning by zooming out in time, they do not substantiate this.

The meaning constructing mechanisms that this thesis describes contribute to the understanding of the mindset of wonder as the chaironic component of the meaning orientation. The various types of contrasts that have been identified may be a starting point further investigation and valorisation, relevant to 
the development of interventions that assist people in developing a meaning orientation towards life.

\section{Meaning as an interactive process}

Key finding in relation to research question 3: how do people experience a sense of meaning to be brought about in the process of sharing meaningful moments with others?

While the first three studies in the chapters two, three and four of this thesis approach meaning from a personal perspective, the final study focuses on meaning as it emerges between people through an interactive process. Chapter five gives insight in the way a sense of meaning may be brought about in the process of sharing meaningful moments with others. In this study, the focus is on the second conceptualization of meaning as presented in the introduction: meaning as connectedness. It aims to develop deeper understanding of connectedness as a real-time shift from self-orientation towards the awareness of relatedness.

In this study, Buber's (1957) philosophy of meeting was chosen as a framework for investigation, a philosophy in which the self-transcendent dimension of connectedness is recognized to be the essence of meaning. The presented case study is a rich account of this dialogical process of meeting within a group intervention in which meaningful moments are shared. The value of the study is in bringing Buber's abstract philosophy to life, by exemplifying the way the dialogical process works and illustrating the different elements of the intervention that contribute to this process.

The study shows the way sharing meaningful moments may lead to authentic encounters and a sense of meaning that is physically felt. It thereby affirms meaning to be an affective state, mirroring the third conceptualization of meaning in this thesis. Findings highlights the value of working with vivid narratives, and the role of silence in seeing the other and being seen in a genuine way. The interaction between participants in the intervention was found to aid the personal process that Buber calls confirmation; participants helping 
each other in both the discovery and creation of meaning from their chosen meaningful moment. The study particularly points out the value the Wonderful Life Question; the power of which lies in the appreciative way of building on the past (one memory) to envision the future (the afterlife). By sharing these moments, participants not only experience a stronger connection to themselves and to the other participants in the group, but also to humanity, to the larger whole of life. "One big story" appears, as one of the participants put it, a selftranscendent experience that may have a transforming impact.

Looking into these findings on the process of meeting throughout the intervention, they clearly align with studies that focus on meeting as a vital aspect of the therapeutic relationship, thereby reflecting several core conditions of this relationship, such as unconditional positive regard, genuineness, empathy, tuning in and stillness (Cooper, 2005; Rogers, 1989; Tangen \& Cahswell, 2016; Vanhooren, 2019a). However, findings from this thesis do not relate to the dyadic relation between counselor and client, but to the interactional process between participants in a group intervention. The importance of this group process having been widely acknowledged (e.g. Dierick \& Lietaer, 2008; Yalom, 1970), this thesis offers practical suggestions for the way therapist and counselors may facilitate the process of meeting within a group to enhance the participants" sense of meaning in life.

Alongside this, the findings are of interest in light of the big and small story discourse within narrative psychology (Bamberg \& Georgakopoulou, 2008; Ochs and Capps, 2001; Sools, 2012; Sools, 2013). The case study approaches narration as a collective process between multiple storytellers, giving insight in the mechanisms of shared storytelling (i.e. the dimension of tellership in the small story approach) that bridge the gap between small and big stories. For findings show how small, individual stories may be strung together to form one collective big story - a story, the "grand narrative of creation" as Wong (2014) put it, that we are all part of. The case study illustrates the value of collective tellership to connect to this grand narrative, thereby contributing to a selftranscendent orientation towards life: seeing and feeling how we are not just individuals but part of humanity, part of a larger whole. 
Finally, it is important to emphasize the role of the Wonderful Life Question in the process of narration, leading people to share memories of extremely meaningful events. Within themselves, people have vast resources for selfunderstanding, for changing their self-concept, attitudes and behavior, Rogers states (1989). Meaningful moments chosen in answer to the Wonderful Life Question appear to be one of these resources, and a specifically compact and powerful one.

\section{Strengths \& limitations}

The value of this study is in its investigation of the potential of meaningful moments to enhance a sense of meaning in life. Incited by a Japanese movie, it gives insight in the landscape of meaningful moments, in meaning as a personal process of discovery and creation, in meaning as a mindset and in meaning as an interactive process. In this paragraph, I discuss the strengths and limitations of the approach that was taken. I successively consider the Wonderful Life Question that stands central in this thesis, the participants and the narrative approach that was taken. Finally, I address an issue I have encountered with the conceptualization of connectedness, and reflect om myself as a researcher/practitioner.

\section{The Wonderful Life Question}

First of all, I address the Wonderful Life Question that was employed to collect narratives of meaningful moments, and is also the foundation of the group intervention that was the object of study in chapter five.

The categorization of meaningful moments developed in chapter two demonstrates that the Wonderful Life Question elicits all kinds of meaningful moments: big and small, intentionally created as well as unintentionally encountered, within a variety of positive, negative and ordinary settings. The combination of small (one memory) and big (eternal consequences) as only selection criteria appears to lead to a focus on the most essential, salient moments of life, without directing to specific types of experiences. Participants in the group intervention described in chapter five articulate the value of the question to "get to the essence," to appeal to the heart instead of the mind, 
and to immediately trigger images of meaningful memories. The Wonderful Life Question has also proven to be of use to study the personal process of meaning emergence. Here, the dual temporal focus within the question is of interest, as it entails both an orientation to the past (a memory) as well as to the future (the afterlife). The study in chapter four illustrates the way this led participants to choose a moment that explicitly or implicitly triggered a process of meaning discovery and creation. Finally, chapter five highlights the value of the Wonderful Life Question in studying the interactive process of meeting between participants in the group intervention. Results show that the Wonderful Life Question facilitates genuine "being" as an aspect of this process.

However, findings also point to a risk in the employment of this question, possibly affecting the internal validity of this thesis. In the case study in chapter five, several participants mentioned that at first, they felt a certain hesitance to share their chosen memories, because these moments are very personal and often vulnerable. Therefore, one may question if participants may sometimes have chosen to share a different, less personal or "safer" memory. Studies on the validity of qualitative research emphasize that people are often resistant to revealing their true thoughts and feelings to others, especially to strangers (Polkinghorne, 2007), and that the relationship between interviewer and participants is a crucial factor in the process of sharing (Kuzmanić, 2009). In this thesis, this factor has been taken into account, as the interviewers were experienced group facilitators, keen to create a safe and confidential setting that stimulates authentic sharing. Alongside this, it needs to be noted that the emotions of wonder were constantly present throughout the workshops and interviews in which data for this thesis was collected; participants often spontaneously mentioning and displaying them. From this observation one may conclude that the moments that were shared must at least in some way have been experienced to be meaningful.

\section{Participants}

Next, it is of interest to reflect on the participants throughout this thesis and the generalization of the results. While the study in chapter two was based 
on meaningful moments from a variety of people, particularly in the studies in chapters four and five the participants formed quite homogeneous groups. In chapter four, the selection of participants on the basis of their meaningful moment unintentionally lead to a group of middle-aged people all having affinity with personal development, while in chapter five, an intentional choice was made to work with highly motivated psychological healthcare professionals. In one way, the reflective skills of these participants have contributed to the richness of the data that was collected, thereby leading to a deep, contextual understanding of the personal process of meaning emergence and the interactive process of sharing meaningful moments. However, these conditions raise questions about the external validity of the results. In regard to the study in chapter four, further research is necessary to discover the degree to which the developed framework of meaning discovery and creation is generally applicable. For the case study of the group intervention, transferability (Polit $\&$ Beck, 2010) is an issue: assuming that the professionals in the case study are sensitive to meaning and familiar with establishing I-Thou connections, one may question if the intervention will have a similar effect on other people, particularly those to whom a sense of meaning is at stake.

Finally, the number of participants needs to be noted. Apart from the first study, data was collected from a limited amount of participants: the second study consisted of memories from thirteen people, the third study comprised nine interviews and the final case study had eight participants. These numbers may not have been enough for a saturated analysis, which brings about the risk of incomplete findings. However, one may question if this is the case in the third and fourth studies on respectively the individual and the interactional process of meaning emergence, as the findings of these studies consistently reflect conceptualizations of meaning found in the literature. Moreover, saturation not only depends on the quantity of data: besides the thickness, it also the richness of the data that counts: the degree to which the data is detailed, nuanced and multilayered (Fusch \& Ness, 2015). From this perspective, saturation is specifically an issue for the study on the - very short - narratives of familiar routines, as presented in chapter three. 


\section{Narrative approach}

This thesis is founded in narrative psychology, that is concerned with the way people construct meaning from events in their lives, going beyond objective facts to subjective interpretations and valuations (Bamberg \& Cooper, 2012; Brockmeier \& Carbaugh, 2001; Bruner, 1991). Particularly, the narrative methods of holistic content analysis (Lieblich et al., 1998), storyline analysis and interactional narrative analysis (Murray \& Sools, 2014), and the narrative devices of breach (Bruner, 1986; Bruner, 1991; Murray \& Sools, 2014) and evaluations (Labov, 1972) were found to fit like a glove in developing deeper understanding of meaning and its process of emergence, both intrapersonal (in the studies in chapters three and four) as well as interpersonal (in the study in chapter five).

On the other side, the choice for these narrative methods and the way they were employed also entail several limitations. First of all, these relate to the interpretive nature of narrative research, demanding effort to provide sufficient justification for the claims that are made (Polkinghorne, 2007). In this thesis, care has been given to the analysis by means of investigator triangulation (Denzin, 1978) and to the presentation of results using persuasive argumentation, building on evidence from quotations in the text (Perelman, 1982). However, overinterpretation is an issue inherent to narrative research and specifically to the analysis of short stories (Nygren \& Blom, 2001). In this thesis, this risk mainly relates to the studies in chapter two and three, in which the only data were the short narratives of meaningful moments, without any extra contextual or evaluative information. In addition, none of these studies included a form of member checking in the research procedure (Doyle, 2007) - a method that may be criticized specifically from a constructivist standpoint (e.g. Riessman, 2008), but that could have provided further validation.

Secondly, the validity of the narrative data needs to be taken into account, as it is argued that the narrated descriptions given by participants may not always accurately reflect their experienced meaning. This may be caused by a hesitance to share certain stories with others, as described above, by the limitations of language to capture meaning, or by a limitation to reflect on 
deeper layers of meaning outside of awareness (Polkinghorne, 2007). In the studies in chapter four and five, this last issue was mitigated by the interviewer/ facilitator, helping the participants to bring these deeper layers of meaning into awareness. However, though the interviewers/facilitators in these studies were experienced counselors, trained in techniques of interrogation, this interference with the participants will to some degree have influenced the narrative data (Polkinghorne, 2007). In this thesis I have strived to be transparent about this issue by providing quotations that illustrate the co-creation of meaning between researchers and participants.

\section{Conceptualization of meaning as connectedness}

Looking back on the research process of this thesis, it needs to be noted that I have specifically struggled with connectedness as an aspect of meaning - and overseeing the literature, it may be remarked that I am not alone in this struggle. As mentioned, the concept is defined in various ways and has been given a variety of names, such as self-transcendence, belongingness and relatedness. Scholars are ambiguous in stating to whom or what this sense of connectedness relates, and while some judge it to be an important source of meaning (e.g. Martela \& Steger, 2016; McDonald et al., 2012), others identify it as a fourth dimension of meaning (Schnell, 2014) or as the core essence of meaning itself (e.g. Buber, 1965; Delle Fave \& Soosai-Nathan, 2014; Frankl, 1966). Alongside this, connectedness is also referred to as a real-time interactional process (Buber, 1957; Delle Fave \& Soosai-Nathan, 2014; Friedman, 1999).

In the first three studies of this thesis, I have addressed connectedness in terms of self-transcendence, defining it as the awareness of being part of a larger whole, of a reality beyond the known. Looking back on the research process, I see how I thereby have put emphasis on what Schnell $(2011,2014)$ calls vertical self-transcendence, as opposed to horizontal self-transcendence which entails a more worldly orientation: a sense of unison with nature, social commitment, and care for others. In the last study, presented in chapter five, I have adopted Buber's philosophy of meeting to investigate connectedness as a dynamic interactional process. Therewith, I have also incorporated Buber's (1965) notion of connectedness in terms of our threefold living relation: to other 
people and mankind, to the world and things, and to the "mystery of being." Buber's philosophy clearly encompasses both vertical as well as horizontal self-transcendence, including social aspects of connectedness that I did not take into account in the first three studies of this thesis. Specifically in the third study, this broader definition would have led to slightly different results: to finding aspects of connectedness throughout all of the interviews in both meaning discovery and creation, which is not reflected in the presented article.

On the positive side, despite the confusion on connectedness in this thesis as well as in literature, connectedness is increasingly recognized to be an important aspect of meaning, emerging from a critique to the "me-first" selfpreoccupied mentality in our western society (Wong, 2016 a,b; Gergen, 2011).

\section{Being a researcher/practitioner}

Finally, I reflect on the strengths and limitations of doing research as a practitioner, specifically in relation to the theories and methods that were used. For as one may have noted, this thesis draws on a variety of epistemologies, varying from existentialism and humanism to constructivism. Therefore, one could argue that this thesis does not have a clear and consistent orientation. And while in one way this may be a weakness of this thesis, it may just as well, or maybe even more, considered to be a strength. It has led to findings that could not have been brought forth from just one single, predetermined epistemological position: to a deeper understanding of meaning as a livedthrough experience, bringing different conceptualizations of meaning to life and highlighting their coherence.

Looking back on the process, it is typically a pragmatist approach that has been taken. Pragmatism as a paradigm does not engage in discussions about truths, but accepts that there may be multiple realities. In pragmatist research, it is the research question that stands central, and philosophies and (combinations of) methodologies are chosen based on their appropriateness to answer that particular question (Tashakkori and Teddlie, 2008). Iterating between experience and theory, pragmatism allows employment of expertise and ideas from practice to develop deeper understanding and create useful knowledge 
(Feilzer 2010; Kaushik \& Walsh, 2019). It is exactly in this way that each of the research questions in this thesis was answered. More specifically, the experience built up by many years of working with meaningful moments in a variety of settings and with a variety of people, guided me in choosing whatever seemed to be of value as a framework or tool for the questions at hand.

The other way around, the research has strengthened me as a practitioner: it has deepened my insight on meaning and its emergence, helping me to finetune the Wonderful Life intervention, adding components and reflective questions. Also, it has led to new insights on my role as a counselor not only in facilitating people and groups, but also in assisting clients in creating meaningful organizations. The different studies brought about a deeper understanding of the disenchanting mechanisms mentioned in the introduction, and as a professional, I feel called to create awareness of the importance of countering these mechanisms. Finally, the research has enriched me as a human being. This $\mathrm{PhD}$ being sparked by existential questions in my personal life, the research has helped me to see "the bigger picture," to embrace mystery and, as Buber says, meeting as the true essence of living.

\section{Suggestions for further research}

In this paragraph, considerations are given for future research in relation to each of the four key findings of this thesis. Both theoretical substantiation and valorization of the findings are taken into regard.

Starting with the developed categorization of meaningful moments, future research should focus on plotting the various types of meaningful moments that appear throughout the meaning literature (e.g. peak experiences, epiphanies and contrast experiences) on this overview. This may contribute to a more comprehensive and coherent understanding of meaningful moments in all of their varieties. Apart from this, it needs to be noticed that up to now the overview is a conceptual framework. Additional research is of value to assess the applicability of the framework in the coaching, counseling and therapeutic 
practice, as an appreciative tool to reflect on the varieties of ways in which meaning may emerge throughout the whole of life.

Next, I turn to the second framework presented in this thesis, of the process of meaning as it emerges from meaningful moments. Firstly, it is of interest to assess the degree to which this framework is universally applicable. As the number of participants in this qualitative study was limited and the participants formed a homogeneous group, it is necessary to address the generalization of these findings in a larger study with a greater variety of participants. This follow up study should also concentrate on further substantiation of the elements within the framework, addressing connectedness not only as vertical selftranscendence but also horizontal, which was omitted in the presented study. Specifically, the interrelatedness between wonder and coherence in meaning discovery and between letting go and purpose in meaning creation are a field for further investigation. In the recognition of non-comprehension, openness and surrender as vital contributors to the meaningful life, it is of value to develop deeper insight in the way these opening and closing mechanisms work. Finally, a subsequent study may focus on evaluating the developed framework on the emergence of meaning in regard to its employment in the coaching, counseling and therapeutic practice.

The third key finding of this thesis investigates meaning as a mindset, and describes several meaning-constructing mechanisms that appear to be fundamental to the functioning of this mindset. The data of the study on this topic being neither thick nor rich (Fusch \& Ness, 2015), future research is necessary to address issues of saturation and interpretation. It is recommended to perform a study on larger group of participants to (potentially) discover additional meaning-constructing mechanisms, and to validate the interpretations of their narratives by discussing the findings with participants.

Alongside this, additional research is of importance in regard to valorization. It should focus on discovering the degree to which participants are consciously aware of these mechanisms, and the effect of this awareness on the experience of meaning in life. For while coherence is often addressed in meaning enhancing 
interventions (e.g. Bohlmeijer et al., 2008; Märtsin, 2018), wonder as its open counterpart has not received equal attention. Recent studies highlighting the crucial role of wonder in the experience of meaning and moral development (e.g. Alma, 2018; L'Ecuyer, 2014; Musaio, 2012; Schinkel, 2018), this is a promising field for further study.

Finally, this thesis sheds a light on the way a sense of meaning is brought about in the process of sharing meaningful moments with others. For this purpose, a case study was performed under quite ideal conditions with highly motivated healthcare professionals, skilled in personal reflection. Further research is necessary to discover if the intervention functions in similar ways with different types of people and in different settings. Also, the intervention has not yet been assessed on its short and long term effect on meaning in life. Qualitative, longitudinal research (e.g. Thomson \& Holland, 2003), that follows individuals in their experience of meaning before and - during a longer period - after taking part in the intervention, would therefore be a relevant next step.

Alongside this, it is specifically promising to perform a further narrative investigation of the way "one big story" appears in the collective process of sharing meaningful moments: the way small stories add up and lead to a sense of connection to a larger, self-transcending story. While participants mention this to happen during the intervention, only few clues are given to the way this experience is brought about. Self-transcendence being vital to the experience of meaning in life, a specific study on this particular aspect of the intervention is of value. It should focus on collective tellership and the mechanisms of coconstruction that lead people to see the bigger picture, and on the way this may be facilitated.

Lastly, from a wholly different point of view, I wish to point to the relevance of the intervention in relation to polarization, which is increasingly a problem in society. Sharing meaningful moments may lead to a strong sense of connectedness, to other participants as well as humanity, this thesis shows. Would the intervention also have this effect when participants represent groups with strongly opposing worldviews and beliefs? Further research is necessary 
to answer this question and discover the value of employing the intervention for this particular purpose.

\section{Implications for practice}

This thesis contributes to a deeper understanding of the experience of meaning and its emergence, and of the way practitioners like myself may contribute to enhancing a sense of meaning in people's lives. Therefore, the implications for practice are primary of value to coaches, counselors, therapists, educators and other professionals directly working with people on their wellbeing and personal growth. However, the insights from this thesis also resonate on another level. In the introduction, I have pointed out the relevance of this thesis by referring to dynamics in our current society that threaten the experience of meaning in ordinary life. Therefore, I feel called to expand the implications of this thesis to wider domains of practice than those mentioned above. Specifically, the findings are of interest to those in charge of shaping society's institutions and organizations, such as managers, HR professionals and organizational development experts. Though maybe less prominent, their role in the facilitation of meaning is crucial, as they create the systems, procedures and routines that may either vitalize and enhance a sense meaning or endanger it.

\section{Implications for professionals working with people on wellbeing and personal growth}

Address meaning through the lived experience of meaningful moments

Within the variety of ways to approach the subject of meaning with clients (or patients, customers or students, depending on the field of practice), this thesis highlights the value of employing meaningful moments. Working with meaningful moments is in essence an appreciative way of relating to life. It directs attention not to problems or loss of meaning (i.e. on what needs to be fixed), but to those real life experiences in or through which meaning is found or created, in whatever kind of way. Meaningful moments may shed a light on the unseen and taken for granted as a source of meaning or lead to the discovery that difficult moments in life may have or have had positive impact. Specifically, the Wonderful Life Intervention may be employed to spark the 
reminiscence of meaningful moments. The question has shown its value in eliciting all kinds of meaningful moments without directing to specific types of experiences. Also, the dual temporal focus within the question is of interest, appealing to the future through the appreciation of a lived experience from the past. The Wonderful Life Intervention thereby not only relates to meaningeliciting interventions that make use of the power of reminiscence (Westerhof, 2019; Westerhof, Bohlmeijer \& Webster, 2010), but also to interventions in the field of narrative futuring (Sools \& Mooren, 2012; Sools, Tromp \& Mooren, 2015). The intervention typically encompasses a meaning orientation towards life as a whole: a positive, accepting stance towards all kinds of experiences, thereby aligning with positive psychology 2.0 (Ivtzan et al., 2015; Lomas, \& Ivtzan, 2016; Wong, 2011, 2019). However, practitioners should be aware of the vulnerability of the memories that this question elicits, and the impact of sharing these memories in a group.

\section{Facilitate meaning as connectedness}

Connectedness is an important aspect of meaning, and possibly the core essence of meaning itself (Buber 1965; Delle Fave \& Soosai-Nathan, 2014; Frank1, 1966). However, connectedness (or self-transcendence) is not very commonly addressed in narrative interventions aimed at enhancing a sense of meaning in life (Giebel, 2018). Meaningful moments are moments in or through which people experience connectedness, and professionals may help clients to enhance their sense of connectedness by retrospective reflection on these moments. However, this thesis shows the way a sense of meaning- as-connectedness may also emerge in the process of sharing meaningful moments in a group: a process through which participants experience an I-Thou connection not only to other participants, but also to humanity and the larger whole of life. Several findings from this thesis on this interactional process may directly be put to practice by professionals facilitating groups. First of all, the thesis highlights the value of silence in the process of sharing, which contributes to an open and respectful way of listening to each other, and to being seen in an affirmative way. Reciprocity of telling and listening between participants enhances an open, authentic way of being present. The thesis also shows the value of vivid narration to arouse empathy; which not only leads participants to meet the 
other by swinging over to the other's life, but also stimulates swinging back to find similarities in their own lives. Finally, confirmation is enhanced by silent, written reactions from participants to each other's stories, while writing a letter for the future stimulates responsibility.

In sum, facilitating meaning as connectedness in a group means stretching relational depth, a crucial factor in counseling and therapy (Cooper, 2005; Rogers, 1989; Vanhooren, 2019a) from the dyadic relation between professional and client to the interactional process between participants in a group.

\section{Cultivate wonder and letting go}

In the emergence of meaning, coherence and purpose are renowned aspects, and they are frequently addressed both in the meaning literature as well as in interventions aimed at enhancing a sense of meaning. Findings from this thesis support the role of coherence and purpose, but also point to the value of their counterparts in the process of meaning discovery and creation: wonder and letting go. To the professional, this entails a focus not solely on comprehension, focus and control, but also on embracing the unknown and disturbing: on openness as well as closure. For some professionals, specifically those who have been trained to facilitate clients in enhancing their self-efficacy, this may involve a shift in their practice as well as their professional beliefs. Specifically wonder is of importance to broaden the client's perspective on life and experience connectedness. Professionals should acknowledge the mindset of wonder as a core competence that is crucial to wellbeing and human functioning, and train clients - as well as themselves! - in this appreciative mindset: by becoming aware of contrasts and paradox, by zooming in and out from the here and now to other contexts and setting, and by highlighting the ritual value of daily activities over their instrumental function. Letting go is of importance to move forward in life and entails an accepting, responsive attitude to whatever happens on the way, a willingness to detach from proven paths and patterns. In assisting clients with letting go, practitioners may benefit from Acceptance and Commitment Therapy (e.g. Hayes et al., 2004; Luoma et al, 2007), that thoroughly addresses this way of relating to life and experience. 
In sum, practitioners should address meaning as a process, in which the receptive component of discovery and the active component of creation belong together like breathing in and out.

\section{Implications for those in charge of creating organizational systems, proce- dures and routines}

More and more, organizations are becoming aware of the crucial importance of employee wellbeing. However, programs aimed at enhancing wellbeing tend to focus on individual happiness and positive emotions more than on meaning (e.g. Grawitch et al., 2006; Parks \& Steelman, 2008). Interventions often do not have a direct relation to work itself, but help employees deal with negative aspects of the working culture, such as stress. A meaning approach aims to strengthen the connection between employees and the purpose of their work, stimulating a calling-orientation instead of a career- or job-orientation (Wrzesniewski et al., 1997). Building on the findings from this thesis, several suggestions can be made about the way to establish a meaning orientation.

Make room for wonder and learning next to performance

This suggestion relates to meaning discovery within organizations. Openness, time and space to reflect and wonder, embracing loss and failure as opportunities for growth: these aspects of a learning culture are crucial to the healthy and meaningful development of people and the organizations that they form, but are often threatened by an overly focus on performance and efficiency. It is of vital importance that those in charge of creating the organizational systems are aware of and allow discussion of paradigms and practices that undermine wonder and learning. They should acknowledge the mindset of wonder as a core competence and invest in its development, through training and by incorporating wonder in organizational routines. How about a department of wonder next to a finance \& control department?

Value the ritual over the routine

This suggestion relates to meaning creation within organizations. Work routines being designed in such a way that they are performed in the most efficient manner may bring about the risk of losing a connection to the higher purpose 
of these routines. Therefore, it is of value to make room for the ritual function alongside the instrumental function of routines. By cultivating this ritual function, work routines may obtain the qualities of what Goldstein (2007) calls "sacred moments": moments in and through which people feel a strong connection to others and experience a sense of purpose.

\section{Make meeting a priority}

How then to cultivate this ritual function? The answer can be found in meeting: in investing in real and authentic connections with customers and clients as well as with co-workers. In contact with customers or clients, this entails a focus not solely on the transaction, but on the relation. The final study in this thesis shows the value of sharing stories with each other, and particularly the value of sharing meaningful moments. Within the organization, the meaning orientation may be stimulated by creating space to share and reflect on stories of meaningful work experiences. This type of meeting at the level of purpose is of vital importance and should be institutionalized next to the more traditional meeting that focuses on practical and economic matters.

\section{Take home message}

Meaning: a basic human need, fundamental to health and wellbeing. A fundament however, that is more and more at stake in the dynamics of an accelerating and increasingly self-centered society. This thesis contributes to building this fundament by giving insight in the way a sense of meaning in life may be enhanced. Wonder, letting go, connectedness - it is this open, appreciative and accepting attitude that runs as a thread through the findings of this thesis and the stories people share of their meaningful moments. Findings that call for wonder next to comprehension and coherence, for surrender and letting go alongside purpose and performance, and for authentic meeting besides a mere functional way of relating. Looking at these findings, the question arises if ratio and understanding, results and control, autonomy and self-efficacy are not overvalued in their role to enhance a sense of wellbeing - in research as well as society. The thesis pleads for a shift in thinking and acting towards a mindset of wonder: an open mindset, in which we see ourselves not as solitary 
beings, but as part of a larger whole. It is this mindset that enables the discovery meaning in all kinds of situations, as well as the creation of meaning that serves this larger whole and thereby, ourselves. For meaning is more than a mental healthcare issue, but is to be part of the fabric of everyday life. 


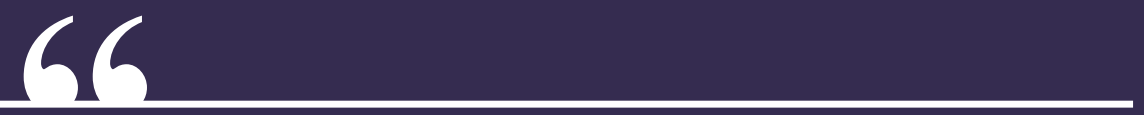

I am, just after my relationship broke up, alone on vacation in the south of Crete. Because I lived there for three years, Greece feels like my second home and it is always special to be there. I always feel that the Greek understand what life is all about: about love, about being together and sharing. The memory I wish to take to the afterlife is a moment during this vacation. The sun is setting, and I am sitting in a little harbor on an outcrop that ends in the ocean. This is may favorite moment of the day. Wen the sun sets, the ocean changes into a smooth surface and becomes such a special color blue that, at the horizon, you cannot see the difference between the ocean and the sky. The sky colors beautifully pink and orange, which is reflected in the water. I am sitting on this rock and the beauty of what I see and feel moves me, and I am sad and happy at the same time. It is a moment of perfection in which everything falls together, in which everything "is." I feel connected to the old wisdom of the country, to my soul and to everything that I am and that lives within me.

\section{y)}




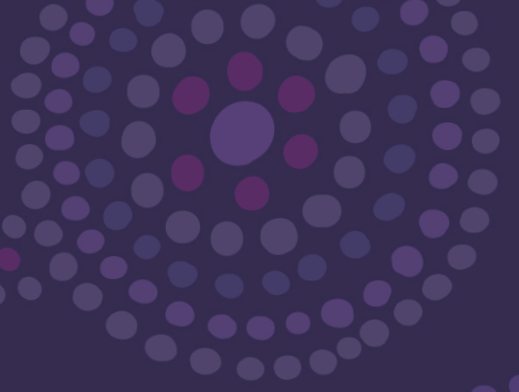

$$
\text { Appendices }
$$

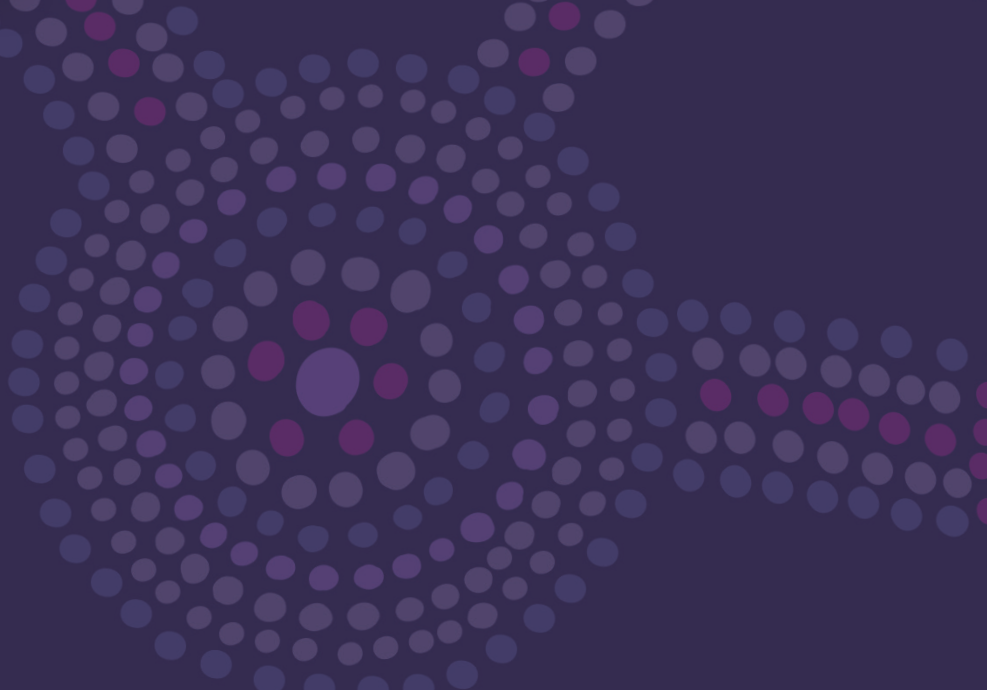




\section{References}

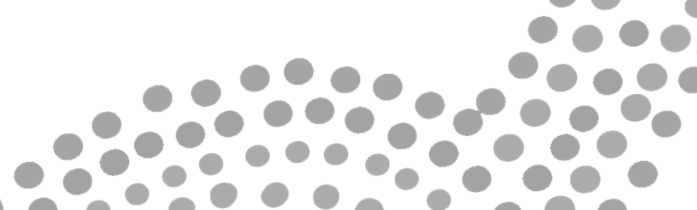
0
0
0
0
0
0
0

$0 \%$

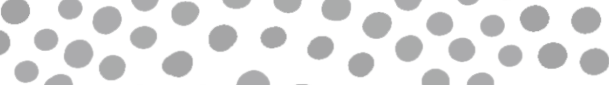

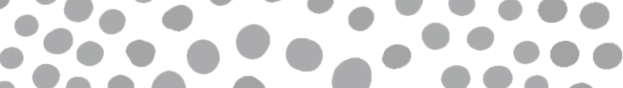

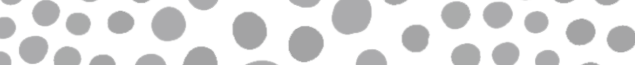

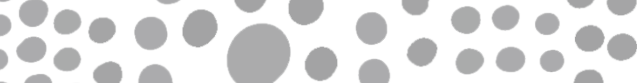

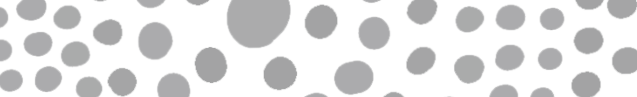
0.0000000 
Alma, H. A. (2018). De Kunst van Samenleven: Een Pleidooi voor een Pluralistisch Humanisme. VUBPress.

Address, R. (2005). Creating Sacred Scenarios: Opportunities for New Rituals and Sacred Aging. Journal of Gerontological Social Work, 45(1-2), 223-232.

Anbeek, C., Alma, H.A., \& van Goelst Meijer, S. (2018). Contrast experiences and social imaginaries as spaces for truth-seeking. In H.A. Alma \& G. Vanheeswijck (eds.), Social Imaginaries in a Globalizing World (pp.95-117). Boston: De Gruyter.

Antalíková, R., Hansen, T. G., Gulbrandsen, K. A., De La Mata, M., \& Santamaría, A. (2011). Adolescents' meaningful memories reflect a trajectory of self-development from family over school to friends. Nordic Psychology.

Antonovsky, A. (1987). Unraveling the mystery of health: How people manage stress and stay well. Jossey-Bass.

Bamberg, M. (2006). Stories: Big or small: Why do we care?. Narrative inquiry, 16(1), 139-147.

Bamberg, M., \& Cooper, I. H. (2012). Narrative analysis. APA handbook of research methods in psychology, 2, 77-94.

Bamberg, M., \& Georgakopoulou, A. (2008). Small stories as a new perspective in narrative and identity analysis. Text \& Talk, 28(3), 377-396.

Bargh, J.A. (1994). The four horsemen of automaticity: Awareness, intention, efficiency, and control in social cognition. In: R.S. Wyer \& T.K. Srull (Eds.), Handbook of social cognition (vol.1). Hillsdale, NJ: Erlbaum.

Bauer, M. W., \& Gaskell, G. (Eds.). (2000). Qualitative researching with text, image and sound: A practical handbook for social research. Sage.

Baumeister, R. (1991). Meanings in life. New York, NY: The Guilford Press.

Baumeister, R., \& Vohs, K. D. (2002). The pursuit of meaningfulness in life. Handbook of positive psychology, 608-618

Baumeister, R. F., Vohs, K. D., Aaker, J. L., \& Garbinsky, E. N. (2013). Some key differences between a happy life and a meaningful life. The Journal of Positive Psychology, 8(6), 505-516.

Bennett, J. (2001). The Enchantment of Modern Life: Attachments, Crossings, and Ethics. Princeton University Press

Berman, M.(1981). The Reenchantment of the World. Ithaca, NY: Cornell University Press

Bettelheim, B. (2010). The Uses of Enchantment: The Meaning and Importance of Fairy Tales. Knopf Doubleday Publishing Group, 22 dec. 2010

Blagov, P. S., \& Singer, J. A. (2004). Four dimensions of self-defining memories (specificity, meaning, content, and affect) and their relationships to self-restraint, distress, and repressive defensiveness. Journal of Personality, 72(3), 481-511.

Bluck, S., Dirk, J., Mackay, M. M., \& Hux, A. (2008). Life experience with death: Relation to death attitudes and to the use of death-related memories. Death Studies, 32(6), 524-549. 
Appendices

Bohlmeijer, E. T., Westerhof, G. J. \& Emmerik-de Jong, M. (2008). The effects of integrative reminiscence on meaning in life: results of a quasi-experimental study. Aging \& Mental Health, 5, 639-646.

Boje, D. M., \& Baskin, K. (2011). Our organizations were never disenchanted: Enchantment by design narratives vs enchantment by emergence. Journal of Organizational Change Management, 24(4), 411-426.

Bonner, E. T., \& Friedman, H. L. (2011). A conceptual clarification of the experience of awe: An interpretative phenomenological analysis. The Humanistic Psychologist, 39(3), 222-235.

Braun, V., \& Clarke, V. (2006). Using thematic analysis in psychology. Qualitative Research in Psychology, 3(2), 77-101.

Brockmeier, J., \& Carbaugh, D. A. (Eds.). (2001). Narrative and identity: Studies in autobiography, self and culture (Vol. 1). John Benjamins Publishing.

Bruner, J. (1986). Actual minds: Possible worlds. Cambridge, MA: Harvard University Press.

Bruner, J. (1991). The narrative construction of reality. Critical inquiry, 18(1), 1-21.

Buber, M. (1957). Elements of the Interhuman. Psychiatry, 20(2), 105-113.

Buber, M. (1965). Between man and man. New York, NY: Charles Scribner's \& Sons

Buber, M. (1970). I and Thou, tr. Walter Kaufmann. T. \& T. Clark.

Burke, K. (1969). A rhetoric of motives (Vol. 111). Univ of California Press.

Castonguay, L. G., \& Hill, C. E. (2007). Insight in psychotherapy. American Psychological Association.

Clark, A. J., \& Simpson, T. M. (2013). Imagination: An essential dimension of a counselor's empathy. The Journal of Humanistic Counseling, 52(2), 164-176.

Cooper, M. (2005). Therapists' experiences of relational depth: A qualitative interview study. Counselling and Psychotherapy Research, 5(2), 87-95.

La Cour, K., Johannessen, H., \& Josephsson, S. (2009). Activity and meaning making in the everyday lives of people with advanced cancer. Palliative and Supportive care, 7(04), 469-479.

Cova, F. \& Deonna, J.A. (2014). Being moved. Philosophical Studies, Volume 169, Issue 3, pp 447-466

Cullhed, E. (2020). What Evokes Being Moved? Emotion Review, 12(2), 111-117.

Curry, P. (2012). Enchantment and Modernity. Philosophy, Activism, Nature, Issue no 12, 2012, p 76-89

Deci, E. L., \& Ryan, R. M. (2000). The "what" and "why" of goal pursuit: Human needs and the self-determination of behavior. Psychological Inquiry, 11, 227-268.

Delle Fave, A., \& Soosai-Nathan, L. (2014). Meaning as inter-connectedness: Theoretical perspectives and empirical evidence. Journal of Psychology in Africa, 24(1), 33-43. 
Denzin, N. K. (1978). Sociological methods: A source book.(2) McGraw-Hill. New York.

Dierick, P., \& Lietaer, G. (2008). Client perception of therapeutic factors in group psychotherapy and growth groups: An empirically-based hierarchical model. International Journal of Group Psychotherapy, 58(2), 203-230.

Doyle, S. (2007). Member checking with older women: a framework for negotiating meaning. Health Care for Women International, 8(10), 888-908.

Ebersole, P. (1972). Effects and classification of peak experiences. Psychological reports, 30(2), 631-635.

L'Ecuyer, C. (2014). The wonder approach to learning. Frontiers in human neuroscience, 8, 764.

Emmons, R. A. (2000). Is spirituality an intelligence? Motivation, cognition, and the psychology of ultimate concern. The International Journal for the psychology of Religion, 10(1), 3-26.

Emmons, R. A. (2005). Striving for the sacred: Personal goals, life meaning, and religion. Journal of Social Issues, 61, 731-745.

Firestone, R. W., Firestone, L. A., \& Catlett, J. (2003). Creating a life of meaning and compassion: The wisdom of psychotherapy. American Psychological Association.

Fludernik, M. (2003). Natural narratology and cognitive parameters. na.

Frankl, V. E. (1959/2006). Man's search for meaning. Boston, MS: Beacon Press.

Frank1, V. (1966). Self-transcendence as a human phenomenon. Journal of Humanistic Psychology, 6, 97-106.

Frankl, V. E. (1969). The Will to Meaning. New American Library, New York.

Freeman, M. (2006). Life "on holiday"?: In defense of big stories. Narrative inquiry, 16(1), 131-138.

Friedman, M. (1996). Becoming aware: A dialogical approach to consciousness. The Humanistic Psychologist, 24(2), 203-220.

Friedman, M. (1999). The interhuman and what is common to all: Martin Buber and sociology. Journal for the Theory of Social Behaviour, 29(4), 403-417.

Friedman, M. (2005). My dialogue with dialogue. In Dialogue as a means of collective communication (pp. 137-157). Springer.

Funk Deckard, M. A. (2008). Sudden Surprise of the Soul: The Passion of Wonder in Hobbes and Descartes, The Heythrop Journal, Volume 49, Issue 6, pages 948-963, November

Fusch, P. I., \& Ness, L. R. (2015). Are we there yet? Data saturation in qualitative research. The qualitative report, 20(9), 1408.

Ganzevoort, R., \& Roeland, J. (2014). Lived religion: The praxis of practical theology. International Journal of Practical Theology, 18(1), 91-101.

Gendlin, E. T. (1996). Focusing-oriented psychotherapy. The Guilford press. 
Appendices

Georgakopoulou, A. (2006). The other side of the story: Towards a narrative analysis of narratives-in-interaction. Discourse Studies, 8: 235-257.

Georgakopoulou, A. (2007). Small Stories, Interaction, and Identities. Amsterdam, PA: John Benjamins Publishing.

George, L. S., \& Park, C. L. (2014). Existential mattering: Bringing attention to a neglected but central aspect of meaning? In A. Batthyany \& P. Russo-Netzer (Eds.), Meaning in positive and existential psychology (pp. 39- 51). New York, NY: Springer.

Gergen, K. (1994). Realities and relationships: Soundings in social construction. Cambridge, MA: Harvard University Press.

Gergen, K. J. (2006). Therapeutic realities: Collaboration, oppression and relational flow. Chagrin Falls, OH: Taos Institute.

Gergen, K. J. (2011). Relational being: A brief introduction. Journal of Constructivist Psychology, 24(4), 280-282.

Gergen, K. J. (2015). Toward a relational humanism. The Journal of Humanistic Counseling, 54(2), 149-165.

Giebel, C. G. J. (2018). Literature review: Narrative interventions about meaning and identity (Master's thesis, University of Twente).

Gillies, J., \& Neimeyer, R. A. (2006). Loss, grief, and the search for significance: Toward a model of meaning reconstruction in bereavement. Journal of Constructivist Psychology, 19(1), 31-65.

Goldstein, E. D. (2007). Sacred moments: Implications on well-being and stress. Journal of clinical psychology, 63(10), 1001-1019.

Grawitch, M. J., Gottschalk, M., \& Munz, D. C. (2006). The path to a healthy workplace: A critical review linking healthy workplace practices, employee well-being, and organizational improvements. Psychology Consulting Journal: Practice and Research, 58(3), 129.

Haidt, J. (2000). The positive emotion of elevation.

Hallberg, L. R. (2006). The "core category" of grounded theory: Making constant comparisons. International journal of qualitative studies on health and well-being, 1(3), 141-148.

Hayes, S. C., Strosahl, K. D., Bunting, K., Twohig, M., \& Wilson, K. G. (2004). What is acceptance and commitment therapy?. In A practical guide to acceptance and commitment therapy (pp. 3-29). Springer, Boston, MA.

Hedayati, M. M., \& Khazaei, M. M. (2014). An investigation of the relationship between depression, meaning in life and adult hope. Procedia-Social and Behavioral Sciences, 114, 598-601.

Heintzelman, S. J., \& King, L. A. (2013). The origins of meaning: Objective reality, the unconscious mind, and awareness. In The Experience of Meaning in Life (pp. 87-99). Springer Netherlands. 
Heintzelman, S. J. \& King, L. A. (2014). (The feeling of) meaning-as-information. Personality and Social Psychology Review, 18, 153-167.

Heinze, R. I. (Ed.). (2000). The nature and function of rituals: Fire from heaven. Praeger Pub Text.

Hepburn, R. (1998). Nature humanised: Nature respected. Environmental Values, 7(3), 267-279.

Heschel, A. J. (1976). God in search of man: A philosophy of Judaism. Farrar, Straus and Giroux.

Hirokazu, K. (Director). (1998). After Life [Motion Picture]. Engine Film TV Man Union

Hobsbawm, E., \& Ranger, T. (Eds.). (2012). The invention of tradition. Cambridge University Press.

Hoffman, E. (1998). Peak experiences in childhood: An exploratory study. Journal of Humanistic Psychology, 38(1), 109-120.

Hoffman, E., Kaneshiro, S., \& Compton, W. C. (2012). Peak-experiences among Americans in midlife. Journal of Humanistic Psychology, 52(4), 479-503.

Hoffman, E., \& Muramoto, S. (2007). Peak-experiences among Japanese youth. Journal of Humanistic Psychology, 47(4), 524-540.

Huber, M., van Vliet, M., Giezenberg, M., Winkens, B., Heerkens, Y., Dagnelie, P. C., \& Knottnerus, J. A. (2016). Towards a "patient-centred'operationalisation of the new dynamic concept of health: a mixed methods study. BMJ open, 6(1).

Imber-Black, E. (1991). Rituals and the healing process. Living beyond loss: Death in the family, 207-223.

Ivtzan, I., Lomas, T., Hefferon, K., \& Worth, P. (2015). Second wave positive psychology: Embracing the dark side of life. Routledge.

Jacobs, G. C. (2020). Zin in geestelijke verzorging.

Jenkins, R. (2012). Disenchantment, enchantment and re-enchantment: Max Weber at the millennium. Mind and Matter, 10(2), 149-168.

Jordan, J. (Ed.). (1997). Women's growth in diversity. New York, NY: Guilford Press

Jordan, J. V. (2017). Relational-cultural theory: The power of connection to transform our lives. The Journal of Humanistic Counseling, 56(3), 228-243.

Kaplan, H., \& Assor, A. (2012). Enhancing autonomy-supportive I-Thou dialogue in schools: Conceptualization and socio-emotional effects of an intervention program. Social psychology of education, 15(2), 251-269.

Kaushik, V., \& Walsh, C. A. (2019). Pragmatism as a research paradigm and its implications for social work research. Social Sciences, 8(9), 255.

Keltner, D., \& Haidt, J. (2003). Approaching awe, a moral, spiritual, and aesthetic emotion. Cognition \& emotion, 17(2), 297-314. 
Appendices

Killeen, C. (1998). Loneliness: an epidemic in modern society. Journal of advanced nursing, 28(4), 762-770.

King, L. A. (2012). Meaning: Ubiquitous and effortless.

King, L. A., \& Hicks, J. A. (2009). Detecting and constructing meaning in life events. The Journal of Positive Psychology, 4(5), 317-330.

King, L. A., Hicks, J. A., Krull, J. L., \& Del Gaiso, A. K. (2006). Positive affect and the experience of meaning in life. Journal of Personality and Social Psychology, 90, 179-196.

Kleftaras, G., \& Psarra, E. (2012). Meaning in life, psychological well-being and depressive symptomatology: A comparative study. Psychology, 3(04), 337.

Kron, T. (1994). Dialogical dimension in therapist-client and supervisor's relations. In T. Kron \& H. Yeroshalmi (Eds.), Supervision in psychotherapy (pp. 18-19). Jerusalem: Magnes (Hebrew).

Kuzmanić, M. (2009). Validity in qualitative research: Interview and the appearance of truth through dialogue. Horizons of Psychology, 18(2), 39-50.

Labov, W. (1972). Language in the inner city: Studies in the Black English vernacular (Vol. 3). University of Pennsylvania Press.

Landmann, H., Cova, F., \& Hess, U. (2019). Being moved by meaningfulness: Appraisals of surpassing internal standards elicit being moved by relationships and achievements. Cognition and emotion, 33(7), 1387-1409.

Leijssen, M. (2007). Making space for the inner guide. American Journal of Psychotherapy, $61,255-270$.

Leontiev, D. (2017). Converging paths toward meaning. Journal of constructivist psychology, 30(1), 74-81.

Lépine, J. P., \& Briley, M. (2011). The increasing burden of depression. Neuropsychiatric disease and treatment, 7(Suppl 1), 3.

Lieblich, A., \& Josselson, R. (Eds.). (1994). Exploring identity and gender: The narrative study of lives (Vol. 2). SAGE Publications, Incorporated.

Lieblich, A., Tuval-Mashiach, R., \& Zilber, T. (1998). Narrative research: Reading, analysis, and interpretation (Vol. 47). Sage.

Lomas, T., \& Ivtzan, I. (2016). Second wave positive psychology: Exploring the positivenegative dialectics of wellbeing. Journal of Happiness Studies, 17(4), 1753-1768.

Luoma, J. B., Hayes, S. C., \& Walser, R. D. (2007). Learning ACT: An acceptance \& commitment therapy skills-training manual for therapists. New Harbinger Publications.

Machell, K. A., Kashdan, T. B., Short, J. L., \& Nezlek, J. B. (2015). Relationships between meaning in life, social and achievement events, and positive and negative affect in daily life. Journal of personality, 83(3), 287-298. 
Machielse, A. (2015). Sociaal isolement als overlevingsstrategie. In T. Jorna (red.), Mag een mens eenzaam zijn? - Studies naar existentiële eenzaamheid en zingeving (tweede editie, p.23-26). Amsterdam: Uitgeverij SWP.

Maddi, S. R. (2004). Hardiness: An operationalization of existential courage. Journal of humanistic psychology, 44(3), 279-298.

Maddi, S. R. (2013). Creating Meaning trough Making Decisions. In The human quest for meaning (pp. 103-126). Routledge.

Martela, F. \& Steger, M. F. (2016). The three meanings of meaning in life: Distinguishing coherence, purpose, and significance. The Journal of Positive Psychology, 11(5), 531-545.

Märtsin, M. (2018). Beyond verbal narratives: Using timeline images in the semiotic cultural study of meaning making. Integrative Psychological and Behavioral science, 52, 116-128.

Mascaro, N., \& Rosen, D. H. (2005). Existential meaning's role in the enhancement of hope and prevention of depressive symptoms. Journal of personality, 73(4), 985-1014.

Maslach, C., Jackson, S. E., Leiter, M. P., Schaufeli, W. B., \& Schwab, R. L. (1986). Maslach burnout inventory (Vol. 21, pp. 3463-3464). Palo Alto, CA: Consulting psychologists press.

Maslow, A. (1959). Cognition of being in the peak experiences. Journal of Genetic Psychology, 94, 43-66.

Maslow, A. H. (1964). Religions, values, and peak-experiences (Vol. 35). Columbus: Ohio State University Press.

Maslow, A. (1968). H.(1968). Toward a psychology of being. New York: John.

Maslow, A. H. (1969). Various meanings of transcendence. Journal of Transpersonal Psychology, 1(1), 56-66.

Maslow, A. H. (1971). The farther reaches of human nature. New York, NY: Penguin.

Mattingly, C. (1998). Healing Dramas and Clinical Plots: The Narrative Structure of Experience. Cambridge, UK: Cambridge University Press

McAdams, D.P. (1985). Power, intimacy, and the life story: Personological inquiries into identity. New York: Guilford Press.

McAdams, D. (1993). The Stories We Live by: Personal Myths and the Making of the Self. Guilford Press

McDonald, M. G. (2008). The nature of epiphanic experience. Journal of Humanistic Psychology, 48(1), 89-115.

McDonald, M. J., Wong, P. T. P., \& Gingras, D. T. (2012). Meaning-in-life measures and development of a brief version of the personal meaning profile. In P. T. P. Wong (Ed.), The human quest for meaning: Theories, research, and applications (2nd ed.) (pp. 357-382). New York, NY: Routledge.

Meira, L., Salgado, J., Sousa, I., Ribeiro, A. P., \& Gonçalves, M. M. (2017). Psychological Change in Everyday Life: An Exploratory Study. Journal of Constructivist Psychology, 1-16. 
Menninghaus, W., Wagner, V., Hanich, J., Wassiliwizky, E., Kuehnast, M., \& Jacobsen, T. (2015). Towards a psychological construct of being moved. PloS one, 10(6), e0128451.

Michiels, J., \& De Wachter, D. (2019). Eenzaamheid en verbondenheid in de therapieruimte. Systeemtherapie, 31(4).

Mishler, E. G. (1991). Research interviewing: Context and narrative. Harvard University Press.

Moffitt, K. H., \& Singer, J. A. (1994). Continuity in the Life Story: Self-Defining Memories, Affect, and Approach/Avoidance Personal Strivings. Journal of Personality, 62(1), 21-43.

Morgan, D. L. (1997). Focus groups as qualitative research (Vol. 16). Sage publications.

Morgan, W. J., \& Guilherme, A. (2012). I and Thou: The educational lessons of Martin Buber's dialogue with the conflicts of his times. Educational Philosophy and Theory, 44(9), 979-996.

Musaio, M. (2012). Rediscovering Wonder in Education: Foundations, Approaching Methods, Feelings.

Murray, M., \& Sools, A. (2014). Narrative research. Qualitative Research in Clinical and Health Psychology. London: Palgrave, 133-154.

Neimeyer, R. A., Herrero, O., \& Botella, L. (2006). Chaos to coherence: Psychotherapeutic integration of traumatic loss. Journal of Constructivist psychology, 19(2), 127-145.

Nygren, L., \& Blom, B. (2001). Analysis of short reflective narratives: a method for the study of knowledge in social workers' actions. Qualitative Research, 1(3), 369-384.

Ochs, E., \& Capps, L. (2001). Living narrative: Creating lives in everyday storytelling. Cambridge, MA: Harvard University Press.

Ordinary. In Merriam-Webster. Retrieved March 13, 2017, from http://www.merriamwebster.com/dictionary/ordinary.

Palinkas, L. A., Horwitz, S. M., Green, C. A., Wisdom, J. P., Duan, N., \& Hoagwood, K. (2015). Purposeful sampling for qualitative data collection and analysis in mixed method implementation research. Administration and Policy in Mental Health and Mental Health Services Research, 42(5), 533-544.

Pargament, K. I. (2011). Spiritually integrated psychotherapy: Understanding and addressing the sacred. Guilford Press.

Park, C. L. (2010). Making sense of the meaning literature: an integrative review of meaning making and its effects on adjustment to stressful life events. Psychological bulletin, 136(2), 257.

Park, C. L., \& Folkman, S. (1997). Meaning in the context of stress and coping. Review of general psychology, 1(2), 115.

Park, N., Park, M., \& Peterson, C. (2010). When is the search for meaning related to life satisfaction? Applied Psychology: Health and Well-Being, 2, 1-13. 
Parks, K. M., \& Steelman, L. A. (2008). Organizational wellness programs: a meta-analysis. Journal of occupational health psychology, 13(1), 58.

Passmore, H. A., \& Howell, A. J. (2014). Nature involvement increases hedonic and eudaimonic well-being: A two-week experimental study. Ecopsychology, 6(3), 148-154.

Perelman, C. (1982). The realm of rhetoric (W. Kluback, Trans.). Notre Dame, IN: University of Notre Dame Press

Peterson, C., Park, N., \& Seligman, M. E. (2005). Orientations to happiness and life satisfaction: The full life versus the empty life. Journal of happiness studies, 6(1), 25-41.

Pillemer, D. B. (2001). Momentous events and the life story. Review of General Psychology, 5(2), 123.

Polit, D. F., \& Beck, C. T. (2010). Generalization in quantitative and qualitative research: Myths and strategies. International journal of nursing studies, 47(11), 1451-1458.

Polkinghorne, D. E. (2007). Validity issues in narrative research. Qualitative inquiry, 13(4), 471-486.

Reed, P. G. (2008). Theory of self-transcendence. In M. J. Smith \& P. R. Liehr (Eds.), Middle range theory for nursing (2nd ed., pp. 105-129). New York, NY: Springer.

Reker, G. T., Peacock, E. J., \& Wong, P. T. (1987). Meaning and purpose in life and wellbeing: A life-span perspective. Journal of gerontology, 42(1), 44-49.

Reker, G. T., \& Wong, P. T. P. (1988). Aging as an individual process: Toward a theory of personal meaning. In J. E. Birren \& V. L. Bengston (Eds.), Emergent theories of aging (pp. 214-246). New York, NY: Springer.

Reker, G. T., \& Wong, P. T. (2012). Personal meaning in life and psychosocial adaptation in the later years. The human quest for meaning: Theories, research, and applications, 433-456.

Riessman, C. K. (2008). Narrative methods for the human sciences. Sage.

Roepke, A. M., Jayawickreme, E., \& Riffle, O. M. (2014). Meaning and health: A systematic overview. Applied Research Quality Life, 9, 1055-1079.

Rogers, C. R. (1989). On becoming a person: A therapist's view of psychotherapy. Houghton Mifflin.

Romanoff, B. D. (1998). Rituals and the grieving process. Death studies, 22(8), 697-711.

Rosa, H. (2013). Social acceleration: A new theory of modernity. Columbia University Press.

Rosa, H. (2016). Resonanz: Eine Soziologie der Weltbeziehung. Suhrkamp verlag.

Rudd, M., Vohs, K. D., \& Aaker, J. (2012). Awe expands people's perception of time, alters decision making, and enhances well-being. Psychological science, 23(10), 1130-1136. 
Ryan, R. M., Curren, R. R., \& Deci, E. L. (2013). What humans need: Flourishing in Aristotelian philosophy and self-determination theory. In A. S. Waterman (Ed.), The best within us: Positive psychology perspectives on eudaimonia (pp. 57-75). Washington, DC: APA Press.

Ryan, R. M., Huta, V., \& Deci, E. L. (2008). Living well: A self-determination theory perspective on eudaimonia. Journal of happiness studies, 9(1), 139-170.

Ryff, C. D., \& Singer, B. (1998). The contours of positive human health. Psychological inquiry, 9(1), 1-28.

Schinkel, A. (2019). Wonder, mystery, and meaning. Philosophical Papers, 48(2), 293-319.

Schneider, K. J. (2004). Rediscovery of awe: Splendor, mystery, and the fluid center of life. Paragon House Publishers.

Schneider, K. J. (2005). Enchanted agnosticism. Spirituality and psychological health, 316321.

Schneider, K. J. (2009). Awakening to awe: Personal stories of profound transformation. Jason Aronson.

Schneider, K. J. (2014). Enchanted agnosticism, awe, and existential-integrative therapy. Spirituality in Clinical Practice, 1(1), 71.

Schnell, T. (2003). A framework for the study of implicit religion: The psychological theory of implicit religiosity. Implicit religion, 6(2-3), 86-104.

Schnell, T. (2011). Individual differences in meaning-making: Considering the variety of sources of meaning, their density and diversity. Personality and Individual Differences, 51(5), 667-673.

Schnell, T. (2014). Meaning in life operationalized: An empirical approach to existential psychology. In S. Kreitler \& T. Urbanek (Eds.), Conceptions of meaning (pp. 173-194). New York, NY: Nova Science.

Schwartz, S. H. (1994). Are there universal aspects in the structure and contents of human values? Journal of social issues, 50(4), 19-45.

Sinclair, N., \& Watson, A. (2001). Wonder, the rainbow and the aesthetics of rare experiences. For the learning of mathematics, 39-42.

Singer, J. A., \& Blagov, P. S. (2000). Classification system and scoring manual for selfdefining autobiographical memories. Unpublished manuscript, Connecticut College.

Singer, J. A., \& Blagov, P. (2004). The Integrative Function of Narrative Processing: Autobiographical Memory, Self-Defining Memories, and the Life Story of Identity.

Slater, C. L. (2003). Generativity versus stagnation: An elaboration of Erikson's adult stage of human development. Journal of Adult Development, 10(1), 53-65.

Sools, A. (2013). Narrative health research: Exploring big and small stories as analytical tools. Health:, 17(1), 93-110. 
Sools, A., \& Mooren, J. (2012). Towards Narrative Futuring in Psychology: Becoming Resilient by Imagining the Future. Graduate journal of social science, 9(2).

Sools, A. M., Tromp, T., \& Mooren, J. H. (2015). Mapping letters from the future: Exploring narrative processes of imagining the future. Journal of health psychology, 20(3), 350-364.

Spagnola, M., \& Fiese, B. H. (2007). Family routines and rituals: A context for development in the lives of young children. Infants \& Young Children, 20(4), 284-299.

Steger, M. F. (2012). Making meaning in life. Psychological Inquiry, 23(4), 381-385.

Steger, M. (2012). Experiencing meaning in life: Optimal functioning at the nexus of well-being, psychopathology, and spirituality. In P. T. P. Wong (Ed.), The human quest for meaning: Theories, research, and applications. Second Edition (pp. 165-184). New York, NY: Routledge.

Steger, M. F., Kashdan, T. B., \& Oishi, S. (2008). Being good by doing good: Daily eudaimonic activity and well-being. Journal of Research in Personality, 42(1), 22-42.

Steger, M. F., Kashdan, T. B., Sullivan, B. A., \& Lorentz, D. (2008). Understanding the search for meaning in life: Personality, cognitive style, and the dynamic between seeking and experiencing meaning. Journal of personality, 76(2), 199-228.

Stillman, T. F., Baumeister, R. F., Lambert, N. M., Crescioni, A. W., DeWall, C. N., \& Fincham, F. D. (2009). Alone and without purpose: Life loses meaning following social exclusion. Journal of experimental social psychology, 45(4), 686-694.

Sullivan, D., Kosloff, S., \& Greenberg, J. (2013). A terror management perspective on the creation and defense of meaning. In The experience of meaning in life (pp. 17-30). Springer Netherlands.

Taleb, Nassim Nicholas (2007). The Black Swan: The Impact of the Highly Improbable. Random House

Tangen, J. L., \& Cashwell, C. S. (2016). Touchstones of connection: A concept mapping study of counselor factors that contribute to relational depth. The Journal of Humanistic Counseling, 55(1), 20-36.

Tashakkori, A. \& Teddlie, C. (2008). Mixed Methodology: Combining Qualitative and Quantitative Approaches. Thousand Oaks: Sage Publications.

Thomson, R., \& Holland, J. (2003). Hindsight, foresight and insight: The challenges of longitudinal qualitative research. International Journal of Social Research Methodology, 6(3), 233-244.

Thorne, A. (2000). Personal memory telling and personality development. Personality and Social Psychology Review, 4(1), 45-56.

Vanhooren, S. (2019a). Existentiële empathie: Over experiëntiële en existentiële aanwezigheid. Tijdschrift persoonsgerichte experiëntiële psychotherapie, 57(1), 3-10.

Vanhooren, S. (2019b). Struggling with meaninglessness: a case study from an experientialexistential perspective. Person-Centered \& Experiential Psychotherapies, 18(1), 1-21. 
Appendices

Vasalou, S. (2015). Wonder: A Grammar. SUNY Press.

Verplanken, B., \& Orbell, S. (2003). Reflections on past behaviour: A self-report index of habit strength. Journal of Applied Social Psychology, 33, 1313-1330.

Westerhof, G. J. (2019). Life review: Lifespan development, meaning processes, and interventions. In F. Gibson (Ed.), International perspectives on reminiscence, life review and life story work (pp. 312-326). London: Jessica Kingsley.

Westerhof, G. J., \& Bohlmeijer, E. T. (2014). Celebrating fifty years of research and applications in reminiscence and life review: State of the art and new directions. Journal of Aging studies, 29, 107-114.

Westerhof, G. J., Bohlmeijer, E. T., van Beljouw, I. M., \& Pot, A. M. (2010). Improvement in personal meaning mediates the effects of a life review intervention on depressive symptoms in a randomized controlled trial. The Gerontologist, 50(4), 541-549.

Westerhof, G. J., Bohlmeijer, E., \& Webster, J. D. (2010). Reminiscence and mental health: A review of recent progress in theory, research and interventions. Ageing \& Society, 30(4), 697-721.

White, M. P., \& Dolan, P. (2009). Accounting for the richness of daily activities. Psychological Science, 20(8), 1000-1008.

Wilkinson, P. J. \& Coleman, P. G. (2011). Coping without religious faith - Ageing among British Humanists. In P. G. Coleman and colleagues, Belief and ageing - Spiritual pathways in later life (pp. 97-111). Bristol, UK: The Policy Press.

Wolf, S. (2010). Meaning in life and why it matters. Princeton University Press.

Wong, P. T. (2011). Positive psychology 2.0: Towards a balanced interactive model of the good life. Canadian Psychology/Psychologie Canadienne, 52(2), 69.

Wong, P. T. (2012a). The meaning mindset: Measurement and implications. International Journal of Existential Positive Psychology, 4(1), 3.

Wong, P. T. P. (2012b). Logotherapy, meaning therapy, and spirituality. Keynote address presented at the 18th Annual Conference of the Japanese Association of Clinical Thanatology, Tokyo, Japan.

Wong, P. T. P. (2014). Viktor Frankl's meaning seeking model and positive psychology. In A. Batthyany \& P. Russo-Netzer (Eds.), Meaning in existential and positive psychology. New York, NY: Springer.

Wong, P. T. P. (2016a). Meaning-seeking, self-transcendence, and well-being. In A. Batthyany (Ed.), Logotherapy and existential analysis: Proceedings of the Viktor Frankl Institute (Vol. 1; pp. 311-322). Cham, CH: Springer.

Wong, P. T. (2016b). Self-transcendence: A paradoxical way to become your best. International Journal of Existential Positive Psychology, 6(1), 9. Art 1

Wong, P. T. (2017). A decade of meaning: Past, present, and future. Journal of Constructivist Psychology, 30(1), 82-89. 
Wong, P. T. (2019). Second wave positive psychology's (PP 2.0) contribution to counselling psychology. Counselling Psychology Quarterly, 32(3-4), 275-284.

Wong, P. T., \& Watt, L. M. (1991). What types of reminiscence are associated with successful aging?. Psychology and aging, 6(2), 272.

Wood, W., Quinn, J. M., \& Kashy, D. A. (2002). Habits in everyday life: thought, emotion, and action. Journal of personality and social psychology, 83(6), 1281.

Wrzesniewski, A., McCauley, C., Rozin, P., \& Schwartz, B. (1997). Jobs, careers, and callings: People's relations to their work. Journal of research in personality, 31(1), 21-33.

Yalom, I.D. (1970). The theory and practice of group psychotherapy. New York: Basic Books

Yalom, I. D. (1980). Existential psychotherapy (Vol. 1). Basic Books.

Yvonne Feilzer, M. (2010). Doing mixed methods research pragmatically: Implications for the rediscovery of pragmatism as a research paradigm. Journal of mixed methods research, 4(1), 6-16.

Zainal, Z. (2007). Case study as a research method. Jurnal Kemanusiaan, 5(1).

Zika, S., \& Chamberlain, K. (1992). On the relation between meaning in life and psychological well-being. British journal of psychology, 83(1), 133-145. 


\section{Summary}

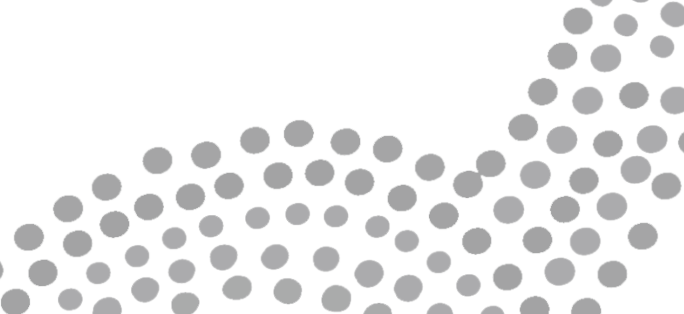

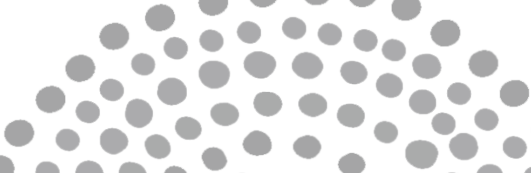

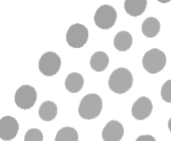

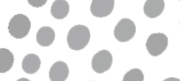

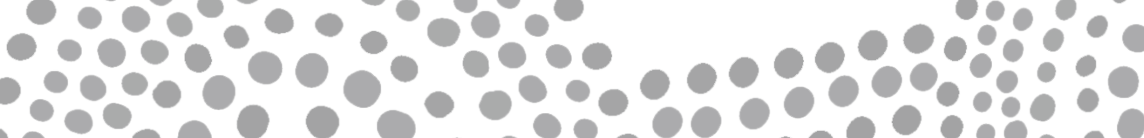

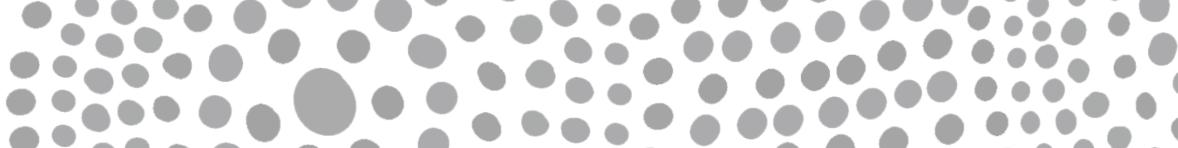
$\because 0 \% 00$ $3 \% 0,0000000$

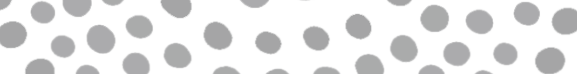

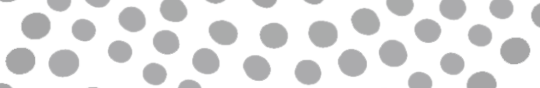
0

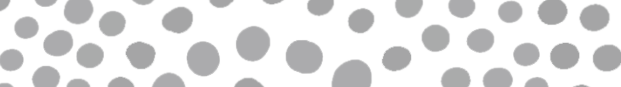

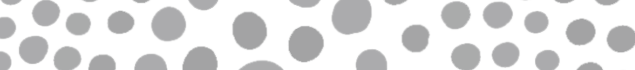

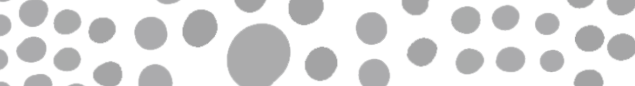

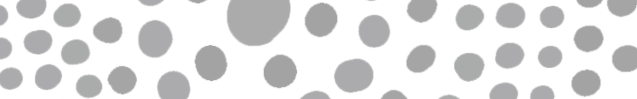
$\because 000000$ 
Meaning: a basic human need, fundamental to health and wellbeing. A fundament however, that is more and more at stake in the dynamics of an accelerating and increasingly self-centered society. This thesis contributes to building this fundament by giving insight in the way a sense of meaning in life may be enhanced. It explores meaning through the personal, lived experience of meaningful moments: memories of specific events in life that are felt to be of great value and significance. The study investigates the way these moments work and the way recollecting and sharing meaningful moments may contribute to enhancing a sense of meaning in life.

Chapter one is an introduction to meaning and meaningful moments. It introduces the Wonderful Life Question as a novel way to elicit meaning moments: What if there is an afterlife. There, all your memories will be erased, except for one. Which memory do you choose to take with you to eternity? This question, derived from the Japanese movie "After Life", has proven to immediately induce a process of scanning life and focusing on the most essential, salient moments, without directing to a specific type of moment. To investigate the emergence of meaning from the memories elicited by this question, a narrative approach was chosen throughout this thesis. Narrative is considered the mode par excellence by which people construct meaning and identity, and narrative psychology accepts that people make sense of events and give meaning to life through the stories they exchange. Taking a narrative approach means employing this meaning-constructing quality of narratives to investigate the emergence of meaning.

Chapter two presents a study aimed at characterizing and categorizing meaningful moments. It describes an investigation of one hundred narratives of meaningful moments from a variety of people, chosen in answer to the Wonderful Life Question. The emotions of wonder, inherently related to the experience of meaning, were used as a lens in this study, and the dimensions of context and intentionality, retrieved from the literature on these emotions, were employed to make a distinction within the dataset. In this way, an overview was developed that colors in the overall picture of meaningful moments and divides the landscape of meaningful moments into five categories with clearly 
distinguished characteristics: opening up to life, facing the precarity of life, celebrations, countering the negative, and familiar routines. The categorization highlights that meaning is not restricted to happy moments in life, thereby empirically supporting the second wave positive psychology movement, that counters the dominant focus on mere positive experiences, and highlights the potential of difficult moments to enrich life and stimulate personal growth. Alongside this, the study sheds light on the meaning potential of familiar routines: small, recurring moments of ordinary life have that as of yet been least recognized for their quality to enhance a sense of meaning in the hustle and bustle of everyday life. Finally, regarding the overview as a whole, it may be seen to support the premise that any moment in life is potentially meaningful.

But how do these moments become meaningful? The study in chapter three aims to answer this question by investigating the mechanisms involved in the construction of meaning. It focuses on meaning as a mindset, a mindset of wonder: an intentional focus, a passion of inquiry to see the extraordinary within the ordinary and taken-for-granted. In this study, familiar routines were chosen as the object of investigation because of their paradoxical relation to meaning: they may be a rich source of meaning, enhancing a sense of connectedness to life, but may just as well become habitual and lose meaning. The chapter describes a narrative investigation of a set of thirteen memories of familiar routines chosen in answer to the Wonderful Life Question. The heuristic devices of evaluations and storyline breach were employed to gain insight in the way these moments are constructed to be meaningful. Contrasts were found to play a crucial role. Findings point to the contrast between instrumental acts and their higher purpose, and to the awareness of opposing values or states of being emerging either simultaneously or subsequently in the routinely moment. Finally, contrasts may arise by zooming out from the moment to another period of time, to another setting or aspect of life in which the value experienced in the moment is absent. The mindset of wonder and these meaning constructing mechanisms have received surprisingly little attention so far, and are a promising field for further study on the development of a meaning orientation towards life. 
Chapter four presents a study on the emergence of meaning from meaningful moments over time, addressing meaning as a process. Out of a preexistent set of narratives of meaningful moments, chosen in answer to the Wonderful Life Question, a purposeful sample of nine moments was chosen to represent each of the five types of meaningful moments identified in the study in chapter two. Narrative interviews were conducted about the way these moments were experienced to be meaningful and affected life; a holistic content analysis lead to the development of an integrated framework in which several main themes in the process of meaning emergence are brought together. The study shows how meaning discovery may lead to meaning creation, which in turn may lead to retrospective meaning discovery. The framework integrates the concepts of coherence, purpose, significance and self-transcendence, and empirically illustrates the way these work together to bring about a sense of meaning and significance in life. In regard to coherence, findings suggest that meaning discovery starts with and thrives on the emotions of wonder, while the understanding of this meaning tends to unfold over time. In relation to purpose, the study points to letting go as an important precondition to meaning: an open, vulnerable and appreciative attitude. Purpose therefore is paradoxical, as it involves both focus and direction as well as the willingness to detach from proven paths and patterns, gaining deeper understanding on the way. As a whole, the developed framework leads to a deeper understanding of meaning as a continuing process in life.

In chapter five, meaning is approached from an interactional perspective. The presented study investigates the way a sense of meaning is brought about in the process of sharing meaningful moments with others. The chapter describes a case study of a group counseling intervention in which eight participants, all professionals in the field of mental health care, took part and shared their meaningful moment, chosen in answer to the Wonderful Life Question. Martin Buber's philosophy of meeting as the essence of meaning was operationalized to gain insight in the way the different elements of the intervention contribute to the emergence of meaning. Two focus groups were conducted in which participants reflected on their experience of meaning throughout the intervention, after which a thematic analysis was performed. Results show 
the way sharing meaningful moments may lead to authentic encounters and a sense of meaning that is physically felt. Findings highlight the value of working with vivid narratives and the role of silence in seeing the other and being seen in a genuine way. The study particularly points out the value the Wonderful Life Question. By sharing memories chosen in answer to this question, participants not only experience a stronger connection to themselves and to the other participants, but also to humanity and the larger whole of life: a self-transcendent experience that may have a transforming impact. Overall, the study exemplifies Buber's philosophy of meeting, a real-time shift from self-orientation towards the awareness of relatedness, in the process of sharing meaningful moments.

The results of this dissertation are brought together in four key findings. In sum, the thesis gives insight in (1) different categories of meaningful moments, in (2) the mechanisms of the mindset of wonder as a crucial aspect of the meaning orientation towards life, in (3) meaning as a personal process of discovery and creation, and in (4) meaning as an interactive process of meeting through sharing meaningful moments. Meaning being fundamental to our health and wellbeing, these findings may contribute to building this fundament and enhancing a sense of meaning in life. Overseeing the dissertation, it is the open, appreciative and accepting attitude of wonder, letting go and connectedness that runs as a thread through the findings and the stories people share of their meaningful moments. Findings that call for wonder next to comprehension and coherence, for surrender and letting go alongside purpose and performance, and for authentic meeting besides a mere functional way of relating. The question arises if ratio and understanding, results and control, autonomy and self-efficacy are not overvalued in their role to enhance a sense of wellbeing - in research as well as society. The thesis pleads for a shift in thinking and acting towards a mindset of wonder: an open mindset, in which we see ourselves not as solitary beings, but as part of a larger whole. It is this mindset that enables the discovery meaning in all kinds of situations, as well as the creation of meaning that serves this larger whole and thereby, ourselves. For meaning is more than a mental healthcare issue, but is to be part of the fabric of everyday life. 
Appendices

A 


\section{Samenvatting}

- 6000.0000000 0
0
0
0
0
0
0
0
0
0
0

008.000 .000

000000000

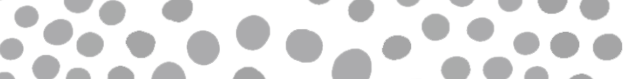

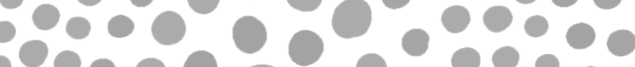

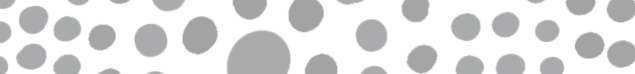

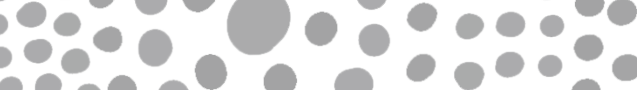
00000 o 
Zin: een menselijke basisbehoefte, cruciaal voor gezondheid en welbevinden. In de dynamiek van een zich almaar versnellende, geïndividualiseerde samenleving is het ervaren van zin echter niet vanzelfsprekend. Deze thesis geeft inzicht in de manier waarop zin als fundament in het alledaagse leven kan worden bevorderd. De thesis richt zich op concrete, persoonlijke ervaringen van zin in de vorm van betekenisvolle levensmomenten: herinneringen aan specifieke gebeurtenissen die mensen als waardevol en belangrijk ervaren. Er wordt onderzocht hoe deze momenten werken en op welke wijze het reflecteren op en delen van deze momenten kan bijdragen aan een gevoel van zin.

Hoofdstuk één is een inleidend hoofdstuk over zin en betekenisvolle levensmomenten. Hierin wordt de Wonderful Life vraag geïntroduceerd als innovatieve manier om mensen in contact te brengen met hun meest betekenisvolle herinneringen: Stel, er is een hiernamaals. Daar worden al je herinneringen gewist, op één na. Welke herinnering kies jij om mee te nemen? Ervaring leert dat deze vraag, afgeleid van de Japanse film "After Life", ertoe leidt dat mensen onmiddellijk hun leven scannen, op zoek naar dat ene moment, zonder daarbij in een bepaalde richting te sturen. Om te onderzoeken hoe deze momenten werken is gekozen voor een narratieve benadering. Als mensen geven we zin en betekenis aan ons leven aan de hand van de verhalen die we vertellen, is het uitgangspunt van de narratieve psychologie. De narratieve benadering benut deze betekenis-construerende kwaliteit van verhalen om te onderzoeken hoe zin zich in en door de gekozen herinneringen manifesteert.

Hoofdstuk twee beschrijft een studie gericht op het karakteriseren en categoriseren van betekenisvolle levensmomenten. De studie is gebaseerd op honderd herinneringen van mensen, variërend in leeftijd, beroep en achtergrond, in antwoord op de Wonderful Life vraag. Om deze momenten te analyseren is gebruik gemaakt van de kenmerken van verwondering, een emotie die inherent verbonden is aan de ervaring van zin. De dimensies context en intentionaliteit, afgeleid van de literatuur over verwondering en aanverwante emoties, zijn gebruikt om de herinneringen te typeren. Op deze wijze is een overzicht ontwikkeld van verschillende soorten betekenisvolle levensmomenten, waarbij vijf categorieën zijn onderscheiden: openende levenservaringen, 
confrontaties met kwetsbaarheid, vieringen, het ombuigen van het negatieve, en vertrouwde routines. Het onderzoek laat zien dat zin zich niet beperkt tot gelukkige levensmomenten en is daarmee een empirische onderbouwing van het gedachtegoed van de positieve psychologie 2.0. Deze stroming biedt tegengeluid aan de dominante focus op positieve ervaringen in de positieve psychologie, en benadrukt het potentieel van moeilijke, pijnlijke en verdrietige ervaringen om het leven te verrijken en persoonlijke groei te bevorderen. Daarnaast benadrukt de studie de waarde van vertrouwde routines: kleine, terugkerende levensmomenten die vooralsnog weinig erkenning hebben gekregen voor hun aandeel in het bevorderen van zin in de rompslomp van het alledaagse leven. Tot slot laat het gehele overzicht zien dat in principe elk moment, positief dan wel negatief, gewoon of bijzonder, bewust gecreëerd of toevallig ervaren, in potentie betekenisvol kan zijn.

Hoe ervaren mensen zin op deze momenten, hoe komt de beleving van zin tot stand? De studie in hoofdstuk drie onderzoekt de manier waarop betekenis wordt geconstrueerd en richt zich op de werking van de mindset van verwondering: op het ervaren van zin vanuit bewuste aandacht voor het bijzondere in het gewone en vanzelfsprekende. Vertrouwde routines staan in dit hoofdstuk centraal, vanwege hun paradoxale relatie tot de ervaring van zin: routines kunnen een belangrijke bron van zin zijn en het gevoel van verbinding - met anderen, met de wereld, met een groter geheel - versterken, maar ze kunnen vanwege hun veelvuldige herhaling ook leiden tot sleur en daarmee zinloosheid. Dit hoofdstuk beschrijft een narratieve analyse van dertien herinneringen aan vertrouwde routines, die mensen hebben gekozen in antwoord op de Wonderful Life vraag. Om inzicht te krijgen in de manier waarop de betekenis van deze momenten wordt geconstrueerd, zijn de verhalen onderzocht op de waarden, emoties en overtuigingen die erin naar voren komen, en op de breuk in de verhaallijn. De resultaten geven zicht op het belang van contrast in de constructie van betekenis. Deze contrasten kunnen verschillende vormen aannemen: ze kunnen betrekking hebben op het verschil tussen instrumentele handelingen en hun hogere doel, en op tegengestelde waarden die zich ofwel tegelijkertijd, ofwel opeenvolgend voordoen in het moment. Daarnaast ontstaan contrasten doordat mensen "uitzoomen" vanuit hun gekozen herinnering naar 
een andere periode in de tijd of een andere setting, waarin de waarde die in de herinnering wordt ervaren afwezig is. Deze vormen van betekenisconstructie hebben in de literatuur vooralsnog verrassend weinig aandacht gekregen. Vervolgstudie op dit gebied is beloftevol en kan bijdragen aan verdiepend inzicht in de manier waarop verwondering als mindset, fundamenteel voor het ervaren van zin, kan worden ontwikkeld.

Hoofdstuk vier onderzoekt de ervaring van zin als een proces, en beschrijft een studie naar de manier waarop de betekenis van de herinnering die mensen kiezen zich door te tijd heen manifesteert. Uit een bestaande verzameling herinneringen, gekozen in antwoord op de Wonderful Life vraag, zijn op basis van een selecte steekproef negen herinneringen gekozen die elk van de vijf categorieën vertegenwoordigen uit het onderzoek in hoofdstuk twee. In narratieve interviews over deze herinneringen werd mensen gevraagd naar de betekenis die ze aan dat moment geven en naar de wijze waarop dat moment hun leven door de tijd heen heeft beïnvloed. Een holistische content analyse leidde vervolgens tot de ontwikkeling van een integraal model dat enkele centrale thema's in het proces van het ervaren van zin bijeenbrengt. Dit model laat zien hoe zin vinden kan leiden tot zin geven, wat in retrospectief weer kan leiden tot zin vinden. Het model integreert de bestaande zingevingsconcepten coherentie, doelgerichtheid, ertoe doen en zelfoverstijging, en laat op empirische wijze zien wat hun samenhang is in het proces om zin en betekenis in het leven te ervaren. In relatie tot coherentie maken de resultaten duidelijk dat zin vinden ontstaat vanuit een ervaring van verwondering, terwijl pas na verloop van tijd begrepen wordt wat deze ervaring precies betekent. Wat doelgerichtheid betreft wijst de studie op overgave als een belangrijke voorwaarde voor de ervaring van zin: een open, kwetsbare en waarderende houding. Doelgerichtheid heeft daarmee iets paradoxaals: het vraagt om focus en richting alsook om de bereidheid om vertrouwde paden en patronen los te laten, en onderweg te blijven leren en ontdekken. Het model als geheel leidt tot een beter begrip van zin als een continu proces in het leven.

Hoofdstuk vijf benadert zin als een interactief proces tussen mensen. De gepresenteerde studie onderzoekt op welke wijze zin wordt ervaren door 
betekenisvolle herinneringen te delen met anderen. Het hoofdstuk beschrijft een case study van een groepsinterventie waarin acht deelnemers, allen professionals uit de geestelijke gezondheidszorg, een herinnering kiezen aan de hand van de Wonderful Life vraag, en deze vervolgens aan elkaar vertellen en erop reflecteren. $\mathrm{Na}$ afloop van de interventie werden deelnemers ingedeeld in twee focusgroepen waarin zij in gesprek gingen over hun ervaring van zin gedurende het verloop van de interventie. Martin Buber's gedachtegoed over zin vanuit ontmoeting ("all real living is meeting"), werd geoperationaliseerd om inzicht te krijgen in de manier waarop de verschillende onderdelen van de interventie bijdragen aan de ervaring van zin. Een thematische analyse liet zien dat het delen van betekenisvolle herinneringen bijdraagt aan authentieke ontmoetingen en een ervaring van zin die ook lijfelijk wordt ervaren. Resultaten benadrukken het belang van het werken met levendig vertelde verhalen, en de rol van stilte in het oprecht zien van de ander en ook zelf gezien worden. De studie geeft specifiek zicht op de kwaliteit van de Wonderful Life vraag. Door herinneringen in antwoord op deze vraag te delen, ervaren deelnemers niet alleen een sterkere verbinding met zichzelf en de andere deelnemers, maar ook met de mensheid en een groter geheel: een zelfoverstijgende ervaring die een transformerend effect kan hebben. De case study als geheel illustreert Buber's dialogische gedachtegoed, waarin het delen van betekenisvolle herinneringen leidt tot een verschuiving in bewustwording: van het individuele, op zichzelf staande naar het verbondene.

De resultaten van deze thesis kunnen worden samengevat in vier kernpunten. De thesis geeft inzicht in (1) verschillende categorieën betekenisvolle levensmomenten, in (2) de werking van de mindset van verwondering als fundament voor het ervaren van zin, in (3) zin als een persoonlijk proces van zin vinden en geven, en in (4) zin als een interactief proces van ontmoeten door het delen van betekenisvolle herinneringen. De ervaring van zin is fundamenteel voor een goed en gezond leven, en de resultaten van deze dissertatie geven inzicht in de manier waarop dit fundament kan worden versterkt. De gehele thesis overziend valt op hoe de open, waarderende en accepterende houding van verwondering, overgave en verbinding als een rode draad door de resultaten loopt, en door de verhalen die mensen vertellen over hun betekenisvolle 
levensmomenten. Het is een pleidooi om ruimte te maken voor verwondering naast begrip en coherentie, voor overgave en loslaten naast doelgerichtheid en prestatie, en voor authentieke ontmoeting naast functioneel contact. De vraag rijst of kennis en ratio, resultaat en controle, autonomie en zelfredzaamheid niet overgewaardeerd zijn in hun bijdrage aan het menselijk functioneren en welbevinden - in wetenschappelijk onderzoek en in de samenleving. Deze thesis pleit voor een verschuiving van ons denken en doen in lijn met de mindset van verwondering: een open houding, waarbij we onszelf niet zien als solitaire, op zichzelf staande wezens, maar als deel van een groter geheel. Het is deze mindset die het mogelijk maakt om zin te vinden in elke situatie, en om zin te geven die dat grotere geheel, en daarmee ook onszelf, dient. Want zin is veel meer dan een vraagstuk voor de geestelijke gezondheidszorg, en dient verweven te zijn in het alledaagse leven. 

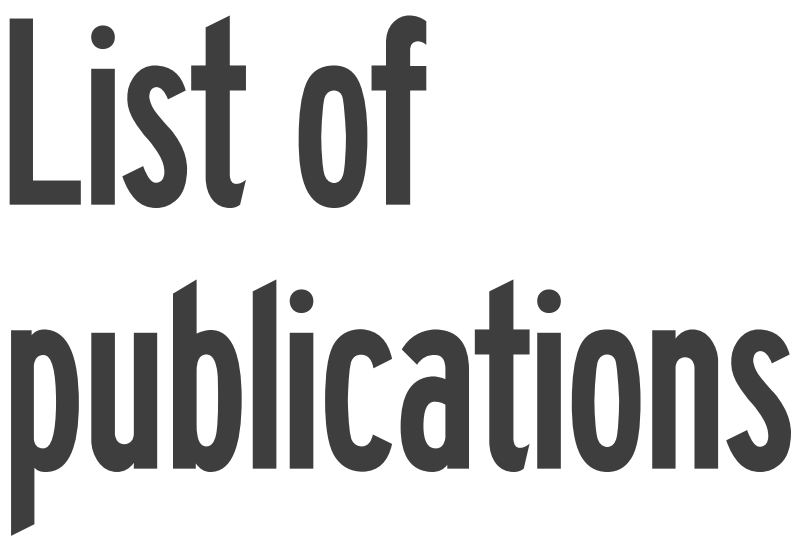

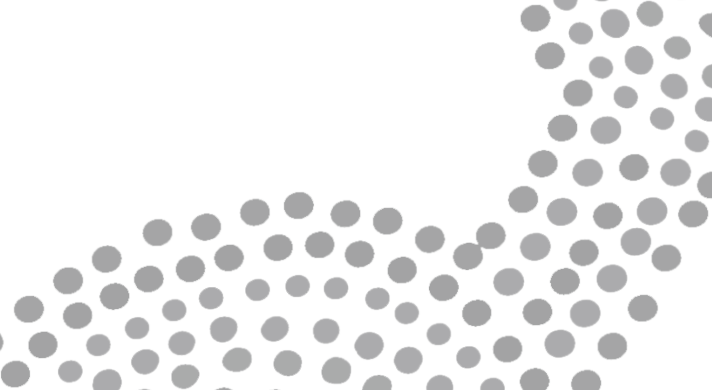

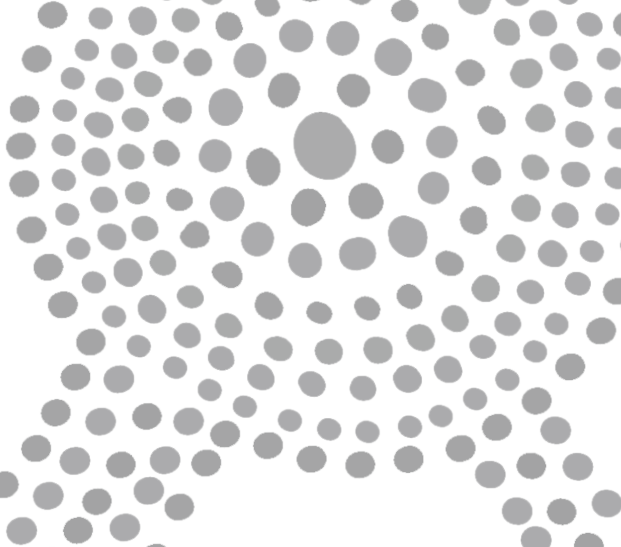
0 0.000000 。

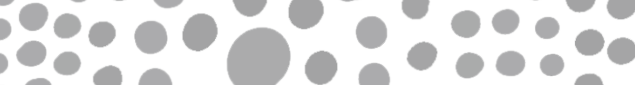

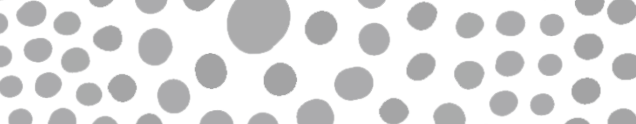




\section{Scientific publications}

Van de Goor, J., Sools, A. M., Westerhof, G. J., \& Bohlmeijer, E. T. (2017). Wonderful life: Exploring wonder in meaningful moments. Journal of Humanistic Psychology, 60(2), 147-167.

Van de Goor, J., Sools, A. M., \& Westerhof, G. J. (2018). Unraveling the wonder of the ordinary: A narrative analysis of meaning construction in memories of familiar routines. Journal of Constructivist Psychology, 32(3), 292-308.

Van de Goor, J., Sools, A. M., \& Westerhof, G. J. (2020). Cultivating a Mindset of Wonder: A narrative analysis on the mechanisms of seeing the extraordinary within the ordinary. In: Schinkel, A. (Ed), Wonder, Education, and Human Flourishing: Theoretical, Empirical, and Practical Perspectives.

Van de Goor, J., Sools, A. M., \& Westerhof, G. J. (2020). The Emergence of Meaning From Meaningful Moments in Life. Journal of Humanistic Psychology.

Van de Goor, J., Sools., A. M., Smits, M. \& Westerhof, G. J. (2020). The Power of Sharing Meaningful Moments: a Buberian analysis of a counseling intervention. Manuscript submitted for publication, under review.

\section{Conference publications}

Van de Goor, J., Sools, A. M., \& Westerhof, G. J. (July 2018). Unraveling the wonder of the ordinary: A narrative analysis of meaning construction in memories of familiar routines. Paper presented at the Narrative Matters conference, Enschede, The Netherlands.

Van de Goor, J., Sools, A. M., \& Westerhof, G. J. (April 2019). Developing a mindset of wonder: a narrative analysis on the mechanisms that lead us to see the extraordinary within the ordinary. Paper presented at the International conference on Wonder, Education, and Human Flourishing, Amsterdam, The Netherlands.

\section{Other publications and presentations}

Jacky van de Goor, (November 2017). Life in One Question. TedX Talk, Venlo, The Netherlands

Jacky van de Goor, (November 2018). Life in One Question - een zoektocht naar zin. Keynote at NOBCO Symposium Coaching \& Onderzoek, Utrecht, The Netherlands

Jacky van de Goor, (February 2020). Aandacht als bron voor zin en verbinding. Presentation at HR congres Liefde voor Leren, Ede, The Netherlands

Jacky van de Goor, (2020). Je leven in één herinnering. Uitgeverij Ten Have, Utrecht. 


\section{About the author}

0
0
0
0
0
0
0
0
0
0
0
0

008.000 .000

000000000

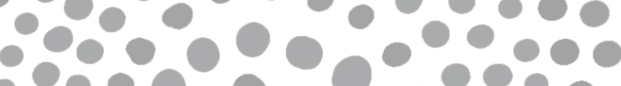

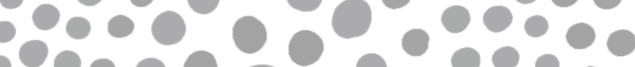
30000 0.000
60

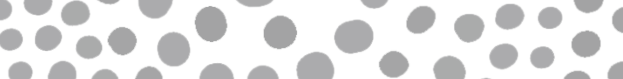
.000 .0000000 
Jacky van de Goor (1968) was born in Pittsburgh, USA from Dutch parents. She spent her childhood in various cities in The Netherlands as well as the USA. After high school, she studied Industrial Design Engineering at the Technical University of Delft. She received her master's degree in 1992, after which she went on an eight month backpacking trip through Asia. Back in The Netherlands, Jacky started working as a researcher, consultant, project and later product manager for telecom company

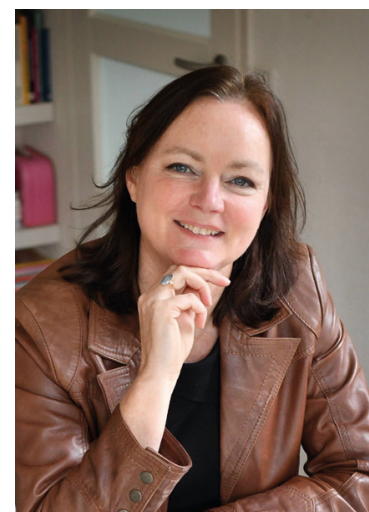
KPN. Discovering that she loves people more than things, she made a career switch in 1999 to work for training and coaching company Schouten en Nelissen. There, she developed her skills as a leadership trainer and organizational coach, specializing in the development of vital teams and meaningful working cultures. Feeling the need for more professional freedom, Jacky resigned her job in 2006 and started her own bureau Legende. Since then, she has worked for many organizations, mainly in the non-profit sector.

In 2012, Jacky came across the Japanese movie "After Life" in which the Wonderful Life Question stands central. Inspired by this question, she developed a meaningful moment intervention that she applies in programs aimed at leadership and team development. In 2014, she started her PhD-research on meaningful moments at the Story Lab of the department of Psychology, Health and Technology at the University of Twente. During her PhD, Jacky supervised several master students and gave a number of presentations at scientific as well as professional conferences, including the TEDx talk Life in One Question. As a practitioner, she has employed the insights from her research to continuously develop and refine the meaningful moment intervention. In 2020, the book Je leven in één herinnering was published by Ten Have, in which she personally reflects on the main insights from her PhD. Earlier books by Jacky are Hartelijk georganiseerd (2011) and Losbrekers voor meer plezier thuis en Losbrekers voor meer plezier op het werk (2019).

Jacky lives in Eindhoven with her husband and three children. She works as a volunteer for the Red Cross and, loving to play, she is a passionate amateur actress in improvisation theater. 


\section{Dankwoord}

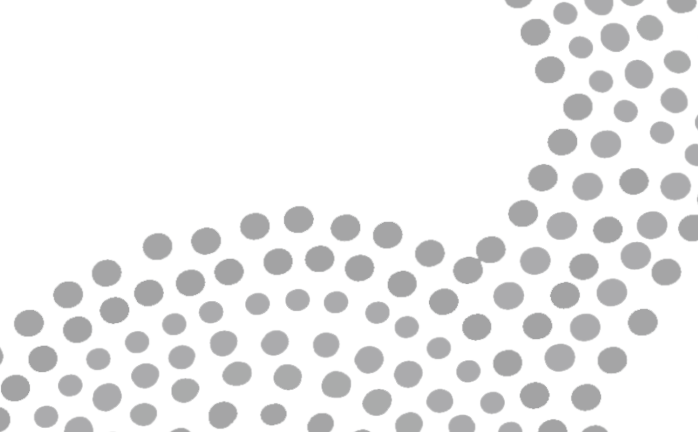

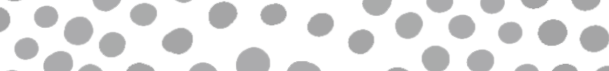
6000

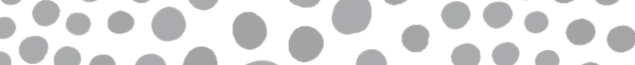
30.00

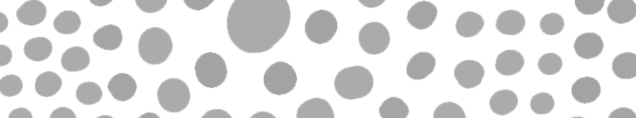

:०:

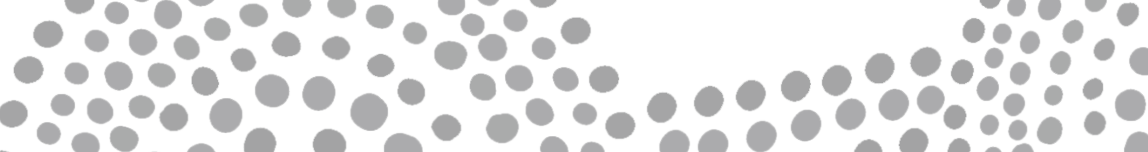
\%००. $\because \%, 0000000 \%$

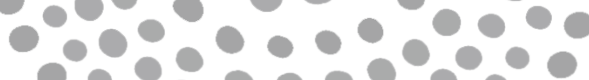
$0.0 \%$

.0000000

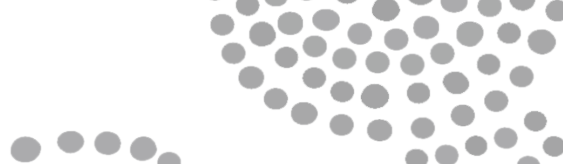


En dan is het ineens klaar: een onderzoek, een boek. Wat acht jaar geleden thuis op de bank begon met een Japanse film, leidde tot een reis waarin honderden mensen, velen wildvreemden, me hun meest dierbare herinnering toevertrouwden, en ik in de bossen van de UTwente een plek vond om het goud in deze prachtige verhalen te delven. Het klinkt een beetje als een sprookje, als een legende, en zo heb ik dat ook al die tijd ervaren. Toen ik startte had ik nog nooit een wetenschappelijk artikel gelezen; opgeleid als ingenieur bewandelde ik ineens de paden van de psychologie en voelde ik de kracht, maar ook de kwetsbaarheid van verwondering. Ondanks de hobbels en kronkels heb ik echter geen seconde getwijfeld of overwogen om te stoppen. Het was gewoon de bedoeling.

"Wil je snel gaan, ga dan alleen, wil je ver gaan, ga dan samen," luidt een oud Afrikaans spreekwoord. Dit proces had nooit zo ver kunnen komen zonder de mensen die er onderweg voor me waren en die er kortere of langere stukken in zijn meegereisd. En daar ben ik dankbaar voor.

Allereerst gaat mijn dank uit naar professor Gerben Westerhof en doctor Anneke Sools, mijn promotor en copromotor. Wat ben ik blij dat ik jullie gevonden heb! Ik had geen betere thuishaven kunnen vinden voor het onderzoek dan bij jullie in het Story Lab. Jullie hebben me de liefde bijgebracht voor het verhaal; een liefde die nooit meer over zal gaan. Ongelooflijk hoeveel ik van jullie heb geleerd. Gerben, ik bewonder de manier waarop je schijnbaar moeiteloos helderheid weet te creëren in het voor mij soms zompige moeras van wetenschappelijke constructen en onderzoeksvragen, en hoe je de essentie vaak in één enkele, bijna poëtische volzin weet te raken. Je gaf me de ruimte, en tegelijkertijd ook houvast en richting. Anneke, je hebt me laten zien wat het betekent om "recht te doen" aan het verhaal. Ergens had ik de angst dat de wetenschap de magie van de verhalen die ik had verzameld teniet zou doen, dat de ratio zou gaan domineren en mijn verwondering zou uitdoven. Niets is echter minder waar: je leerde me een manier van kijken en onderzoek doen die de verhalen des te meer deed schitteren, en die mijn verwondering alleen maar aanwakkerde. Bovenal ben ik jullie beiden dankbaar voor het warme welkom en de onvoorwaardelijke support; de reizen naar Enschede zal ik gaan missen. 
Daarnaast zijn er de leden van mijn promotiecommissie. Professor Hans Alma, professor Ernst Bohlmeijer, professor Gaby Jacobs, professor Siebrecht Vanhooren en doctor Mark van Vuuren: wat een rijkdom om jullie bij mijn onderzoek te betrekken! Ik voel me vereerd dat ik mijn werk met jullie mag delen en dank jullie voor jullie tijd en aandacht in deze laatste etappe.

Ook Danielle Boelen en Talitha Ruarus van het secretariaat van de vakgroep waren in deze fase onmisbaar, dank voor jullie hulp en steun bij het regelen van alle formaliteiten. Terug naar het begin; op de summerschool Narrative Analysis leerde ik Sheila Adjiembaks en Silvia Pol kennen, en later Monique Engelbertink. Als zzp-er en buitenpromovenda is het bestaan soms eenzaam; fijn om, hoe kort ook, met jullie inhoudelijk te kunnen sparren en succesjes, frustraties en andere promoveerperikelen te kunnen delen. Ook emeritus hoogleraar Mia Leijssen ontmoette ik gaandeweg de reis, waarna ik regelmatig de grens met België overstak voor een gezamenlijke wandeling. Ik dank je, Mia, voor het fijne contact. Ik heb je als een waardevolle mentor ervaren de afgelopen jaren, voor mij als persoon en mijn onderzoek.

En dan zijn er de honderden mensen die in de loop van de jaren hun herinnering met me hebben gedeeld: vrienden, cursisten, onbekenden. Het voert te ver om alle namen hier te noemen, maar jullie verhalen staan in mijn hart gegrift. Ik ben eindeloos dankbaar voor jullie toestemming om te mogen werken met deze persoonlijke en vaak ook kwetsbare herinneringen. Dank voor de prachtige ontmoetingen en de verrijkende inzichten die jullie me gegeven hebben. Groot is ook mijn dank aan de verschillende organisaties waarin ik met de Wonderful Life interventie heb mogen werken de afgelopen jaren, waaronder gemeente Veldhoven, gemeente Gilze Rijen, gemeente Weert, gemeente Roermond, Summa college, Rabobank, PWN, UTwente, Kom Erbij Festival, New Financial Forum, Stichting Neos, CC Excellence en KU Leuven. In het bijzonder gaat mijn dank uit naar Toon Walravens van GGzE voor het vertrouwen en de ruimte om het laatste gedeelte van het onderzoek bij GGzE uit te voeren. Ook jou, Micole Smits, ben ik dankbaar voor je actieve betrokkenheid bij deze laatste deelstudie. Je was al een fijne collega en goede vriendin, nu ook een waardevol onderzoeksmaatje. 
Ook buiten de onderzoeksbubbel heb ik me gesteund gevoeld. Fijn om zoveel mensen te hebben om mee te spelen, te lachen, te huilen en te wandelen. Dankjewel lieve teamgenootjes van theatersportgroep Dulcinea, dankjewel Nanda, Claudine, Elien, Delphine, Monique en Astrid voor de fijne vriendschappen. Echt leven is ontmoeten, heb ik geleerd, en jullie laten me iedere keer weer zien hoe waar dat is.

En als laatste is er de thuisbasis. Dit onderzoek had ik niet kunnen doen zonder dat wat ik van mijn ouders heb meegekregen: de verwondering, de nieuwsgierigheid, het denken in mogelijkheden en - de laatste jaren van jou, mama - ook de volharding in moeilijke tijden. En Guido, mijn lief: gaandeweg deze reis hebben we ook zelf ervaren dat het leven kwetsbaar is - wat niet altijd makkelijk was, maar wel veel verdieping heeft gebracht. Ik ben je dankbaar voor je geloof in mij en mijn verhaal, en ik ben jou en Ceder, Helder en Elan dankbaar voor het fijne, levendige nest van waaruit ik deze reis kon ondernemen en kan vervolgen. 


\section{What if there is an afterlife. There, all your memories will be erased, except for one. Which memory do you choose to take with you to eternity?}

This thesis investigates the emergence of meaning and the way a sense of meaning in life may be enhanced. It explores meaning through the personal, lived experience of meaningful moments and is based on the memories of more than one hundred people, varying in age, profession and background, chosen in answer to the question above. The study investigates the way these moments work and the way recollecting and sharing these moments may strengthen a sense of meaning in life. It pleads for a shift in thinking and acting towards a mindset of wonder: an open mindset, that enables the discovery and creation of meaning in any moment in life. 